\title{
Die Rolle Karls I. von Liechtenstein bei den Konfiskationen nach der Schlacht am Weißen Berg
}

\section{The Role of Charles I of Liechtenstein in the Post-White Mountain Confiscations}

\author{
Tomáš Knoz / knoz@phil.muni.cz \\ Historický ústav, Filozofická fakulta, Masarykova univerzita, Brno, CZ
}

\begin{abstract}
In Czech historiography, Prince Charles I of Liechtenstein personifies the process of the postWhite Mountain confiscations and the political and social changes in the post-White Mountain Czech lands. Between 1918 and 1945 he even became the subject of historiographical and journalistic discussion within Czech historiography, which was directly linked to the foundation and strengthening of the Czechoslovak Republic. These attitudes also led to discussions between historians standing on the side of the emergent Czechoslovak Republic and historians from the circle of the Prince of Liechtenstein. Contemporary research shows that the role of Charles I of Liechtenstein was by no means straightforward. This was due to the personal ambitions of the ruler of the emergent princely house, but also because of the complex historical context, when the representatives of the Central European aristocracy were searching for a place between the estates' community and the ruling dynasty. Charles I of Liechtenstein's case was also different due to geography and the individual countries where the Liechtensteins held positions, functions and offices. In the Margraviate of Moravia in particular, Charles I of Liechtenstein was the victim of confiscation declared during the Estates' Uprising. After the uprising had been defeated he could return to the country and reclaim his land. In Bohemia, Liechtenstein was rewarded for his loyalty to the Austrian house during the rebellion by soon becoming the emperor's commissar and then the emperor's governor. It was in that capacity that he arrested and tried the main rebels and presided over their execution at the Old Town Square. In the 1620s he organised the imperial confiscations in Bohemia. In Opava, which was gradually moving towards the Silesian principality, Liechtenstein attempted to enter as the supreme ruler and organise his own confiscations from this position. However, this manoeuvre came up against the interests of Emperor Ferdinand II and his central offices, which did not agree with such
\end{abstract}

Die Studie entstand im Rahmen des von der Forschungsagentur der Tschechischen Republik geförderten Projekts "Centrum pro transdisciplinární výzkum kulturních fenoménů ve středoevropských dějinách: obraz, komunikace, jednání (Centre for Cross-Disciplinary Research into Cultural Phenomena in the Central European History: Image, Communication, Behaviour)" - Reg. Nr. 14-3652G. Für die Übersetzung ins Deutsche dankt der Verfasser Dr. Thomas Krzenck. 
a division of the monarchy. But Charles I of Liechtenstein did make gains in Moravia, where he was awarded a large amount of property from his erstwhile opponent, the rebel provincial governor Ladislav Velen of Žerotín, the most important being the domain of Moravská Tŕebová. Charles I of Liechtenstein died in 1627 when, from the emperor's perspective, peace and normality had finally returned to the Czech lands. His role in the confiscation process, albeit with certain dark shadows, nevertheless contributed towards the great advancement of the Princely House of the Liechtensteins, which would last for centuries.

\section{Keywords}

Charles I of Liechtenstein, Post-White Mountain confiscations, estates' uprising, Habsburg monarchy, Czech lands, nobility

\section{Einführung: Karl I. von Liechtenstein als Objekt eines historiographischen Streits}

Der Terminus „Konfiskationen nach 1620“, d. h. nach der Schlacht am Weißen Berg, wird in der tschechischen bzw. mitteleuropäischen Historiographie für gewöhnlich in doppelter Bedeutung benutzt. In einem ersteren, engeren Wortsinn handelt es sich um den rechtlichen - die Bestrafung der Teilnehmer des Ständeaufstands in den Jahren 1618-1620 umfassenden - Prozess. Konkret betrifft dies die Applikation einer der Sanktionen, die die zeitgenössische Rechtsordnung Personen auferlegte, die sich nach einem Gerichtsurteil des Verbrechens gegen das Haupt des Staates - crimen laesae maiestatis - schuldig gemacht hatten. ${ }^{1}$ In einem zweiten Wortsinn geht es um den Gesamtprozess

1 Der vorliegende Beitrag geht von älteren - in einer umfangreichen Monographie gipfelnden - Forschungen des Autors zur Frage der Konfiskationen nach der Schlacht am Weißen Berg in Mitteleuropa aus. Vgl. Knoz, Tomáš: Pobělohorské konfiskace. Moravský prủběh, středoevropské souvislosti, obecné aspekty (Die Konfiskationen nach 1620. Ihr Verlauf in Mähren, die mitteleuropäischen Zusammenhänge, allgemeine Aspekte). Brno 2001. In deutscher Sprache vgl. Ders.: Die Konfiskationen nach 1620 in der (erb)länderübergreifenden Perspektive. Thesen zu wesentlichen Aspekten und Prinzipien des Konfiskationsprozesses. Mata, Petr - Winkelbauer, Thomas (Hg.): Die Habsburgermonarchie1620-1740. Stuttgart 2006, S. 99-130. Die aktuelle Forschung wurde dessen ungeachtet heuristisch und methodologisch erweitert. Auf dem Gebiet der Quellen bemüht sich der Verfasser nachfolgende Quellengruppen einander gegenüberzustellen: Quellen aus der Dietrichstein'schen Statthalterkanzlei in Mähren, die im Mährischen Landesarchiv aufbewahrt werden (v. a. das Familienarchiv der Dietrichstein, Materialien zur Verwaltung Mährens), Dokumente zur Administration des Königreichs Böhmen und der angegliederten Länder aus der Provenienz der Böhmischen Kanzlei und der Böhmischen Hofkammer im Nationalarchiv Prag (v. a. Česká dvorská komora - ČDK; Stará manipulace/Böhmische Hofkanzlei/Alte Manipulation, Dokumente zu den Liechtenstein und weiteren Adelsfamilien), Dokumente aus der Kaiserlichen Hofkammer mit reichhaltigem Material zum Wirken Karls I. von Liechtenstein in Liechtenstein. The Princely Collections - Hausarchiv der regierenden Fürsten von und zu Liechtenstein [HAL] (v. a. Familenarchiv [FA], Karl I. von Liechtenstein. Biographica). Sofern es sich um die im vorliegenden Text formulierte Fragestellung handelt, geht der Beitrag von der aktuellen Diskussion um die Rolle Karls I. von Liechtenstein aus, die ihren Ausgang in der Zeit der Ersten Bodenreform vor allem zwischen den Historikern František Hrubý a Franz Wilhelm nahm, wobei diese Diskussion auf den verschiedensten Ebenen appliziert wurde und in unterschiedlicher Gestalt auch nachfolgend ihre Fortsetzung fand und bis in die Gegenwart reicht. Der vorliegende Beitrag greift auf authentische Quellen zurück um aufzeigen zu können, welche Rolle(n) Karl I. von Liechtenstein 
der rechtlichen, politischen und gesellschaftlichen Veränderungen, die sich im Kontext der Konfiskationen nach der Schlacht am Weißen Berg vollzogen.

Fürst Karl I. von Liechtenstein spielte in der böhmischen (tschechischen) und mitteleuropäischen Geschichte eine bedeutende Rolle. Gut möglich dürfte sein, dass stärker noch als sein eigentliches Wirken an der Wende vom 16. zum 17. Jahrhundert die Thematisierung seiner Taten und der Konstruktion seines Bildes, das die moderne Historiographie schuf und das sich auch im gegenwärtigen Bewusstsein bzw. in der Welt der Politik und des Rechts reflektiert, Interesse verdient. Gerade der Konstruktion des Bildes Karls I. von Liechtenstein und der Sekundärarbeiten, die dieses Bild nutzen, haben sich in jüngster Zeit gleich mehrere Autoren gewidmet. Eine nicht unerhebliche Rolle unter diesen Autoren spielte auch Thomas Winkelbauer, und dies gleich aus mehreren Gründen: aufgrund der u. a. mit Hilfe seines Bruders Gundaker vorgenommenen Beschreibung Karls I. von Liechtenstein, ${ }^{2}$ darüber hinaus durch die genaue Definition der frühneuzeitlichen Liechtenstein als eines „grenzüberschreitenden Adels“3 ${ }^{\text {" }}$ und nicht

im Prozess der Konfiskationen nach der Schlacht am Weißen Berg spielte. Zugleich wird versucht zu klären, in welcher Art und Weise der primär politische und strafrechtliche Prozess der Konfiskationen nach 1620 mit dem sich vollziehenden Karriereaufstieg des führenden Repräsentanten der „neuen Fürstenschicht“ im ersten Viertel des 17. Jahrhunderts zusammenhing. Zur Problematik der Konfiskationen nach 1620 vgl. auch Tikovský, Ondřej: S údělem prosebnika. Restitučni úsili šlechty českého severovýchodu potrestané pobělohorskými konfiskacemi (Mit dem Los eines Bittstellers. Restitutionsbemühungen des durch die Konfiskationen nach 1620 bestraften böhmischen Adels im Nordosten. České Budějovice 2013.

2 Winkelbauer Thomas: Karl von Liechtenstein und das „Prager Blutgericht" vom 21. Juni 1621 als tschechischer Erinnerungsort im Spiegel der Historiographie. In: Liechtensteinisch-Tschechische Historikerkommission (Hg.): Liechtensteinische Erinnerungsorte in den böhmischen Ländern. Vaduz 2012, S. 51-71; Ders.: Fürst und Fürstendiener. Gundaker von Liechtenstein, ein österreichischer Aristokrat des konfessionellen Zeitalters (Mitteilungen des Instituts für Österreichische Geschichtsforschung, Ergänzungsband 34, Wien-München 1999); Ders.: Gundaker von Liechtenstein als Grundherr in Niederösterreich und Mähren. Normative Quellen zur Verwaltung und Bewirtschaftung eines Herrschaftskomplexes und zur Reglementierung des Lebens der Untertanen durch einen adeligen Grundherrn sowie zur Organisation des Hofstaates und der Kanzlei eines "Neufürsten" in der ersten Hälfte in der ersten Hälfte des 17. Jahrhunderts. Wien - Köln - Weimar 2008; Ders.: Das „Fürstentum Liechtenstein “ in Südmähren und Mährisch Kromau (bzw. Liechtenstein) als Residenzstadt Gundakers von Liechtenstein und seines Sohns Ferdinand. In: Bůžek, Václav (ed.): Život na dvorech barokní šlechty. Opera Historica 5. České Budějovice 1996, S. 309-334. Die Tatsache, dass das Thema „Karl I. von Liechtenstein “ und die „liechtensteinischen Besitzungen“ in der tschechischen, österreichischen und liechtensteinischen Historiographie weiterhin Aktualität besitzt, unterstreichen neben den Beiträgen von Arthur Stögmann, Jiří Brňovják und Tomáš Knoz in der vorliegenden Publikation auch die aktuellen Forschungen Herbert Haupts bzw. die soeben erschienene Studie von Jürgen Schweinberger zum Thema Fürst Karl I. von Liechtenstein. Adeliger und Staatsmann im konfessionellen Zeitalter (Jahrbuch des Historischen Vereins für das Fürstentum Liechtenstein 117, 2018, S. 115-171) bzw. Paul Vogts Untersuchung Eine Skizze der Besitzungen des Hauses Liechtenstein vor 1914 (ebd., S. 173-188)

3 Winkelbauer, Thomas: Lichtenštejnové jako „šlechta neznajicí hranice“. Náčrt majetkového vývoje pánů a knížat lichtenštejnských v Dolních Rakousích a na Moravě v rámci politických dějin (Die Liechtenstein als „grenzüberschreitender Adel“. Abriss der Besitzentwicklung der Herren und Fürsten von Liechtenstein in Niederösterreich und in Mähren im Rahmen der politischen Geschichte). In: Komlosy, Andrea - Bůžek, Václav - Svátek, František: Kultury na hranici. Waidhofen 1995. Wien, 1995, S. 215-218; Ders.: Karrieristen oder fromme Männer? Adelige Konvertiten in den böhmischen und österreichischen Ländern um 1600. In: Chocholáč, Bronislav - Jan, Libor - Knoz, Tomáš (ed.): Nový Mars Moravicus. Brno 1999, S. 431-452. Vgl. darüber hinaus Winkelbauers Reflektionen zur Thematisierung der Rolle Karls I. von Liechtenstein in der tschechischen Geschichte. Winkelbauer, Thomas: Karl von Liechtenstein und das „Prager Blutgericht" vom 21. Juni 1621 als tschechischer Erinnerungsort im Spiegel der Historiographie. In: Liechtensteinisch- 
zuletzt auch aufgrund der Kontextualisierung der österreichischen Geschichte des 16. und 17. Jahrhunderts in mitteleuropäischen Konturen. ${ }^{4}$

Bereits der Archivar Franz Wilhelm, der in der Vergangenheit Dokumente aus dem Fond „Familienarchiv der Liechtenstein“ ordnete, titelte einige über das Lebensschicksal Karls I. von Liechtenstein informierende Faszikel mit dem Begriff „Mission“: Mission in Mähren 1604, Mission bei der kaiserlichen Armee 1620, Böhmische Mission 1621 usw. ${ }^{5}$ Auf dieser Grundlage vermögen wir uns vorzustellen, dass Fürst Liechtenstein in den entscheidenden Augenblicken seines Lebens, die sich mit den entscheidenden Momenten der entstehenden Habsburgermonarchie deckten, zu speziellen Missionen entsandt wurde, um hier im Namen der habsburgischen Herrscher eine wichtige Rolle zu spielen. Auch wenn diese Rolle zuvor festgelegt worden war und sie dem Ruhm des Hauses Österreich dienen sollte, vermochte Karl I. diese Missionen zugleich auch für seinen eigenen Erfolg zu nutzen, so dass praktisch parallel die Konstituierung des Fürstenhauses Liechtenstein erfolgte.

Die Frage der Rolle bzw. der Rollen Karls I. von Liechtenstein in den mit dem böhmischen Ständeaufstand und seiner Niederlage verbundenen Ereignissen ist nicht allein eine - einer zeitlich begrenzten und weit zurückliegenden Epoche der Frühen Neuzeit gewidmete - Angelegenheit der wissenschaftlichen historischen „Lehrstuhl“-Forschung. Im Gegenteil. Die Ereignisse der Jahre 1618-1624 und Karl I. von Liechtenstein als deren Verkörperung spielten wiederholt eine grundsätzliche Rolle im 20. Jahrhundert, und dies gleich mehrfach: nach 1918, nach 1945 und auch aktuell nach 2009. Für dieses „zweite Leben“ der „liechtensteinischen“ Konfiskation nach 1620 gilt dabei, dass sie in bemerkenswerter Weise die Welt der Geschichtswissenschaft mit der applizierten Welt der Publizistik, Politik und des Rechts verbinden. Bei der Vereinigung des Gebietes der Geschichtswissenschaft mit dem Bereich der politisierenden Publizistik spielten dabei nach 1918 u. a. zwei bedeutende Historiker und Archivare eine Rolle - auf tschechischer Seite František Hrubý und auf liechtensteinischer Seite Franz Wilhelm. Auf allgemeiner Ebene darf hier konstatiert werden, dass das Problem des Konflikts der Identitäten zwischen den böhmischen Ländern und der Familie Liechtenstein bereits relativ ausgeprägt vor der Entstehung der Tschechoslowakischen Republik existierte, zumal es sich im Unterschied zu anderen aristokratischen bzw. fürstlichen Häusern um einen Konflikt staatlicher Identitäten handelte. Nach 1918 verschärfte sich dieses Problem noch, da sich der Konflikt staatlicher Identitäten zu einem Konflikt staatlicher Ideen ausweitete (auf Seiten der Liechtenstein existierte die Idee von Tradition und Katholizismus, auf Seiten der entstehenden Tschechoslowakei hingegen die Idee des Fortschritts und Hussitentums) und daran anknüpfend das Problem des Konflikts der Loyalität. An dieser Stelle trat in die Welt der aktuellen Politik auch die Geschichtswissenschaft. Der aus Kremsier

-Tschechische Historikerkommission (Hg.): Liechtensteinische Erinnerungsorte in den böhmischen Ländern. Vaduz 2012, S. 51-71.

4 Winkelbauer, Thomas: Österreichische Geschichte 1522-1699. Ständefreiheit und Fürstenmacht. Teil 1, 2. Wien 2003.

5 LiECHTENSTEIN. The Pricely Collections. Hausarchiv Liechtenstein (HAL), Familienarchiv (FA), Kart. 480. 
(Kroměříž) stammende Historiker Jindřich Slovák veröffentlichte bald nach Gründung der Tschechoslowakei eine Edition des Mährischen Konfiskations- und Konkursprotokolls. ${ }^{6}$ Während sich die bereits vorliegende Edition von Christian d'Elvert noch durch eine archivalische Herangehensweise, verbunden mit einem Landespatriotismus, auszeichnete, ${ }^{7}$ war Slováks Edition bereits eindeutig von dem Bemühen gekennzeichnet aufzuzeigen, dass sich die Liechtenstein unmittelbar bei der Bestrafung der Teilnehmer des Ständeaufstands engagiert und dass sie durch ihre Haltung mit großen Besitzgewinnen profitiert hatten. Slováks Edition sowie die beigefügte Interpretation ist weder frei von methodologischen noch von interpretatorischen Fehlern. Dessen ungeachtet ist es keineswegs ein Zufall, dass eine ähnliche Interpretation sich im Zeitraum nach 1918 auch bei Josef Pekař finden lässt, der ansonsten die nationale tschechische Idee und jene des Hussitismus und des Fortschritts nicht teilte. In seinen die vorgeschlagene Bodenreform, die er ansonsten nicht empfahl, betreffenden Texten sprach er sich dessen ungeachtet für eine gewisse Beschlagnahme des Besitzes der Familie Liechtenstein aus, und dies gerade auf der Grundlage historischer Argumente, die sich auf den Zeitraum nach 1620 bezogen. $^{8}$

Eine solche Haltung, die zudem noch mit den zeitgenössischen Enthusiasmus der Gründer der Tschechoslowakischen Republik zusammenhing, nahm lange Zeit der spätere Direktor des Mährischen Landesarchivs und Professor der Masaryk-Universität in Brünn, František Hrubý ein. Zu Beginn der zwanziger Jahre begrüßte er die vorbereitete Parzellierung der liechtensteinischen Güter im Rahmen der ersten Bodenreform. In einem in den Lidové noviny veröffentlichten Artikel stellte er zwei historische Adelsfamilien in Mähren - die Liechtenstein und die Žerotín - gegenüber. Die Žerotín repräsentierten für ihn dabei die Tradition des böhmischen Adels, der im Grunde genommen den aktuellen nationalen und republikanischen Ideen entsprach. Die Liechtenstein hingegen stellten für ihn die aktiven Organisatoren und zugleich Profiteure der nach 1620 durchgeführten Konfiskationen dar, mit deren Besitzgewinnen er zugleich den Prozess der Germanisierung der Territorien der vormaligen Güter der Žerotín in den Regionen um Mährisch Trübau (Moravská Třebová) und Hohenstadt an der March (Zábřeh) verband. Offensichtlich wird, dass Hrubý in diese Schlussfolgerung seine subjektive Sicht der Dinge fließen lässt, zumal sich sehr ähnliche Formulierungen auch in seinem Tagebuch aus der Jugend, die er gerade in Nordmähren verlebt hatte, finden. ${ }^{9}$ Die Bodenreform begreift er als natürlich Weg zur Revision des Konfiskationsprozesses aus der Zeit

6 Slovák, Jindřich (Hg.): O konfiskovaných statcích na Moravě (Über die konfiszierten Güter in Mähren). Brno 1919; Ders. (Hg.): Moravský konfiskačni protokol z r. 1623 (Das Mährische Konfiskationsprotokoll aus dem Jahre 1623). Kroměříž 1920.

7 D'Elvert, Christian (Hg.): Mährisches Confiscations- und Crida-Protocoll von 1624. In: Ders. (Hg.): Beiträge zur Geschichte der Rebellion, Reformation, des dreißigjährigen Krieges und der Neugestaltung Mährens im siebzehnten Jahrhunderte. Schriften der historisch-statistischen Sektion. Bd. 16. Brünn 1867, S. 237-280.

8 Pekař, Josef: Omyly a nebezpeč pozemkové reformy (Irrtümer und Gefahren der Bodenreform). Praha 1923.

9 Moravský zemský archiv, Osobní archiv Františka Hrubého (Mährisches Landesarchiv. Privatarchiv František Hrubý). Für die liebenswürdige Information danke ich Dr. Tomáš Borovský. Borovský, Tomáš Lach, Jiří: Josef Šusta a František Hrubý. In: Dies. (Hg.): Josef Šusta a František Hrubý ve vzájemné korespondenci (Josef Šusta und František Hrubý in ihrer gegenseitigen Korrespondenz). Brno 2006, S. 9-57. 
nach 1620 und seiner späteren Folgen. Die methodologische, interpretatorische und quellenmäßige Grundlage für dieses Schlussfolgerung erweist sich im Grunde genommen identisch mit jener, die er im Verlaufe der zwanziger und zu Beginn der dreißiger Jahre in seinen führenden wissenschaftlichen Aufsätzen und Büchern zu diesem Thema erkennen lässt: vor allem in den Studien Moravská šlechta roku 1619, její jměni a náboženské vyznání (Der mährische Adel im Jahre 1619, sein Besitz und sein konfessionelles Bekenntnis, 1922) ${ }^{10}$ und Odhady konfiskovaných moravských velkostatků (Schätzungen der konfiszierten mährischen Großgrundbesitzungen, 1927), ${ }^{11}$ in der Edition Moravské korespondence a akta (1934 und 1937), vor allem jedoch in der Monographie Ladislav Velen ze Žerotína (1930), in der Hrubý wiederum unmittelbar das politische Wirken der Liechtenstein und Žerotín in der Zeit der Schlacht am Weißen Berg, das in die Konfiskation und den Erwerb von Grundbesitz in Nordwestmähren mündete, gegenüberstellt, wobei er den Streit zwischen beiden Adelsfamilien dokumentiert, den er bereits in einem Beitrag von 1922 thematisiert hatte. ${ }^{12}$

Sofern die Aufsätze František Hrubýs zu Beginn der zwanziger Jahre von der Loyalität gegenüber der entstehenden Tschechoslowakischen Republik beeinflusst waren, handelt es sich bei seinem Gegenspieler Franz Wilhelm um die Loyalität eines Angestellten des Fürsten Liechtenstein. Es ging hierbei um die Anknüpfung an eine seit Jahrhunderten wirkende Tradition, in der Historiker ähnlich wie Künstler als Bedienstete der Fürstenfamilie agierten, wobei deren Aufgabe darin bestand, ein Familienbild zu formen, auch wenn dieses Bild nicht immer ausschließlich vorrangig konstruiert wurde. Dem Fürsten Liechtenstein musste unmittelbar nach dem Oktober 1918 - also noch relativ zeitig vor der Verabschiedung der ersten Bodenreform - klar sein, dass die Situation der Familie unter den neuen Verhältnissen nicht einfach sein würde. ${ }^{13}$ Nach der Verabschiedung der Reform, die sich im Falle der Liechtenstein in ihrem ideologischen Teil auf die Aktivitäten Karls I. von Liechtenstein im Zeitraum nach 1618 bezog, wurde der fürstliche Historiker Franz Wilhelm beauftragt, ein sich auf die fachlich-historische Argumentation stützendes Dokument zu erstellen, das die Thesen der Autoren der Reform widerlegen könne. Wilhelm stellte ein mehrseitiges Material unter dem Titel „Erwerbungsgeschichte der fürstlich Liechtenstein'schen Herrschaften und Güter im Gebiete des čechoslovakischen Staates" zusammen, das in einem kurzes Abriss die Geschichte des Erwerbs der liechtensteinischen Güter zusammenfasst, wobei die Rolle des althergebrachten Familienerbes

10 Hrubý, František: Moravská šlechta roku 1619, jeji jměni a náboženské vyznání (Der mährische Adel im Jahre 1619, sein Besitz und sein konfessionelles Bekenntnis). Časopis Matice moravské 46, 1922, S. 107-169.

11 Hrubý, F.: Odhady konfiskovaných moravských velkostatků. (1622-1633) [Schätzungen der konfiszierten mährischen Großgrundbesitzungen (1622-1633)]. Časopis Matice moravské 51, 1927, S. 124-149.

12 Hrubý, F.: K parcelaci lichtenštejnských velkostatků v Moravské Třebové a Zábřehu. Z historie jich konfiskace. I-II (Zur Parzellierung der liechtensteinischen Großgrundbesitzungen in Mährisch Trübau und Hohenstadt an der March. I-II). Lidové noviny, Jg. 304, 13. 6. 1922, S. 11; 20. 6. 1922, S. 11; Ders.: Ladislav Velen ze Žerotína (Ladislaus Velen von Žerotín). Praha 1930.

13 Hiervon zeugt beispielsweise ein Brief, in dem der Fürst über die zwangsweise Einquartierung einer Einheit der Tschechoslowakischen Armee im Schloss Neuschloss (Nové Zámky) bei Nessowitz (Nesovice) in der Herrschaft Butschowitz (Bučovice) in Kenntnis gesetzt wurde, wobei er zusammen mit den dortigen Verwaltern eine adäquate Lösung zu finden suchte. 
(vor allem im Falle von Eisgrub/Lednice; Feldsberg/Valtice gehörte zu dieser Zeit noch nicht zu den der Tschechoslowakei zugeschlagenen Territorien) und auch die Rolle der vor 1620 erworbenen Güter, die aus den Lehen der liechtensteinischen Ehefrauen (vor allem Butschowitz/Bučovice, Posorschitz/Pozořice, Černahora/Černá Hora, Mährisch Aussee/Úsov) entsprangen, hervorgehoben wird. Aus dem Begleitbrief geht hervor, dass Wilhelm darüber den Auftrag hatte, zeitnah eine ähnlich konzipierte detaillierte Übersicht zu den Besitzerwerbungen der Familie Liechtenstein vorzulegen. ${ }^{14}$ Vermutlich handelt es sich bei diesem avisierten Dokument um das umfangreiche und detailliert komponierte, in französischer Sprache verfasste maschinenschriftliche Manuskript unter dem Titel „Historique de l'acquisition de domaines propriétés de la maison princiérs de Liechtenstein sur le territoirs de l'Etat Tchécoslovaque ". ${ }^{15}$ Dieses Dokument zeichnet sich durch mehrere wichtige Eigenschaften aus, die für das Verständnis der Familienerinnerung relevant sind. In erster Linie geht es um die Akribie, mit der die Quellen benutzt werden. Zum anderen werden Art und Weise sowie die Zeit des Erwerbs der einzelnen liechtensteinischen Güter verzeichnet. In Übereinstimmung mit der geläufigen Wahrnehmung der Familiengeschichte im Verhältnis zu den Besitzungen, die sich in der Beziehung zu den Liechtenstein in einem langen Zeitraum verfolgen lässt (den beispielsweise Ondřej Horák in seiner Dissertation über die modernen liechtensteinischen Konfiskationen als einen der Schlüsselmomente ihrer Familiengeschichte, charakterisiert durch die Konfrontation der trockenen Quellenbegriffe und der großen Emotionen ${ }^{16}$ ), kann bei den einzelnen Lokalitäten die unterschiedliche Art und Weise des Erwerbs verfolgt werden: 1. Alte Familienbesitzungen, die die Liechtenstein seit dem Mittelalter für Dienste gegenüber den böhmischen Königen und mährischen Markgrafen erhielten (z. B. Nikolsburg/Mikulov, Eisgrub/Lednice, Feldsberg/Valtice); 2. Durch das Butschowitzer Erbe hinzugewonnene Güter (z. B. Mährisch Aussee/Úsov, Butschowitz/Bučovice, Posorschitz/Pozořice mit Wranau/Vranov u Brna); 3. Durch Kauf erworbene Güter; in diesem Falle lassen sich durch Kauf von Repräsentanten bedeutender böhmischer bzw. mährischer Adelsfamilien - häufig vor dem Hintergrund der Verwandtschaft oder der gesellschaftlichen Partnerschaft - erworbene Güter (u. a. Prossnitz/Prostějov, Plumenau/Plumlov) und kleinere oder größere Käufe, die der Arrondierung und der Vereinigung der einzelnen Familienbesitzungen dienten, unterscheiden, wobei diese Erwerbungen zeitlich dem Dokument zufolge vornehmlich den Zeitraum zwischen 1600 und etwa 1730 betreffen, dennoch aber keineswegs ausschließlich geschahen (z. B. Wiedererwerb von Eisgrub/Lednice, Lundenburg/Břeclav, Sternberg/Šternberk); 4. Gewinne aus Konfiskationen nach 1620: diese werden sehr detailliert beschrieben, und zwar einschließlich der grundlegenden Informationen über die besitzmäßigen und politischen

14 HAL Wien, Herrschaften (H), Kart. 1616, Velké Losiny (Gross Ullersdorf), Erwerbungsgeschichte.

15 HAL Wien, FA, Kart. 482, Karl I. von Liechtenstein, Biographica, Historique de l'acquisition de domaines propriétés de la maison princiérs de Liechtenstein sur le territoirs de l'Etat Tchécoslovaque.

16 Horák, Ondřej: Liechtensteinové mezi konfiskaci a vyvlastněním. Př́spěvek k poválečným zásahům do pozemkového vlastnictví v Československu v prvni polovině dvacátého století (Die Liechtenstein zwischen Konfiskation und Enteignung. Ein Beitrag zu den Nachkriegseingriffen in den Grundbesitz in der Tschechoslowakei in der ersten Hälfte des 20. Jahrhunderts). Praha 2010. 
Zusammenhänge vor deren Erwerb durch die Liechtenstein; deren Gewinn wird im Kontext von Punkt 1 als Gewinn für den Dienst gegenüber Herrscher und Staat oder im Kontext von Punkt 3 als Kauf von der kaiserlichen Hofkammer oder vom vorherigen Besitzer, beispielsweise Albrecht von Wallenstein (z. B. Jägerndorf/Krnov, Mährisch Trübau/ Moravská Třebová) bewertet. ${ }^{17}$

Während Franz Wilhelm in den erwähnten Dokumenten faktographisches Material zusammentrug, das auf den durch die archivalischen Quellen gebotenen Daten fußte, unterstützte er in den parallel vorbereiteten, die Zusammenhänge zwischen den Konfiskationen nach 1620 und der ersten Bodenreform beleuchtenden Studien bereits offener die Positionen des Fürsten Liechtenstein. Wilhelm bringt in seinen unter dem Begriff „Richtigstellung“ versammelten Texten zwei grundlegende Standpunkte zur Sprache: 1. Während die sich auf die Partei des Fürsten Liechtenstein beziehenden Argumente auf historischen Fakten begründet sind und sich auf historische Forschungen stützen, handelt es sich im Falle der zur Unterstützung der Bodenreform vorgetragenen Argumente um journalistische und politisch motivierte Haltungen (das diese Standpunkte auch relevante Historiker wie Pekař oder Hrubý vertreten, wird nicht zur Kenntnis genommen), 2. Die politische Motivation der pro-liechtensteinischen Argumente besitzt einen konkreten politischen Hintergrund, und zwar innerhalb der Sozialdemokratie. ${ }^{18}$

17 HAL Wien, FA, kart. 482, Karl I. von Liechtenstein, Biographica, Historique de l'acquisition de domaines propriétés de la maison princiérs de Liechtenstein sur le territoirs de l'Etat Tchécoslovaque. Zur Eigentumspolitik der Liechtenstein in der Zeit um 1620 vgl. auch Merki, Christoph Maria: Lichtenštejnské majetky a práva v Čechách, na Moravě a ve Slezsku od pozdního středověku až do 20. století (Die liechtensteinischen Besitzungen und Rechte in Böhmen, Mähren und Schlesien vom Spätmittelalter bis ins 20. Jahrhundert). In: Merki, Christoph Maria - Löffler, Josef: Lichtenštejnové v českých zemích od středověku do 20. století. Majetky, práva, správa. Brno 2015.

18 Franz Wilhelm lehnt in seinen Artikeln unter dem Titel „Richtigstellung“ nach 1918 vor allem die Auffassungen von Dr. Hugo Traub und Dr. Karel Stloukal ab (vgl. beispielsweise Stloukal, K.: Bílá hora a Staroměstské náměstí [Der Weiße Berg und der Altstädter Ring]. Praha 1921), die er als „chauvinistisch diktierte Rache“ zurückweist, doch auch die Auffassungen des Schriftstellers Gustav Poláček, der im Presseorgan der Sozialdemokratie den Artikel „Majetek Lichtenštejnů“ (Das Vermögen der Liechtenstein) veröffentlicht hatte, weist er zurück. HAL Wien, FA, Kart. 479, Dokument (Wilhelm, Franz): Richtigstellung. In den liechtensteinischen Materialien finden sich zahlreiche Dokumente (aus der Zeit nach 1918 bzw. auch nach 1945), die bezeugen, dass die liechtensteinische Verwaltung sehr intensiv die tschechoslowakische Publizistik verfolgte, die sich mit ihrer causa beschäftigte, eingeschlossen die Kommentare zur Tätigkeit Karls I. von Liechtenstein nach der Schlacht am Weißen Berg. In dieser Hinsicht nahm man die publizistische Tätigkeit von Jaroslav Hrubant wahr, dessen Artikel ins Deutsche übertragen wurde. Zugleich entstanden Dokumente und Artikel, in denen Karls positive Handlungen gegenüber Teilnehmern des Ständeaufstands und deren Verwandten hervorgehoben wurden, wobei diese Materialien in geeigneten tschechoslowakischen Zeitungen und Zeitschriften erschienen. Die ganze Angelegenheit dieses historiographisch-juristisch-publizistischen Duells nach 1918 bzw. 1945 erweist sich dessen ungeachtet als kompliziert und würde eine eigene Veröffentlichung erfordern. HAL Wien, FA, Kart. 647, u. a. Dokument „Zeitung ,Svobodné Slovo“ vom 15. August 1945. Einmarsch der Liechtensteinischen in Böhmen. JUDr. und PhDr. Jar. Hrubant“. Hrubant zählte zu den radikalsten Kritikern des Wirkens der Familie Liechtenstein in den böhmischen Ländern. Für seine Kritik nutzte er sog. historische Argumente, in erster Linie verwies er auf das Auftreten Karls I. von Liechtenstein nach der Schlacht am Weißen Berg. Hätte es die Konfiskation nach 1620 nicht gegeben, wären die Liechtenstein ihm zufolge eine „unbedeutende deutsche Familie aus Österreich“ geblieben. In der Familie Liechtenstein erblickte Hrubant gleichsam eine „fünfte Kolonne“. Vgl. Hrubant, Jaroslav: Liechtensteinové. K dějinám páté kolony u nás (Die Liechtenstein. Zur Geschichte der fünften Kolonne bei uns), Praha 1945. 
František Hrubý und Franz Wilhelm knüpften dabei in ihren Positionen des Archivrats und späteren Direktors des Mährischen Landesarchivs auf der einen und des Direktors des Familienarchivs der Fürsten von Liechtenstein auf der anderen Seite vielschichtige Kontakte, etwa als es galt, die Situation des liechtensteinischen Archivs auf Schloss Butschowitz bzw. den Umgang mit den in den wertvollen Schlosssälen gelagerten Archivalien und die Einhaltung der damaligen Regeln des Umgangs mit Archivalien seitens des liechtensteinischen fürstlichen Personals zu klären. Die Kontakte in diesen Fragen dürfen dabei keineswegs ausschließlich konfliktbeladen bezeichnet werden. ${ }^{19}$

In jedem Falle sind sich beide Seiten der faktischen und symbolischen Zusammenhänge zwischen dem aktuellen Geschehen, das in die erste Bodenreform in der Tschechoslowakei und die Parzellierung des liechtensteinischen Besitzes mündete, sowie der historischen Rolle Karls I. von Liechtenstein im Konfiskationsprozess nach 1620 bewusst. Eine Differenzierung zwischen den Argumentationen der beiden bedeutenden Historiker ist dabei unter anderem auch deshalb möglich, da Karl I. von Liechtenstein in der Zeit des Ständeaufstands sowie im nachfolgenden Prozess von dessen Niederlage und der Bestrafung sich wandelnde politische Einstellungen, verschiedene offizielle amtliche Funktionen in der ständischen Gesellschaft bzw. am kaiserlichen Hofe, unterschiedliche, aus der Stellung als Oberhaupt des Fürstenhauses Liechtenstein hervorgehende Interessen vertrat und somit gleich mehrere unterschiedliche Rollen spielte.

\section{Mähren: Karl I. von Liechtenstein als Opfer der ständischen Konfiskationen}

In der Frühen Neuzeit betrachtete man Konfiskationen keineswegs als einmalige Angelegenheit. Im Gegenteil! Diese galten als natürlicher Bestandteil einer verhängten Sanktion aufgrund eines begangenen Delikts gegen das Oberhaupt des Staates. Diese Tatsache lässt sich offenkundig als Überbleibsel des Lehnssystems interpretieren. In der aktuellen Rechtssituation musste dies dabei nicht davon abhängen, ob der konfiszierte Besitz Lehnscharakter besaß (was in Mähren nach 1620 beispielsweise für bischöfliche Güter zutraf) oder ob es sich um ein freies Tafelgut, d. h. in den Landtafeln verzeichnetes Gut, handelte. Um 1600 ging man im mitteleuropäischen Milieu vonseiten des Herrschers zur Konfiskation des Besitzes in Einzelfällen gleich mehrfach über, unter anderem im Falle von Christoph und Georg von Lobkowitz. Im allgemeinen Bewusstsein der damaligen

19 In der Zwischenkriegszeit äußerte das Institut für Denkmalpflege in Brünn Befürchtungen hinsichtlich des Umgangs mit Archivalien und der Beschädigung des Interieurs in Schloss Butschowitz durch eine Manipulierung der historischen Dokumente. František Hrubý verfasste für die Organe der Denkmalpflege Gutachten, denen zufolge derartige Befürchtungen unbegründet erschienen und lediglich entbehrliche Dokumente entsprechend den geltenden Vorschriften skartiert worden seien. Národní památkový ústav Brno, Starý památkový archiv, fond Bučovice (Nationales Denkmalinstitut Brünn, Altes Denkmalpflegearchiv, Fond Butschowitz), Korrespondenz F. Wilhelm - F. Hrubý. Knoz, Tomáš - Drašnar, Vojtěch: Konstrukce obrazu lichtenštejnského knízecího domu v moravské památkové péći (Die Konstruktion des Bildes des Fürstenhauses Liechtenstein in der mährischen Denkmalpflege). Časopis Matice moravské 134, 2015, Supplementum 7, S. 95-131. 
Zeitfindet sich darüber hinaus eine massenhafte Applizierung der Konfiskation vor allem nach der Niederlage der sog. ersten antihabsburgischen Rebellion im Jahre 1547. ${ }^{20}$ Die Ständedirektorien, die selbst die Legalität der Staatsgewalt dedizierten, applizierten in Böhmen und auch in Mähren in den Jahren 1618 bis 1620 die Sanktion der Konfiskation, auch wenn sie sich (im Falle Böhmens) der Verletzung des Majestätsbriefes Rudolfs II. bewusst waren und mit diesem Akt in evidenter Weise den Rubikon eines möglichen künftigen Kompromisses mit Kaiser Matthias bzw. mit Ferdinand II. überschritten. Beide Direktorien bzw. beide Landtage stellten jene juristischen und physischen Personen, die es ablehnten sich ihrer Autorität zu unterwerfen, außerhalb des Gesetzes. ${ }^{21}$

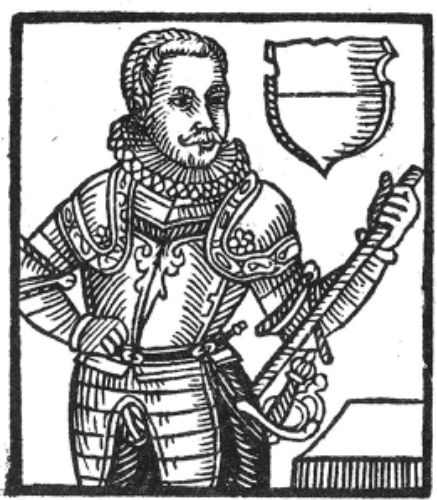

Abb. 1. Karl von Liechtenstein als junger protestantischer Adeliger

Der im Verlaufe des Ständeaufstands durch das mährische Direktorium geleitete Konfiskationsprozess verlief in mehreren Phasen. Die ersten Konfiskationen wurden unmittelbar nach dem Sieg der radikalen Partei auf dem Brünner Landtag im Mai 1619 verkündet, als es um die Beschlagnahme des Besitzes der Gesellschaft Jesu, Albrechts von Wallenstein, Adam Levs Licka von Riesenburg, Georgs von Nachod und Wilhelm Brabantskýs von Chobřany ging. ${ }^{22}$ Die zweite Phase berührte bereits die Person Karls I. von Liechtenstein. Auf dem Brünner Landtag, der nach der Erinnerung an die Verwandlung des Herren, d. h. nach dem Sieg der Stände bei Unter Wisternitz (Dolní Věstonice) stattfand, kam es zur Beschlagnahme der Güter jener Mährer, dies sich im August des Jahres

20 Pánek, Jaroslav: Proní krize habsburské monarchie (Die erste Krise der Habsburgermonarchie). In: Vorel, Petr (Hg.): Stavovský odboj roku 1547. První krize habsburské monarchie. Pardubice - Praha 1999, S. 11-28; Rezek, Antonín: Statky skonfiskované r. 1547 a jejich rozprodávání(Die im Jahre 1547 konfiszierten Güter und deren Verteilung). Památky archeologické 10, 1874-1877, S. 451-482.

21 Knoz, T.: Pobělohorské konfiskace. Moravský průběh, středoevropské souvislosti, obecné aspekty (Die Konfiskationen nach 1620. Der Verlauf in Mähren, die mitteleuropäischen Zusammenhänge, allgemeine Aspekte). Brno 2001; Ders.: Political Culture in the Period of the Estates Rebellion, the Post-White Mountain Confiscations and the Thirty Years War. In: Manikowska, Halina - Pánek, Jaroslav - Holý, Martin (Hg.): Political Culture in Central Europe (10th - 20th Century). Prague 2005, S. 283-295

22 „O vypovědění některých osob ze země“ (Über die Verbannung einiger Personen aus dem Lande). Moravský zemský archiv Brno (MZA), A 3, Stavovské rukopisy, Památky sněmovní, Bd. 7, fol. 144r-150r. 
1619 an den Kämpfen gegen das Ständeheer beteiligt und eine Unterwerfung unter das Direktorium abgelehnt hatten. Damals wurden die Güter Karls von Liechtenstein, Zdeněk Žampachs von Pottenstein, Georgs d. Ä. Kavka von Říčany, Kardinal Franz' von Dietrichstein sowie des Olmützer und Brünner Kapitels konfisziert. ${ }^{23}$ Der dritte analoge Eingriff in die Form des Grundbesitzes war die Aufhebung des Lehnssystems des Bistums Olmütz und die Proklamation aller bisheriger Lehnsgüter zu freiem Allodialbesitz. Diese Maßnahme sollte die bisherige Macht des Bistums Olmütz gravierend beschränken und zur Säkularisierung des Landes beitragen. ${ }^{24}$

Die Prinzipien, die die mährischen Stände bei ihren Konfiskationen anwandten, waren insgesamt schlicht und unterschieden sich weder von den durch die böhmischen Stände noch später jenen durch Kaiser Ferdinand II. zur Geltung gebrachten Prinzipien. Die Konfiskation wurde dabei als rechtliche Sanktion für den Verrat gegenüber dem Staat aufgefasst, der damals also nicht durch den Herrscher, sondern Ständegemeinde, Landesrecht und Landessitte repräsentiert wurde und sich auf althergebrachte Gewohnheiten stützte. Diese besaßen ebenso einen rein rechtlichen als auch einen konfessionellen Charakter. Ähnlich wie in den übrigen Fällen waren die ständischen Konfiskationen in Mähren zielgerichtet gegen konkrete Personen gerichtet, die sich des Verrats durch ihre konkreten Taten schuldig gemacht hatten, beispielsweise Wallenstein durch sein Verhalten in Olmütz, die Flucht von seinem Heer und die Entfremdung des Landesgelder, oder Liechtenstein durch die Teilnahme am militärischen Auftreten gegen seine Ständegemeinde. ${ }^{25}$ Mit einer Konfiszierung wurden dabei stets die aktuellen Feinde belegt, die als „treulose Söhne der Heimat“ galten. Um die konfiszierten Güter sollte sich ein hierfür bestimmtes Regierungsorgan kümmern, das für die finanzielle Verwaltung (Direktor der Landesgelder) zuständig war. Die Landesregierung proklamierte im Einklang mit allgemeinen Prinzipien zudem einen Wettbewerb zum Erwerb der beschlagnahmten Güter, in dem Personen bevorzugt werden sollten, denen die eigenen Besitzungen während der ausgetragenen Kämpfe zerstört worden waren. ${ }^{26}$

Karl I. von Liechtenstein gehörte zu den bedeutendsten, von den ständischen Konfiskationen in Mähren betroffenen Personen. In der kaiserlich-höfischen und mährischen Ständepolitik knüpfte er an die lange Tradition seiner Familie an und engagierte sich hier von Jugend an. An der Wende vom 16. zum 17. Jahrhundert erklomm Liechtenstein in seiner

23 „Strany těch, kteříž se zjevně za nepřáteli této postavuji““ (Jene betreffend, die sich offen als Feinde gezeigt haben). MZA Brno, A 3, Stavovské rukopisy, Památky sněmovní, Bd. 7, fol. 152v-155r.

24 Der entsprechende Landtagsartikel lautete „Die Lehen des Bistums Olmütz betreffend“ Kardinal Dietrichstein wurde darin als Feind bezeichnet und auf diese Weise auch seine Verbannung aus dem Lande und die Beschlagnahme seiner Güter begründet. MZA Brno, A 3, Stavovské rukopisy, Památky sněmovní, Bd. 7, fol. 156-157.

25 So wurde beispielsweise Ladislaus von Lobkowitz durch den entsprechenden Artikel „Über den Herrn Hauptmann“ auf dem Landtag in Brünn am Montag nach dem zweiten Adventssonntag 1619 mit rückwirkender Gültigkeit („,bereits auf dem vorangegangenen Landtag“) enteignet und in seine Funktion Ladislaus Velen von Žerotín eingesetzt. MZA Brno, A 3, Stavovské rukopisy, Památky sněmovní, Bd. 7, fol. 161v.

26 „Die Bewohner betreffend, die vom Feind Schaden erlitten hatten“. MZA Brno, A 3, Stavovské rukopisy, Památky sněmovní, Bd. 7, fol. 163r. 
ständischen Karriere den höchstmöglichen Gipfel, als er zum mährischen Landeshauptmann aufstieg. Zuerst agierte er als einer der führenden Vertreter der protestantischen mährischen Stände als Vertreter des erkrankten Landeshauptmanns Friedrich von Žerotín und zugleich als oberster Landrichter. Dabei sollte nicht einmal der Übertritt zum Katholizismus seiner Karriere schaden. Mit Unterstützung Kaiser Rudolfs II. und der katholischen Partei in Mähren wurde er zum Landeshauptmann gewählt und in dieser Funktion wirkte er in den Jahren 1604-1607. ${ }^{27}$ Nach der Berufung zum Mitglied des kaiserlichen Geheimen Rates, der Ernennung zum böhmischen Obersthofmeister und Fürsten von Troppau (Opava) begannen sich seine politische Ambitionen in eine etwas andere Richtung zu entwickeln und Liechtenstein, der in der Zwischenzeit nach anfänglichen Misserfolgen das Vertrauen von Rudolfs Nachfolger Matthias zu erwerben vermochte, übte in der unmittelbar dem Ständeaufstand vorausgehenden Zeit keinerlei ständische Ämter mehr aus..$^{28}$ Doch auch zu diesem Zeitpunkt verließ er keineswegs die politische Bühne Mährens. Der Ständeaufstand ereilte ihn in Brünn, und es drohte die Gefahr, dass er zu einem Kompromiss mit den Aufständischen gezwungen werden könnte oder letztere ihn ins Gefängnis werfen würden. ${ }^{29}$ Zur rechten Zeit jedoch gelang ihm die Flucht nach Wien. Die mährischen Stände schritten zwar - im Unterschied zu Wallenstein -, zur Konfiskation seiner Güter erst mit einem gewissen zeitlichen Abstand und verwiesen ihn (in der aktuellen Lage eher symbolisch) des Landes, doch zeichnete sich diese Handlungsweise weder durch eine durchdachte politische Taktik noch durch ein juristisches Vorgehen aus. Die Anklage lautete demzufolge auch anders. Dem Fürsten von Troppau wurden „lediglich“ dessen Weggang aus dem Lande, sein Nichterscheinen vor dem aufständischen Landtag, die Weigerung, der Konföderation beizutreten und das Nichtablegen des geforderten Eids vorgeworfen. Seine Güter sollten daher auf der Grundlage einer Entscheidung der Stände aus dem Jahre 1620 „zu Händen des Landes" gehen. Sie sollten nicht verkauft und auch an keinerlei Einzelpersonen übergeben werden, sondern als Besitz aller (in diesem Augenblick) drei Landstände gelten, darüber hinaus war geplant, aus ihnen nicht den weiteren Verlauf des Aufstands zu finanzieren. Es bestand „lediglich“ die Notwendigkeit, für die einzelnen liechtensteinischen Güter einen loyalen und dabei fachlich kompetenten Verwalter zu finden. ${ }^{30}$

27 Válka, Josef: Vlastivěda morauská. II. Morava reformace, renesance a baroka (Mähren während der Reformation, Renaissance und des Barock). Praha 1995; Boček, Antonín: Přehled knižat a markrabat i jiných nejuyššich di̊stojniků zemských v Markrabstvi moravském (Übersicht zu den Fürsten und Markgrafen sowie anderen höchsten Würdenträgern auf Landesebene in der Markgrafschaft Mähren). Brno 1850.

28 Im kaiserlichen Geheimen Rat saß Liechtenstein in den Jahren 1600-1607 und 1612-1627. Er fehlte hier also lediglich in der Zeit des sog. habsburgischen „Bruderzwists“. Vgl. Schwarz, Henry Frederick: The Imperial Privy Council, s. 281-283. Khevenhüller (Khevenhiller), Franz Christoph: Conterfet-Cupferstich. II. Leipzig 1722, pag. 39.

29 Die Stände verlangten beispielsweise von Karl von Liechtenstein, dass seine Eisgruber Untertanen dem Ständeheer Proviant stellen sollten. Liechtenstein hatte jedoch zu dieser Zeit bereits der kaiserlichen Partei Proviant geliefert, so dass die Stände sein Haus in Znaim (Znojmo) konfiszierten, wo dieses Getreide gelagert wurde. Vgl. Urbánková-Hrubá, Libuše (Hg.): Povstáni na Moravě v roce 1619. Z korespondence moravských direktorů (Der Aufstand in Mähren im Jahre 1619. Aus der Korrespondenz der mährischen Direktoren). Praha 1979, S. 171, 174.

Dem Fürsten Liechtenstein wurde offeriert, zu einem festgelegten Termin seine mährischen Güter zu ver- 
Die Güter Karls von Liechtenstein, die im Sommer des Jahres 1619 die ständische Konfiskation betreffen sollte, wiesen einen doch ziemlich bedeutenden Umfang auf. František Hrubý zufolge umfassten sie zum betreffenden Zeitpunkt die Dominien Eisgrub (Lednice) und Auspitz (Hustopeče) mit 659 ansässigen Untertanen, die Herrschaft Černahora (Černá Hora) mit 307 Untertanen, das Gut Mährisch Aussee (Úsov) mit 1303 ansässigen Untertanen sowie das Gut Plumenau (Plumlov) mit Prossnitz (Prostějov) mit wiederum 1403 Untertanen. ${ }^{31}$ Aus dem genannten Verzeichnis geht hervor, dass es sich mit Blick auf den Umfang der Güter, die geographische Lage und Geschichte im Rahmen des Landes und der liechtensteinischen Dominien keineswegs um einen homogenen Besitz handelte. Die mährischen Direktoren verfügten nicht einmal in der „siegreichen Zeit“ nach der Schlacht bei Unter Wisternitz über ausreichend Kräfte, um den legislativen Akt der Konfiskationen in die Tat umzusetzen. Auf der anderen Seite standen aber auch dem betroffenen Fürsten Karl I. von Liechtenstein nicht genügend Mittel zur Verfügung, sich effektiv gegen die ständischen Konfiskationen zu verteidigen - weder juristisch noch militärisch. Unter den gegebenen Umständen versuchte er dennoch sowohl die inneren Zerwürfnisse innerhalb der mährischen Ständegemeinde wie auch die erwähnte Disparität der eigenen Güter auszunutzen. Wohl für am meisten bedroht sah er seine traditionellen Familiengüter, d. h. vor allem Eisgrub. Besser für eine Verteidigung geeignet schienen ihm hingegen jene Besitzungen, die er durch die Vermählung mit Anna Maria von Boskowitz erworben hatte, wo er im Bedarfsfall mit dem Verweis auf das Ehegut bzw. die Tradition dieser bedeutenden mährischen Aristokratenfamilie argumentieren konnte. Im Lande befanden sich darüber hinaus auch die Güter seines Bruders Maximilian von Liechtenstein, auf die sich die Konfiskationsmaßnahmen der Stände freilich nicht bezogen. Die Reaktionen Karls von Liechtenstein auf die ständischen Konfiszierungen bedürfen im Grunde genommen weiterer spezieller Forschungen, dessen ungeachtet lässt sich beispielsweise aus den liechtensteinischen Rechnungsbüchern die vorläufige Schlussfolgerung ziehen, dass Karl von Liechtenstein gerade auf die subjektiv weniger bedrohten mährischen Güter einige seiner Aktivitäten

kaufen und nachfolgend das Land zu verlassen. Der entsprechende, auf dem Olmützer St. Veits-Landtag des Jahres 1620 verabschiedete Artikel lautete „Den Fürsten Liechtenstein betreffend“ und es hieß hierin: „Da der Fürst und Regent des Hauses Liechtenstein nicht in das Land zurückkehren und unserer Konföderation gegenüber keinen Eid ablegen will, hat unser Landtag sodann beschlossen, dass insonderheit die auf den Generallandtagen auf der Prager Burg beschlossenen Punkte, zur Anwendung kommen, in denen klar festgelegt wurde, das demjenigen, der unserer Konföderation gegenüber keinen Schwur zu leisten bereit ist, die Güter entzogen werden sollen und an das Land fallen, und zwar deshalb, weil der betroffene Fürst auf Seiten der gegnerischen Partei verbleibt und sich dort gegen uns stellt, weshalb wir, d. h. alle drei Stände der Markgrafschaft Mähren, gemeinsam beschlossen haben, dass alle und jederart Güter desselben im Lande dem Gemeinwohl dienen mögen. [...]." MZA Brno, A 3, Stavovské rukopisy, Památky sněmovní Bd. 7, fol. 212v-213. David, Jiří: Moravské zemské sněmy v trícetileté válce (Die mährischen Landtage im Dreißigjährigen Krieg). Brno 2003 (an der Philosophischen Fakultät der Masaryk-Universität Brünn eingereichte Bachelorarbeit), S. 13-15.

31 Hrubý, F.: Moravská šlechta roku 1619, její jměni a náboženské vyznání (Der mährische Adel des Jahres 1619, sein Besitz und sein konfessionelles Bekenntnis). Časopis Matice moravské 46, 1922, S. 107-169. 
richtete (vor allem seinen hier Prossnitz und Plumenau genannt, unter Umständen auch Maximilians Butschowitz). ${ }^{32}$

Noch bevor die Güter der Anhänger der kaiserlichen Partei in der Praxis beschlagnahmt und neuen Interessenten übereignet wurden, wendete sich das Blatt und an die Stelle der Vollendung der Konfiskationen wurde der Prozess der Restitutionen eingeleitet.

Hinter dem Begriff „Rückführung in den ursprünglichen Stand“ verborgt sich eine der wesentlichen ideologischen und juristisch-theoretischen Klauseln für sämtliche Veränderungen, die sich in Regie Ferdinands II. in den böhmischen und in bedeutendem Umfang auch in den österreichischen Ländern nach der Schlacht am Weißen Berg vollzogen. Die Restitution von Grundbesitz musste dabei aus rechtlicher Sicht keineswegs durch ein besonderes Gesetz bzw. eine Entscheidung des Herrschers oder des mährischen Gubernators durchgeführt werden. In dieser Hinsicht beruhte sie im Gegenteil auf einer Proklamation des Kaisers, die aus rechtlicher Sicht alle legislativen Akte, die durch das Ständedirektorium sowie sämtliche mährischen Landtage und diesen unterstellte Organe beschlossen worden waren, von Beginn an für null und nichtig erklärte. In den Büchern der „Denkwürdigkeiten der mährischen Landtage“ zeigte sich die angesprochene kaiserliche Verfügung dergestalt, dass die entsprechenden, von den Landtagsschreibern in der Zeit des Aufstands beschriebenen Seiten einfach durchgestrichen wurden. ${ }^{33}$ Damit beseitigte man sämtliche aufständischen Rechtsakte, einschließlich der Gesetze, die die Güter der Institutionen und einzelnen Adeligen - die sich nach Auffassung des Ständedirektoriums des Verrats am eigenen Land und des vor den Ständeorganen abzulegenden Eids schuldig gemacht hatten - zu konfiszieren anordneten. Alle weiteren rechtlichen und politischen Begründungen für Restitution und Re-Introduktion schienen nämlich aus Sicht einer strengen juristischen Logik überflüssig zu sein. In der Rechtspraxis in Mähren in den zwanziger Jahre des 17. Jahrhunderts kann man eine subsidiäre Begründung dieses Schrittes Kaiser Ferdinands dennoch antreffen. Vor allem wurde die Rechtsgültigkeit der Konfiszierung, soweit diese von anderen als den rechtmäßig durch den Herrscher inthronisierten Personen durchgeführt wurde, in Zweifel gestellt. Ohne dass der Kaiser grundsätzlich die „alte Rechte“ des mährischen Landtags und weiterer Ständeorgane hätte negieren müssen, definierten die Juristen das Konfiskations- und Restitutionsrecht nämlich als ein ausschließlich königliches Regal, das aus dem mittelalterlichen Lehnsrecht abgeleitet worden sei und mit dessen Hilfe der Herrscher seine Untertanen disziplinierte. ${ }^{34}$

Restitution und Re-Introduktion können als rein rechtliche Begriffe aufgefasst werden, die allerdings auf der Grundlage konkreter Bedingungen der Zeit um 1620 in Mäh-

32 Als Beispiel lassen sich hier die baulichen Aktivitäten in Prossnitz und Plumenau im Betrachtungszeitraum anführen HAL Wien, Herrschaften $(\mathrm{H})$, Kart. 77, Materialien Hofzahlakten.

33 MZA Brno, A 3, Stavovské rukopisy, Památky sněmovní, Bd. 7, fol. 142r-216r. Knoz, T.: Pobělohorské konfiskace (Die Konfiskationen nach 1620), Kap. Restituce, rehabilitace a reintrodukce (Restitution, Rehabilitation und Re-Introduktion), S. 123-143, hier v. a. S. 124

34 Sturmberger, Hans: Ferdinand II. und das Problem des Absolutismus. Wien 1957, Kap. Fürst und Stände nach der böhmischen Katastrophe, S. 23-31, bzw. das Kap. Der Kaiser und die Ragione di stato, S. 38. 
ren eine Applikation fanden. Als Restitution definierte man in den kaiserlichen Mandaten zu Beginn der zwanziger Jahre des 17. Jahrhunderts die Rückgabe sämtlichen Besitzes an Boden und beweglicher Habe an jene physischen Personen und Institutionen, die auf der Grundlage der entsprechenden Konfiskations- und legislativen Entscheidungen des aufständischen Landtages aus dem Jahre 1619 vorbereitet worden war. ${ }^{35}$ Die Re-Introduktion wiederum betraf laut Auffassung der kaiserlichen Hoforgane in der Ära nach 1620 auch die Wiedereinführung der pro-kaiserlich orientierten geistlichen und weltlichen Personen. Dies waren durch die ständischen Rebellen nicht allein um ihren Landbesitz gebracht worden, wie man für gewöhnlich betonte, sondern zugleich auch ihrer ständischen Rechte für verlustig erklärt und häufig darüber hinaus zugleich mit physischer Gewalt aus dem Lande vertrieben worden. Vor allem jedoch hatten sie ihre Ämter und Funktionen verloren, die ihnen vor Ausbruch des Ständeaufstands Geld und politische Macht garantiert hatten. ${ }^{36}$

Die Restitution der liechtensteinischen Güter erfolgte unter ähnlichen Umständen wie beispielsweise im Falle Wallensteins. Der Unterschied bestand lediglich darin, dass die vormaligen Untertanen Karls I. von Liechtenstein im Gegensatz zu Wallensteins widerspenstigen Wallachen ihrem Herrn der Zeit vor 1620 sehr bald ihre Loyalität zu bekunden begannen. Diesen schlossen sich bald auch weitere Mährer an, die sich vom Einfluss des Fürsten eine Verhinderung plündernder Truppen erhofften. So verhielten sich beispielsweise bereits am 10. Januar 1621 Bürgermeister und Rat der Stadt Littau (Litovel), als sie betonten, dass die Littauer unter allen Umständen Karl I. von Liechtenstein Treue und Gehorsam wahren wollten und sie sich wie "Schafe ohne Hirten" fühlten.

Vom Fürsten Liechtenstein erwarteten sie, dass er die Stadt vor dem Wüten der Truppen und vor drohender Hungersnot schützen möge. Auch wenn Karl I. von Liechtenstein am Ende die Herrschaft Mährisch Aussee (zu der Littau gehörte) im Verlaufe des Aufstands nicht direkt unterstand bzw. er am Ende diese gar zu beherrschen vermochte, wurden ihm diese Güter nicht offiziell konfisziert, da es sich bei seiner offiziellen Besitzerin um Karls Gemahlin Anna von Boskowitz handelte, auf die sich nach althergebrachtem Recht die Konfiszierung von Besitz nicht bezog. ${ }^{37}$

35 Bei dem Begriff „restitutio“ bzw. „restitutio in integrum“ handelt es sich um eine natürlich im klassischen System des Römischen Rechts präsente Kategorie, aus der ihn auch im 17. Jahrhundert das Recht rezipierte. Vgl. Bartošek, Milan: Encyklopedie ř́mského práva (Enzyklopädie des römischen Rechts). Praha 1994, S. 238-239.

36 Artikel „O nařízení správy v zemi“ (Über die Ordnung der Verwaltung im Lande). MZA Brno, A 3, Stavovské rukopisy, Památky sněmovní, Bv. 7, Brünner Landtag nach st. Philippus und Jacobus 1619, fol. $147 \mathrm{r}$.

37 Hrubý, F. (Hg.): Moravské korespondence a akta (Mährische Korrespondenzen und Akten), I., S. 63-65. Als oberster Hauptmann des Fürsten Karl von Liechtenstein, dem auch Littau unterstand, agierte Georg Flott auf Bockstein und Dobromilitz, zu dem die Littauer angeblich keine guten Beziehungen pflegten. Flott war zwar oberster fürstlicher Hauptmann und hätte damit theoretisch auf der Seite Karls von Liechtenstein stehen sollen, nach der Niederlage des Ständeaufstands jedoch fand er sich in einer Urkunde unter den Schuldigen wieder und seine eigenen Güter wurden ihm durch die kaiserliche Konfiskationskommission zur Hälfte entzogen. Dobromilitz (Dobromilice) wurde später an den kaiserlichen Rat Hieronymus Bonacin verkauft. D'Elvert, Ch. (ed.): Confiscations- und Crida-Protokoll von 1624. In: Ders: Beiträge zur Geschichte der Rebellion, Reformation, des dreißigjährigen Krieges und der Neugestaltung Mährens im siebzehnten Jahrhunderte. Schriften der historisch-statistischen Sektion. Bd. 16. Brünn 1867, S. 265. 
Ein weiterer Unterschied bestand darin, dass Karl I. von Liechtenstein zu keinem Zeitpunkt an einen Ausverkauf seiner mährischen Güter dachte und dass er hier auch nach der Schlacht am Weißen Berg seine Hauptbesitzungen glaubte bewahren und den Besitz am Ende gar erweitern zu können, wenngleich er sich zu dieser Zeit politisch - ähnlich wie Wallenstein - bereits am kaiserlichen Hofe engagierte, neuerlich in das Herzogtum Troppau eingeführt worden war und zugleich in dieser Zeit bereits die Funktion des obersten böhmischen Statthalters bekleidete. ${ }^{38}$ Die faktische Re-Introduktion in die Wiederübernahme seiner vormaligen Güter und Würden erleichterten ihm zahlreiche mährische Adelige, die zwar noch kurz zuvor den Konfiskationsschritten des Ständedirektoriums ihre Zustimmung erteilt hatten, sich jetzt jedoch ihrer einstigen Freundschaft mit dem Troppauer Fürsten erinnerten und von diesem Hilfe in ihren eigenen Fällen sowie die Vermittlung eines jeweils individuellen Pardons durch den Kaiser erwarteten. ${ }^{39}$ Es hat den Anschein, dass Karl von Liechtenstein, der sich ansonsten sehr aktiv an der Bestrafung der Aufständischen beteiligte und der schließlich auch dem böhmischen und mährischen Exekutionstribunal vorsaß, für derartige Anliegen ein gewissen Verständnis aufbrachte. Der Senior der Brüderunität Georg Erastus gab schließlich das Verhalten und die Toleranz des Fürsten gegenüber nichtkatholischen Untertanen und Geistlichen Karls eigenem Bruder Gundaker von Liechtenstein zum Vorbild, und auch verschiedene nichtkatholische Adelige vom Typ eines Karl von Žerotín, die sich nicht sehr aktiv am Aufstand beteiligt hatten, erfreuten sich von Zeit zu Zeit seiner Fürsprache beim Kaiser. Karl von Liechtenstein gewann auf diese Wendemanöver nicht allein sehr schnell und ohne größere Verluste seine vor 1620 besessenen Güter und Ämter zurück, sondern vermochte diese in ungewöhnlichem Umfang zu erweitern. ${ }^{40}$

38 Zu Karls Position im Kontext des Ständeaufstands Petráň, Josef: Staroměstská exekuce (Die Altstädter Exekution). ${ }^{2}$ Praha 1995. Nach der Schlacht am Weißen Berg wurde Karl von Liechtenstein zum kaiserlichen Staathalter in Böhmen ernannt. Vgl. Press, V.: Das Haus Liechtenstein in der europäischen Geschichte, S. 44-47. Im Herzogtum Troppau und Jägerndorf wurde der fürstliche Besitz nicht allein restituiert, sondern gewann am Ende völlig an neuer Qualität. Zukal, Josef: Slezské konfiskace. Pokutováni provinilé šlechty v Krnovsku, Opavsku a Osoblažsku po bitvě bělohorské a po vpádu Mansfeldově (Die schlesischen Konfiskationen. Die Bestrafung des schuldigen Adels in Jägerndorf, Troppau und Hotzenplotz (Osoblaha) nach der Schlacht am Weißen Berg und nach dem Einfall Mansfelds). Praha 1916, S. 59.

39 Die auf dem Landtag in Brünn versammelten mährischen Stände sandten Karl von Liechtenstein am 21. Januar 1621 einen Brief, in dem sie zugunsten Johann Bernards von Fünfkirchen intervenierten, dem in Böhmen auf Befehl Liechtensteins dessen Besitzungen beschlagnahmt worden waren. Die mährischen Stände bezeugten ihrerseits, dass sich Fünfkirchen in ihrem Lande loyal gegenüber dem Kaiser verhalten habe, es folglich nicht zu einer Konfiskation seiner mährischen Güter kommen dürfe, zumal man Fünfkirchen nicht als geflohenen Rebellen bezeichnen könne. Fünfkirchen habe Böhmen heimlich verlassen, weil sein Schloss in Jung Woschitz (Mladá Vožice) vom Krieg und aufständischen Bauern heimgesucht worden sei, sein Sohn sich jedoch angeblich am kaiserlichen Hof aufhalte. Die Stände erwarteten, dass Liechtenstein ihre Gutachten zur Kenntnis nehme und Fünfkirchen vor dem Kaiser erscheinen könne. (Die Supplik wurde gleichzeitig ungeachtet der Tatsache verschickt, dass sich Fünfkirchen in Wahrheit am Ständeaufstand in Mähren beteiligt hatte.). Vgl. Hrubý, F. (Hg.): Morauské korespondence a akta (Mährische Korrespondenzen und Akten), I. Praha 1934, S. 67-68.

40 Der Verwalter des Brüderchores in Eibenschitz (Ivančice) Georg Erastus schrieb am 17. Dezember 1622 Gundaker von Liechtenstein einen Brief, in dem er eine Konvertierung zum Katholizismus ablehnte. Er bat darum, dass Gundaker die Böhmischen Brüder nicht von ihren Gütern vertreiben und ihnen die Freiheit lassen solle, wie dies auf seinen Besitzungen auch sein Bruder Karl handhabe: „...Anobrž i za to V[aši] 


\section{Böhmen: Karl von Liechtenstein als Garant der kaiserlichen Konfiskationen}

Die Konfiskationen nach 1620 in Böhmen bildeten den umfangreichsten und am genauesten applizierten Bestandteil des Gesamtprozesses politischer, rechtlicher und sozialer Veränderungen innerhalb der mitteleuropäischen Gesellschaft. ${ }^{41}$ Sie begleiteten praktisch die gesamte Regierungszeit des römischen Kaisers und böhmischen Königs Ferdinands II. und reichten zudem in gewissem Sinne über diese hinaus. ${ }^{42}$ Die Konfiskationen lassen sich dabei in zwei große Wellen untergliedern. Die erste Welle bildeten die eigentlichen Konfiskationen nach der Schlacht am Weißen Berg. Diese Welle setzte im Jahre 1620 ein, d. h. unmittelbar nach der Niederlage des Ständeaufstands, bzw. in einigen konkreten Fällen noch im Verlaufe der Kämpfe gegen die Aufständischen und das Ständeheer. ${ }^{43}$ Grundlegende Entscheidungen in der Frage der ständischen Konfiskationen

M[ilost] - pokorně žádáme, abyšte ruku ochranou nad námi, jako pán milostivý a vrchnost křestanská, otcovsky držeti a tomu, aby ani od jiných lidí překážek nám činěno nebylo, laskavě brániti ráčili pro hojnou a milostivou boží odplatu, poněvadž i J[eho] M[ilos]t kníže Karel z Liechtensteina, pan bratr V[aší] M[ilos]ti nejmilejší, v Prostějově i na jiných gruntech svých, kdež naši bratři jsou, milostivě jim toho příti ráčí..." (Und auch hierfür. Wir bitten Euer Gnaden untertänig, dass Ihr die schützende Hand über uns als mildtätiger Herr und christliche Obrigkeit väterlich haltet und auch darum, dass uns auch vonseiten anderer Menschen keinerlei Hindernis bereitet werde, dass Ihr liebevoll um reichen und mildtätigen göttlichen Lohn uns zu schützen geruht, zumal auch seine Gnaden Fürst Karl von Liechtenstein, Euer allerliebster Bruder, in Prossnitz und auf anderen seinen Gütern, wo sich unsere Brüder befinden, ihnen dies gnädig zu gewähren geruht...). An Karl von Liechtenstein wandte sich zu dieser Zeit darüber hinaus auch Karl d. Ä. von Žerotín, der vom Empfänger Hilfe bei der Restitution seiner ostböhmischen Herrschaft Brandeis an der Adler (Brandýs nad Orlicí) erbat. Hrubý, F. (Hg.): Morauské korespondence a akta (Mährische Korrespondenzen und Akten), I., S. 301-303, 449-451. Zu den Verhandlungen zwischen Žerotín und Liechtenstein vgl. des Weiteren Národní archiv Praha (NA), Stará manipulace, Fasz. Z 22, Nr. 4176/21, Kart. 2595, Žerotínové, Správa brandýských panství (Familie Žerotín, Verwaltung der Herrschaft Brandeis), fol. 19-20; Knoz, T.: Državy Karla staršího ze Žerotína po Bílé hoře. Osoby, př́běhy, struktury (Die Besitzungen Karls d. Ä. von Žerotín nach der Schlacht am Weißen Berg. Personen, Ereignisse, Strukturen. Brno 2001, S. 64-69. Vgl. darüber hinaus auch též Kokojanová, Michaela: Karel z Lichtenštejna a Prostějov (Karl von Liechtenstein und Prossnitz). In: Francek, Jindřich (Hg.): Rekatolizace v českých zemích. Sborník příspěvků z konference v Jičíně konané 10. září 1993. Jičín 1995, S. 119-124.

41 Evans, Robert John Weston: The Making of the Habsburg Monarchy. Oxford 1979. Zitiert nach der deutschen Version Evans, Robert John Weston: Das Werden der Habsburgermonarchie 1550-1700. Gesellschaft, Kultur, Institutionen. Wien - Köln - Graz 1986.

42 Die Konfiskationen nach der Schlacht am Weißen Berg verliefen in Böhmen in Gestalt des Wirkens verschiedener Revisions- und Liquidationskommissionen noch in der zweiten Hälfte des 17. Jahrhunderts. Das sog. „Zweite Revisions- und Liquidationsprotokoll“ stammt beispielsweise aus den Jahren 1662-1663, ähnliches Material ist für die Jahre 1669-1689 überliefert. NA Praha, 23, ČDKM - Rukopisy, Nr. 92, Auszug aus dem fortgesetzten Inventario der in der Kay. König. Böhmischen alten Cammer-Registratur zu Prag befindlichen Schriften Sub. Rubr. zur Confiscations- Revisions- und Liquidations- Sache gehörigen Bücher, worauf nachstehende Rubricum zu lassen. (Zweytes Revisions- und Liquidations-Protocollum ab anno 1661-1663. Per extensum ringetragene Kay. Befehle und Schreiben, so an die Königl. Revisions- und Liquidations-Commission ergangen ab A. 1669 bis 1689.), fol. 1-5. František Kavka führt aus, dass die Konfiskationen in Böhmen nach 1620 insgesamt 680 Personen betrafen, von denen 166 ihren gesamten Besitz, 45 Personen zwei Drittel, 128 die Hälfte ihres Besitzes, 215 schließlich ein Drittel verloren. Der Allodialbesitz von 112 Personen verwandelte sich in ein Lehen. Kavka, František: Bílá hora a české dějiny (Der Weiße Berg und die tschechische Geschichte). Praha 1962, S. 240.

43 Tomáš V. Bílek untergliederte seine Darstellung in mehrere Kapitel, die zugleich die innere Periodisierung des böhmischen Konfiskationsprozesses bzw. seine erste Welle reflektieren: 1. Vorbereitungen für 
in Böhmen wurden noch im Verlaufe des Jahres 1620 sowie im nachfolgenden Jahr 1621 getroffen. Für das Jahr 1622 darf die erste Phase der ständischen Konfiskationen in Böhmen als mehr oder weniger abgeschlossen angesehen werden. Die Verhandlungen über das Schicksal der konkret konfiszierten Herrschaften fanden dann im nachfolgenden Abschnitt statt und verliefen in mehreren Phasen. Zunächst bis zum Jahr 1624, dann bis zur Verabschiedung der Verneuerten Landesordnung (und zugleich bis zum Zeitpunkt des Todes des Statthalters Karl von Liechtenstein) $1627 .{ }^{44}$ In geringem Umfang fanden die böhmischen Konfiskationen dann in den Jahren 1828 bis 1634 ihren Ausklang.

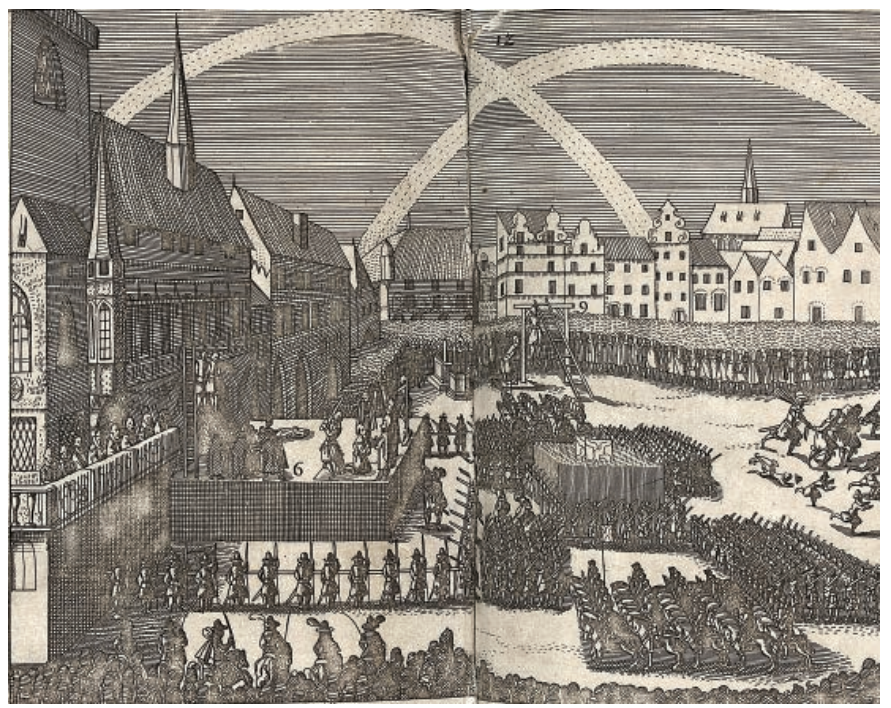

Abb. 2. Die Prager Exekution unter dem Vorsitz Karl's von Liechtenstein

die Bestrafung der Aufständischen nach der Schlacht am Weißen Berg. 2. Ergreifung der Rädelsführer der vorangegangenen Rebellion. 3. Die vom Kaiser eingerichtete Exekutionskommission gegen die führenden Vertreter des böhmischen Aufstands. 4. Geldbußen für die Anführer und führenden Repräsentanten des böhmischen Aufstands. 5. Durchführung der Exekutionen der führenden Teilnehmer des Aufstands, der aus dem Lande verbannten Personen und Städtebürger. 6. Einrichtung der Konfiskationskommission zur Bestrafung der übrigen Teilnehmer des Aufstands. 7. Verurteilung zur Lehnspflicht. 8. Kommission zur Gewährung eines Pardons und Überlassung der Güter für einige Rebellen aus dem höheren Stand, die sich weniger schuldig gemacht haben, und Aufhebung der Konfiskationskommission. 9. Zur Untersuchung der Schulden und Forderungen auf den konfiszierten Gütern eingerichtete Kommission. 10. Verpfändung, Verkauf und Verteilung der Güter. Vgl. Bílek, T. V.: Dějiny konfiskací (Geschichte der Konfiskationen), S. XXV. Den Terminus „Welle“ nutzte im Zusammenhang mit der mehrere Phasen umfassenden Konfiskation in Böhmen auch Petr Čornej, der von der „ersten Konfiskationswelle nach der Schlacht am Weißen Berg“ (nach 1620), „Konfiskationen nach dem sächsischen Einfall“ (nach 1631) und den „Konfiskationen der Güter Wallensteins“ (nach 1634) spricht. Vgl. Čornej, Petr: Vliv pobělohorských konfiskaci na skladbu feudálni tř́dy (Der Einfluss der Konfiskationen nach 1620 auf die Zusammensetzung der feudalen Klasse). Acta Universitatis Carolinae. Philosophica et Historica 1. Studia historica 14, 1976, S. 165-194, hier S. 178-189.

44 Nach dem Tode Karls von Liechtenstein wurde über die Durchführung der Revision einiger Konfiskationsschritte entschieden. Dies geschah u. a. deshalb, weil sich zahlreiche Personen gemeldet hatten, die auf Verhandlungen mit dem Fürsten Liechtenstein verwiesen, die zum gegebenen Zeitpunkt niemand glaubwürdig zu bezeugen wusste. 
Zu Beginn der zwanziger Jahre des 17. Jahrhunderts bzw. nach der siegreichen Schlacht am Weißen Berg schien es, als ob das Amt des kaiserlichen Staathalters in den einzelnen von den Habsburgern beherrschten Ländern eine Schlüsselrolle im politischen, rechtlichen und auch ökonomischen Kontext einnehmen würde. Diese Tatsache war selbstverständlich durch das verfassungsrechtliche Erbe der entstehenden Habsburgermonarchie vorgezeichnet, in der innerhalb der komplizierten Struktur eines „zusammengesetzten“ Staates die Länder auch weiterhin eine grundlegende Rolle spielten. Auf der Ebene der Länder hatten in den zurückliegenden Jahren die Landstände bzw. die ständischen Landesdirektorien die Ständerebellionen geleitet. Aus der Position des Landes sollte - trotz der unbestrittenen Zunahme der Rolle der zentralen Organe - auch deren Bestrafung geregelt werden. Auf Landesebene sollte schließlich die Disziplinierung und Restrukturalisierung der bisherigen Ständegesellschaft stattfinden. Selbstverständlich wurden nicht alle Länder im Untersuchungszeitraum als gleichbedeutend angesehen; neben anderen Gründen auch deshalb, weil zwischen dem imaginären Zentrum am kaiserlichen Hof und den Ländern eine „Gruppe von Ländern“ eine nicht wichtige Rolle spielte. Im Falle der Länder der St. Wenzels-Krone, in rechtlichen Dokumenten bezeichnenderweise immer mehr mit dem Begriff „Böhmen und seine inkorporierten Länder“ bezeichnet, verwies die Rolle Böhmens auf der einen Seite auf die gemeinsame Geschichte der Länder der Böhmischen Krone mit einigen gemeinsamen Ämtern und Institutionen, zugleich aber auch auf die aktuelle Rolle Prags und Böhmens im Ständeaufstand, wie auch auf die Vereinfachung der Exekutionsprozesse zum Zwecke eine leichteren Durchsetzung künftiger Disziplinierung. Der Beginn der Konfiskationen als ein Bestandteil der breiteren Bestrafung der Rebellen wird gemeinhin mit den Beschlüssen des damaligen kaiserlichen Kommissars für Böhmen, Herzog Maximilians von Bayern, vom 10. und 20. November 1620 in Verbindung gebracht. Den böhmischen Ständen wurde hierin eine verpflichtende Huldigung dem Kaiser gegenüber auferlegt. Den zeitgenössischen Gewohnheiten zufolge und analog zu ähnlichen Erlässen für Österreich gehörte hierzu auch eine Klausel, sie sich auf Personen bezog, die es - unter welchem Einwand auch immer - abgelehnt hatten, dem Kaiser zu huldigen. Die Hauptvertreter des Aufstands sollten "mit ihrem Leben und ihren Gütern" bestraft werden, alle Teilnehmer am Aufstand sodann an Gütern und beweglicher Habe. Der Erlass Maximilians von Bayern wurde durch Kaiser Ferdinand II. höchstpersönlich bestätigt, und zwar in einem Schreiben an den Präsidenten der böhmischen Hofkanzlei Wilhelm Slawata von Chlum sowie Fürst Karl von Liechtenstein. Seit Anfang Dezember 1620 konnten die Konfiskationen nicht allein rechtlich, sondern auch physisch mit Hilfe der hierfür bestimmten Konfiskationskommissare beginnen. ${ }^{45}$

45 Tomáš V. Bílek zufolge wurden auf Befehl Liechtensteins am 9. Dezember 1620 Exekutions- und Konfiskationskommissare in alle Kreise des Königreichs Böhmen entsandt. An deren Spitze stand Don Don Martin Huerta. Bílek, T. V.: Dějiny konfiskací (Geschichte der Konfiskationen), S. XXVI-XXVII; D’Elvert, Christian: Die Bestrafung der böhmischen Rebellion, insbesondere die Correspondenz Ferdinand II. mit dem Fürsten Liechtenstein. Brünn 1868; Válka, J.: Česká společnost v 15.-18. století. II. Bělohorská doba. Společnost a kultura „manýrismu“ (Die tschechische Gesellschaft im 15.-18. Jahrhundert. II. Die Zeit nach 1620. Gesellschaft und Kultur des „Manierismus“). Praha 1983, S. 80-81. 
Die „böhmische Mission“ Karls von Liechtenstein begann im Jahre 1621 mit seiner Ernennung zum Präsidenten im Strafprozess gegen die Rebellen ${ }^{46}$ und fand im Januar 1622 mit der Berufung in das Amt des königlichen Statthalters ihre Fortsetzung. ${ }^{47}$ Karl I. von Liechtenstein vermochte dank seiner persönlichen Ambitionen und aufgrund der zeitgenössischen Umstände diesem Amt ein neues Gewicht zu verleihen. Er wurde über die übrigen „obersten Landesbeamten“ unter anderem dadurch gestellt, dass ihm im Jahre 1620 der Kaiser den Fürstentitel bestätigte, was angesichts der Umstände der ursprünglichen Erhebung im Jahre 1608 ein wenig widersprüchlich aufgefasst werden könnte. ${ }^{48}$ Zuweilen wird angeführt, Karl von Liechtenstein habe sich angeblich wegen des Amts des Statthalters in Böhmen mit Kardinal Dietrichstein getroffen, aus den archivalischen Quellen wird dieser Konkurrenzkampf eher nur indirekt ersichtlich, dessen ungeachtet fand die Konkurrenz zwischen beiden auch in den Folgejahren ihre Fortsetzung. ${ }^{49}$

Im Mandat Kaiser Ferdinands II. wird im Zusammenhang mit Karl von Liechtenstein im Einklang mit der üblichen Rhetorik auf die Dienste verwiesen, die letzterer zu Gunsten von Ferdinands Vorgängern auf dem Kaiserthron und zu seinem eigenen Vorteil geleistet habe. Zugleich wird auf die Tatsache verwiesen, dass Karl von Liechtenstein faktisch bereits im unmittelbaren Zeitraum nach der Niederlage der Aufständischen am Weißen Berg im Königreich Böhmen die kaiserliche Verwaltung ausgeübt habe. Augenscheinlich wird hier unter anderem auch auf seine Präsidentschaft im Prozess gegen die Rebellen verwiesen, die im Jahre 1621 mit dem Vorsitz bei der Exekution auf dem Altstädter Ring ihren Höhepunkt fand. ${ }^{50}$ Sofern es um die oben erwähnte Rechtsgewalt geht, war diese im Mandat eindeutig definiert. Liechtenstein besaß das volle Recht, im Namen Kaiser Ferdinands II. Entscheidungen zu treffen. Eine Ausnahme bildete lediglich die Tatsache, dass er nicht von der Gesamtpolitik des Kaisers abweichen durfte. Die Kompetenzen Liechtensteins wurden in drei bzw. vier Bereiche unterteilt: Er besaß die obersten Exekutivfunktionen, war oberster militärischer Kommandant, höchster Repräsentant im Bereich der Justiz und nicht zuletzt auch im Bereich der Finanzverwaltung. ${ }^{51}$ Eine andere Frage lautete, inwieweit konnte Karl I. von Liechtenstein die per Mandat

46 HAL Wien, FA, Kart. 480, 1621, Fürst Karl Präsident im Process der böhmischen Rebellen.

47 HAL Wien, FA, Kart. 480, 1622 Jänner 17., Statthalter in Böhmen.

48 Österreichisches Staatsarchiv Wien (ÖStA), Allgemeines Verwaltungsarchiv (AVA), Adelsakten, Liechtenstein, Karl, Fürstenstand, Bestätigung, 1620. Frank, Karl Friedrich: Standeserhebungen und Gnadenakte für das Deutsche Reich und die Österreichischen Erblande bis 1800. III. Schloss Senftenegg 1972, S. 140 (Liechtenstein, Carl Fürst von, Herr von Nikolsburg, Feldsberg, Paumgerten, Eisgrub, Plumenau, Prossnitz, Aussee und Czernahora, kais. Geheimer Rat und Kämmerer, Maximilian, Gundaker, Brüder, Best. Des Ersterem dd. 1608 verliehenen Fürstenstandes, und Ausdehnung auf die beiden anderen und ihre männliche und weibliche Descendenz, im Falle des Todes ohne Descendenz, Wien 23. VI. 1620). Zum Titularaufstieg Karls von Liechtenstein vgl. den Beitrag von Jiří Brňovják in diesem Band. Brňovják, Jiří: Primi oder ultimi inter pares? Zum Titularaufstieg der Liechtenstein im 17.-18. Jahrhundert (aus der Sicht der Länder der böhmischen Krone). Studia Historica Brunensia.

49 HAL Wien, Urkunden, Wien, 1622, Januar, 7.

50 HAL Wien, FA, Kart. 480, Präsidentschaft im Prozess gegen Rebellen.

51 HAL Wien, Urkunden, Wien, 1622, Januar, 7. 
erhaltene Rechtsgewalt im nachfolgenden Zeitraum wirklich nutzen bzw. inwieweit in ähnlicher Form etwa in Mähren bzw. den übrigen Ländern der Monarchie Ferdinand II. und seine Wiener Hofbeamten in die ausübende Funktion des Statthalters eingriffen.

Der gesamte, von Karl I. von Liechtenstein geleitete Prozess gab den aktivsten Aufständischen sozusagen keinerlei Chance auf Rettung. In der Vergangenheit wurde die Frage aufgeworfen, inwieweit dieses Vorgehen, das in einer derartigen Rasanz ledig im Königreich Böhmen zur Anwendung kam, dem persönlichen Hass Ferdinands II. gegenüber den böhmischen Ständen als Hauptschuldigem der Unruhen geschuldet war bzw. inwiefern die Strenge der Bestrafung auf die Aktivitäten der böhmischen Verbündeten des Kaisers zurückzuführen ist, die nach den Ämtern und Gütern der böhmischen Anführer des Aufstands Ausschau hielten. Der zweiten Möglichkeit würden beispielsweise die nach Wien gesandten Briefe Karls von Liechtenstein entsprechen, in denen der Absender eine strenge Bestrafung für Heinrich Otto von Los verlangte, der angeblich bei seinem Verhör eine große Arroganz gegenüber seinen Richtern und dem Kaiser offenbart hatte. ${ }^{52}$

Die grundlegendste Aufgabe Karls I. von Liechtenstein bestand in einer restriktiven und nichtrestriktiven Pazifizierung des Landes sowie einer erneuten Wiederherstellung der Loyalität gegenüber dem Kaiser. Wie bereits im Ernennungsschreiben angedeutet übernahm Karl diese Rolle unmittelbar nach dem Sieg der kaiserlichen Partei am WeiBen Berg. Offiziell war diese Rolle mit seiner Funktion als bevollmächtigter kaiserlicher Kommissar im Königreich Böhmen verbunden, die ihn dazu berechtigte, sich in einem auf den 15. November 1620 datierten Brief an die ganze Einwohnerschaft zu wenden und diese zur Wahrung der Treue gegenüber dem Kaiser und zur Ablehnung jeglicher Unterstützung für die feindlichen Heere aufzufordern..$^{53}$

Im Jahre 1622 veröffentlichte die Konfiskationskommission im Namen Liechtensteins mehrere Patente, in denen peu à peu die Namen von Personen auftauchten, die die Konfiskationen betreffen sollten. Einfacher gestaltete sich dies im Falle von Emigranten und verstorbenen Personen, mitunter auch bei Gütern, die im Verlauf des Aufstands auf militärischem Wege beschlagnahmt worden waren. Sämtliche aufgeführten Arten von Gütern wurden automatisch für konfisziert erklärt. Komplizierter gestalteten sich die Verhandlungen demgegenüber für gewöhnlich im Falle von lebenden Personen, die in einigen Fällen versucht hatten, sich gegen ihre Bezeichnung als Rebellen und gegen die Beschlagnahme ihres Besitzes zu wehren. Offenkundig gab es hiervon derart viele

52 In Ausnahmefällen griffen allerdings die Richter aus den Reihen des böhmischen Adels in die Urteilssprüche, die ihnen der Kaiser zur Konsultation zugesandt hatte, auch in positivem Sinn ein. Dies betraf vor allem das Urteil gegen Wilhelm von Lobkowitz, dessen Hinrichtung aufgehoben und der Beschuldigte lediglich zur Konfiskation seines Besitzes und zu lebenslanger Kerkerhaft verurteilt wurde. Einige Richter äußerten darüber hinaus die Befürchtung, dass eine zu große Zahl von zum Tode Verurteilten in Böhmen weitere Unruhen auslösen könne. Die Urteile wurden schließlich vom Kaiser in einem Erlass vom 26. Mai 1621 in einigen Fällen in der Tat abgemildert. Vgl. Bílek, T. V.: Dëjiny konfiskací (Geschichte der Konfiskationen), S. XLV. Wie in der Einleitung betont, zählte in der Zeit der Auseinandersetzungen um eine „Vergeltung für den Weißen Berg“ die liechtensteinische Partei wiederum jene Fälle auf, in denen Karl I. von Liechtenstein einige der verurteilten Personen dem Kaiser gegenüber verteidigte.

53 HAL Wien, FA, Kart. 482, Biographica, Karl von Liechtenstein an die böhmischen Stände, 1620, November 16 . 
Fälle, dass individuelle Konfiskationsurteile nicht in einem Zuge gefällt werden konnten, wie dies beispielsweise später in Mähren der Fall war, wobei man sich stets auf Gruppen von annähernd 30 Rebellen konzentrieren musste. ${ }^{54}$ Der gesamte Konfiskationsprozess unter der Führung von Karl von Liechtenstein dauerte dann in seiner ersten Phase etwa bis zum Jahre 1624 und einer zweiten Phase bis 1627. Zu diesem Zeitpunkt fand der Prozess im Wesentlichen seinen Abschluss, und zwar sowohl mit der Veröffentlichung der Verneuerten Landesordnung als auch durch Liechtensteins Tod. In dieser Zeit wurde bereits ein Prozess gegen Karl I. von Liechtenstein im Zusammenhang mit dem Verdacht, der Fürst habe sich durch den Einsatz der langen Münze im Konfiskationsprozess der eigenen Bereicherung nicht allein zu Lasten der geschädigten Personen, sondern vor allem zu Lasten des Staates schuldig gemacht, eröffnet. Es ist eine immerhin bemerkenswerte Tatsache, dass nach Liechtensteins Tod der Abschluss des Prozesses der Konfiskationen Karls großem Konkurrenten, Albrecht von Wallenstein, anvertraut wurde. Letzterer beaufsichtigte die Konfiskationen - zumindest in formaler Hinsicht praktisch bis zu jenem Augenblick, als unmittelbar vor seiner Egerer „Hinrichtung“ die Konfiskationskommissare auch auf seinen eigenen Herrschaften Reichenberg (Liberec) und Friedland (Frýdlant) erschienen. ${ }^{55}$

Die Tätigkeit Karls von Liechtenstein im Verlaufe seiner „böhmischen Mission“ ist archivalisch nicht so gut dokumentiert wie etwa im Falle der Verwaltung Mährens durch Kardinal Franz von Dietrichstein. Im Falle Liechtensteins lassen sich dessen ungeachtet die Materialien aus der kaiserlichen Hofkammer, der böhmischen Hofkanzlei sowie aus Karls Privatarchiv miteinander vergleichen. ${ }^{56}$ Aus den genannten Dokumenten geht dabei beispielsweise hervor, dass sich an Karl I. von Liechtenstein als böhmischen Statthalter durch die ständischen Konfiskationen betroffene Personen mit der Bitte um Regelung ihrer Restitutionen wandten. Die vermutlich bekannteste Causa dieses Typs stellte die Bitte Karls d. Ä. von Žerotín dar, die die Restitution von Žerotíns beschlagnahmtem Gut Brandeis (Brandýs nad Orlicí) betraf. ${ }^{57}$ Einen weiteren Bereich der Tätigkeit bildete die Verwaltung der beschlagnahmten Güter der ständischen Rebellen in der Zeit vor

54 Ein Beispiel für ein derartiges Urteil bietet Bílek. Bílek, T. V.: Dějiny konfiskací (Geschichte der Konfiskationen), S. LXXI-LXXII.

55 Knoz, T.: Pobělohorské konfiskace (Die Konfiskationen nach 1620), S. 401-407. Kollmann, Josef: Valdštejnưv konec. Historie 2. generalátu 1631-1634 (Wallensteins Ende. Die Geschichte des II. Generalats 1631-1634). Praha 2001, S. 192-200.

56 Die Materialien aus der kaiserlichen Hofkammer sind in Gestalt der sog. Gedenkbücher im Hofkammerarchiv in Wien aufbewahrt, die Archivalien aus der böhmischen Hofkanzlei und -kammer finden sich vor allem im Bestand „Alte Manipulation“ im Nationalarchiv in Prag sowie in Karls persönlichen Dokumenten im Hausarchiv Liechtenstein, Karl I. von Liechtenstein, v. a. Abteilung Biographica.

57 NA Praha, Stará manipulace, Fasz. Z 22, Nr. 4176/21, Kart. 2595 Žerotínové (Familie Žerotín). Lobkowicz-Archiv Nelahozeves, Lobkowiczové roudničtí - Rodinný archiv, Materiály Brandýsa nad Orlicí, Dopis Karla staršího ze Žerotína nejvyšším českým úředníkům (Zweig Raudnitz der Familie Lobkowitz - Familienarchiv, Materialien Brandeis, Brief Karls d. Ä. von Žerotín an die obersten böhmischen Beamten), 1620, Januar 6., fol. 8-9. Hrubý, F. (Hg): Moravské korespondence a akta (Mährische Korrespondenzen und Akten) I., S. 450-451; Knoz, T.: Državy Karla staršiho ze Žerotína (Die Güter Karls d. Ä. von Žerotín), S. 57-69. Im Jahre 1620 veröffentlichte Karl I. von Liechtenstein in dieser Angelegenheit zu Gunsten Karls d. Ä. von Žerotín eine gedruckte Urkunde. HAL Wien, FA, Kart. 482, Karl von Liechtenstein als Statthalter in Böhmen, Urkunde für Karl von Zierotin - Restitution. 
deren Übergabe an neue Besitzer, in einigen Fällen jedoch auch die Disziplinierung dieser Güter nach deren Übergabe. Wiederum sei hier exemplarisch auf ein Beispiel verwiesen, und zwar die Disziplinierung der vormaligen Untertanen des Wenzel Budowetz von Budow auf der Herrschaft Münchengrätz (Mnichovo Hradiště), die sich weigerten, Wilhelm von Vřesovice als ihrem neuen Grundherrn zu huldigen. ${ }^{58}$

Während der gesamten Zeit, in der die Konfiskationen stattfanden, wurde Karl I. von Liechtenstein sowohl unmittelbar durch Kaiser Ferdinand II. als auch die Beamten der kaiserlichen Hofkammer in Wien instruiert. Die Schreiben betrafen für gewöhnlich der einzelnen Fälle: in der ersten Phase handelte es sich um Instruktionen zu einzelnen, von der Konfiskation betroffenen Personen und deren Güter sowie deren Bewertung, in der zweiten Phase um die Zuteilung der Konfiskate. Einen Versuch zur statistischen Auswertung der Ergebnisse dieser Welle der Konfiskationen zu Beginn der sechziger Jahre des 20. Jahrhunderts unternahm František Kavka. Die von ihm vorgelegten Zahlen können insgesamt auch heute noch als verlässlich angesehen werden, wenngleich sie nicht die unterschiedlichen inneren Zusammenhänge, Komplikationen und Probleme des Konfiskationsprozesses zum Ausdruck bringen. Den Angaben Kavkas zufolge wurden in Böhmen durch die Konfiskationskommission insgesamt 680 Personen verurteilt, davon 166 Personen zum Verlust ihres gesamten Besitzes, 45 zum Verlust von zwei Dritteln, 128 Personen verloren die Hälfte ihres Besitzes, 215 wiederum ein Drittel. Insgesamt 122 Personen verurteilte man, indem deren Allodialbesitz den Status eines Lehens erhielt; die verbleibende Zahl der betroffenen Personen musste eine Geldstrafe zahlen oder verlor ihre bewegliche Habe. ${ }^{59}$ Schrittweise wurden die böhmischen Konfiskate kostenfrei militärischen Führern übertragen, denen der Kaiser Sold schuldete. Die Möglichkeit, ihnen die ausstehenden Schulden in Form von Immobilienbesitz zu begleichen, wurde von beiden Seiten als willkommen angesehen. ${ }^{60}$ Auf ihre Kosten mussten selbstverständlich auch

58 NA Praha, 17/2, Morava, Nr. 6148.

59 Die Methode, mit deren Hilfe František Kavka zu den genannten Zahlen gelangte, ist - ebenso wie die Quelle, aus der er sein Wissen bezog - nicht völlig klar. Die entsprechenden Zahlen sind vermutlich zumindest partiell den Forschungen von Tomáš V. Bílek entnommen. Kavka, F.: Bílá hora a české dějiny (Der Weiße Berg und die tschechische Geschichte). Praha 1962, S. 240. Zahlreiche weitere Schriftzeugnisse zu den Konfiskationen nach 1620 im Königreich Böhmen befinden sich im Fond „Stará manipulace“ im Zentralen Staatsarchiv Prag und sind hier nach Personen und Lokalitäten geordnet. In diesem Bestand überwiegen Akten, die sich mit verschiedensten Forderungen und Streitigkeiten auf den konfiszierten Gütern beschäftigen. Das genannte Material bildete darüber hinaus eine der Hauptquellen auch für Tomáš V. Bílek. NA Praha, Stará manipulace, v. a. Nr. 651-672, Kart. 344-524, Sign. C 215, Pobělohorské konfiskace (Konfiskationen nach 1620).

60 Buquoy erhielt auf diese Weise aus dem Besitz der Schwanberger Gratzen (Nové Hrady), Rosenberg (Rožmberk) und Libejowitz (Libějovice), Marradas wurden jene Güter in den Regionen Bechin (Bechyňsko), Prachin (Prácheň) a Pilsen (Plzeň) zugesprochen, die Balthasar von Marradas mit seinen Verbänden selbst erobert hatte, vor allem Frauenberg (Hluboká), Jung Woschitz (Mladá Vožice), Welhartitz (Velhartice), Mokrosuk (Mokrosuky), Nemilkov, Miltschin (Miličín) und Rothlota (Červená Lhota). Zugleich erhielt er den Auftrag, sich finanziell auch mit Huerta zu einigen. Julius Heinrich von Sachsen-Lauenburg erhielt die Herrschaft Schlackenwerth (Ostrov), Wolf Illburg von Vřesovice wiederum Trnovany, Achilles de Soye Tuchorschitz (Tuchořice) und Hettau (Hettov), Wolf von Mansfeld seinerseits Schluckenau (Šluknov), Philipp von Salm Heraletz (Herálec) und Humpoletz (Humpolec) usw. Bílek, T. V.: Dějiny konfiskaci (Geschichte der Konfiskationen), S. CXXIII-CXXIV. Bereits zu dieser Zeit schloss sich Albrecht von Wallenstein der Jagd auf konfiszierte Güter an, zumal er gleich in mehrfacher Hinsicht den 
die zivilen Anhänger Kaiser Ferdinands II. mit Adam d. J. von Wallenstein oder Paul Michna von Vacínov kommen, doch auch Karl von Liechtenstein selbst. ${ }^{61}$

Im Unterschied zu Albrecht von Wallenstein, der sich nach der Restitution der Besitzungen in Ostmähren aus der Markgrafschaft zurückzog und seine Gütererwerbungen in Böhmen konzentrierte, beließ Fürst Karl I. von Liechtenstein zu Beginn der zwanziger Jahre des 17. Jahrhunderts den Kern seiner Besitzungen in Mähren; dessen ungeachtet differenzierte er diese unter einer größeren Zahl von Ländern. Im Königreich Böhmen hatte sich Liechtenstein bereits im Jahre 1608 um Neuerwerbungen bemüht, als er - freilich erfolglos - den Versuch unternahm, von der königlichen böhmischen Kammer die vormalige Herrschaft der Pernsteiner, Pardubitz (Pardubice), zu kaufen. ${ }^{62}$ Nach seiner Einführung in das Amt des böhmischen Statthalters war Liechtensteins Anwesenheit weitaus mehr an Prag gebunden, als dies vor 1620 der Fall gewesen war. Wie in den zurückliegenden Jahren vor allem Eliška Fučíková aufzuzeigen vermochte, richtete Karl I. von Liechtenstein in dieser Zeit sein Augenmerk auf den Bau eines imposanten Palais auf dem Kleinseitner Platz, der mit der Prager Burg und dem Neubau des unweit gelegenen ähnlichen Palastes Albrechts von Wallenstein zu konkurrieren suchte. Der exponierte, im Stil des Manierismus erbaute Palast inmitten der böhmischen Metropole benötigte dessen ungeachtet auch ein ländliches Hinterland, was Karl von Liechtenstein dazu veranlasste, seine Stellung und den Zugang zu Informationen zum Erwerb einiger konfiszierter Güter zu nutzen, die sich in der unmittelbaren Umgebung Prags befanden..$^{63}$

In Böhmen erwarb Karl I. von Liechtenstein vor allem die Herrschaften Schwarzkosteletz (Kostelec nad Černými lesy) und Auřinewes (Uhříněves) aus dem der Familie Smiřitzký konfiszierten Besitz. Darüber hinaus handelte es sich um kleinere Güter: die südböhmischen Dörfer Vosek und Kblelnice von Zdeněk Čejka von Olbramowitz, das Gut Malé Cerhenky in der Region Kouřim, vormals im Besitz von Heinrich Hlaváč von Vojenice, das Gut Př́toky bei Kuttenberg (Kutná Hora) von Ladislaus Hrobčický, das Dorf Chotiš von Johann Sigismund von Solopysky, Planian (Plaňany) und einige Dörfer

Kategorien von Anwärtern der Konfiskate entsprach, wobei er selbstverständlich an erster Stelle zu den verdienten Heerführern gehörte. „An Fürsten von Liechtenstein de dato 17ten February 1621, zu Überschickung einer Copy, wasgestalt Albrecht Wenzl Eusebius vo Wallenstein für die IM heimgefallene Herrschaft Jitschin bis zu m/60 fl." HKA Wien, Gedenkbücher, Böhmische Reihe, Karton. 333, 17. 2. 1621, fol. 4; NA Praha, 23, C̆DKM - Rukopisy (Handschriften), Inv. Nr. 91, Böhmisches Confiscations-Protocollum. Zur Problematik der Entlohnung von militärischen Anführern, die selbstverständlich im Rahmen der Konfiskationen nach 1620 im Grunde genommen die Dimension der böhmischen Konfiskationen überschreitet, weitere Ausführungen im entsprechenden Kapitel (Militärische Aspekte der Konfiskationen).

61 Knoz, T.: Pobělohorské konfiskace (Die Konfiskationen nach 1620), S. 397-401.

62 HAL Wien, FA, Kart. 480, 1608, Ansprüche an die Herrschaft Pardubitz. Klesal, Petr: Úsili Lichtenštejnů o zisk někdejš̀̌ pernštejnského dominia Pardubice (Die liechtensteinischen Bemühungen zum Erwerb der vormaligen Herrschaft der Pernsteiner Pardubitz). Ungedruckte Bachelorarbeit an der Philosophischen Fakultät der Masaryk-Universität. Brünn 2018.

63 Fučíková, Eliška: Das Palais Liechtenstein in Prag. In: Liechtensteinisch-Tschechische Historikerkommission (Hrsg.): Die Liechtenstein und die Kunst. Band 3. Vaduz 2014, S. 47-55. Tschechische Version: Fučíková, E.: Lichtenštejnský palác v Praze (Das Palais Liechtenstein in Prag). Časopis Matice moravské 132, 2013, Supplementum 5, S. 43-51. 
im Kreis Kouřim aus dem vormaligen Besitz von Georg Mirek von Solopysky, das Gut Nupaky in Mittelböhmen, das Wenzel Štastný Rous von Vražkovo gehört hatte, das Gut Kralowitz (Kralovice) bei Prag von Johann Heinrich Rozenhajn von Janovice, das Gut Šluštice bei Böhmisch Brod (Český Brod) von Nikolaus Skalský von Dub, die Güter Dubeč und Kyje bei Prag, vormals Adam Zapský von Zapy gehörend, einen Weinberg in Šárka bei Prag sowie vier Weinberge bei Leitmeritz (Litoměřice) aus dem vormaligen Besitz von Martin Frühwein. Karl von Liechtenstein verkaufte seine innerhalb des Konfiskationsprozesses erworbenen Güter darüber hinaus zumeist postwendend an andere Personen. Seine künftigen böhmischen Besitzungen erstreckten sich in der Langzeitperspektive auf Konfiskationen ehemaliger Smiřitzky-Güter zwischen Schwarzkosteletz, Auřinewes, Škvorec und Rostok (Roztoky). Wie beispielsweise Franz Wilhelm aufgezeigt hat, kam es auch in diesen Fällen jedoch zu mehreren Ver- und einigen Rückkäufen. Tomáš V. Bílek hat demgegenüber statistisch belegt, dass Karl von Liechtenstein Herrschaften in Böhmen mitunter von der Böhmischen Kammer für einen Schätzpreis erwarb und nachfolgend einige praktisch postwendend mit großem Gewinn wieder verkaufte. Einige Güter kaufte er demgegenüber von dritten Personen (Makler), wie dies etwa im Falle von Schwarzkosteletz der Fall war, wo als Vermittler Albrecht von Wallenstein auftrat. ${ }^{64}$

Mit dem Prozess der Konfiskationen und sekundär mit den liechtensteinischen Gütergewinnen nach 1620 ist auch der Fall der sog. langen Münze verbunden, in dem Karl von Liechtenstein eine bedeutsame Rolle spielte. Es handelte sich dabei um eine Münzverschlechterung vonseiten des kaiserlichen Münzkonsortiums. Mit Münzen schlechter Qualität wurden dabei konfiszierte Güter bezahlt. Dies schädigte zum einen die konfiszierten Personen, zum anderen aber auch die Staatskasse bzw. den Kaiser. Auf der anderen Seite bereicherten sich die Mitglieder des Konsortiums und die die Konfiskate erwerbenden Personen. Aus diesem Grunde erwies sich eine Münzreform als notwendig, und es galt eine Verordnung herauszugeben, dass das Geld für konfiszierte Güter (Konfiskationsschillinge) lediglich in „alter guter Münze“ zu entrichten war, keineswegs jedoch in verdorbener guter Münze.

Der Mangel an Bargeld war daher auch einer der entscheidenden Gründe, weshalb Ferdinand II. in einem Patent vom 29. September 1622 einen Verkauf von Gütern verfügte, die konfisziert worden waren und jetzt vorübergehend zu den Kammergütern

64 Bílek, T. V.: Dějiny konfiskací (Geschichte der Konfiskationen), S. 32, 63, 107, 110, 187, 373-374, 371-372, 549, 933. MZA Brno, G 436, Rodinný archiv Kouniců (Familienarchiv der Kaunitz), Inv. Nr. 6011, Karton 731, Konfiskační kniha statků v Čechách zkonfiskovaných po porážce stavů 1620 (Conficationsbuch Anno 1643). NA Praha, 23, ČDKM - Rukopisy, Inv. Nr. 90, Böhmisches Confiskations-Protocollum, 1630, fol. 23r-25r. Vgl. des Weiteren auch HAL Wien, FA, Karton. 482, Karl I. von Liechtenstein, Biographica, (Wilhelm, Franz): Historique de l'acquisition de domaines propriétés de la maison princiérs de Liechtenstein sur le territoirs de l'Etat Tchécoslovaque. In jüngerer Zeit zur Besitzpolitik der Liechtenstein Oberhammer, Evelin: „Viel ansehnliche Stuck und Güeter“. Die Entwicklung des fürstlichen Herrschaftsbesitzes. In: Oberhammer, Evelin (Hg.): Der ganzen Welt ein Lob und Spiegel. Das Fürstenhaus Liechtenstein in der frühen Neuzeit. Wien - München 1990, S. 33-45; Merki, Ch. Maria - Löffler, J.: Das Haus Liechtenstein in den böhmischen Ländern vom Mittelalter bis ins 20. Jahrhundert: Güter, Rechte, Verwaltung. Vaduz 2013. Wie auch Christoph Merki bemerkt, handelte es sich im Falle von Schwarzkosteletz um einen Kauf von Albrecht von Wallenstein. Ein derartiger Typ der Transaktion beim Erwerb eines konfiszierten Gutes erwies sich im Prozess der Konfiskationen als relativ gängig. 
gehörten. In dieser Situation bestand allerdings die Gefahr, dass den Wert derartiger Dominien nicht allein der fortschreitende Krieg und das Fehlen einer ordentlichen obrigkeitlichen Administration verringern würden, sondern auch die Tatsache, dass der Kaiser für die verkauften Güter wertlose lange Münzen erhalten werde. Dies bedeutete, dass er selbst ökonomisch das verlieren würde, was ihm den ursprünglichen Absichten zufolge Profit einbringen sollte. Verlieren sollten hingegen seine Gegner. Der Gewinn wanderte jedoch nicht in die Staatskasse, sondern in die Taschen der Mitglieder des Münzkonsortiums und ging zudem an jene Personen, die bislang erworbene Güter hatten in langer Münze bezahlen dürfen. Thomas Winkelbauer hebt unter diesen Personen vor allem Albrecht von Wallenstein, Johann Ulrich von Eggenberg und Karl von Liechtenstein hervor. Die Münzreform, die seit dem Sommer 1623 vorbereitet und schließlich am 11. Dezember desselben Jahres verkündet wurde, beendete die Validität der langen Münze und damit auch die Epoche finanzieller Spekulationen mit der langen Münze. Die lange Münze wurde auf ein Achtel des ursprünglichen Wertes devalviert, die Konfiskate durften fortan ausschließlich in neuer Münze bezahlt werden. ${ }^{65}$

In den Konfiskationsmaterialien der kaiserlichen Hofkammer taucht die Erwähnung einer schlechten Münze erstmals kurze Zeit nach der Proklamation der Münzreform auf. Dies geschah in der dem Statthalter in Böhmen, Karl von Liechtenstein, am 21. Dezember 1623 zugesandten Resolution der kaiserlichen Hofkammer, der zufolge sämtliche finanziellen Operationen des Konfiskationsprozesses ausschließlich in alter guter Münze realisiert werden durften. ${ }^{66}$

Auch wenn sich Karl von Liechtenstein trotz dieser Affäre im Amt des Statthalters zu halten vermochte, konnte er sich doch fortan zu keinem Zeitpunkt mehr einer solchen Gunst des Kaisers erfreuen und am Ende seines Lebens musste er sich selbst und - nach seinem Tode - sein Sohn Karl Eusebius in einem Gerichtsprozess verantworten und am Ende eine hohe Geldstrafe in die Staatskasse zahlen. Der Missbrauch des Prozesses der Konfiskationen nach der Schlacht am Weißen Berg durch Personen, die eigentlich darauf achten sollten, dass alles rechtlich und finanziell sauber verlief, veranlasste den Kaiser dazu, das Funktionieren der Regierung in den böhmischen Ländern zu verändern und das Amt des Statthalters in der Gestalt, wie es Karl von Liechtenstein ausgeübt hatte, abzuschaffen. ${ }^{67}$

65 Winkelbauer, Thomas: „Das Geld est sanguis corporis politici“. Notizen zu den Finanzen der Habsburger und zur Bedeutung des Geldes im 16. und 17. Jahrhundert. In: Häusler, Wolfgang (Hg.): Geld. 800 Jahre Münzstätte Wien . Wien 1994, S. 143-159, S. 153; Šimek, Eduard: Česká mince v proních desetiletích 17. století (Die böhmische Münze in den ersten Jahrzehnten des 17. Jahrhunderts). Sborník Národního muzea - řada historická A-31, 1977, S. 201-272.

66 Diese Resolution betraf die Güter Patzau (Pacov) und Dub in Südböhmen, die dem am Aufstand beteiligten Ladislaus Vít von Rzavy konfisziert worden waren. „Kaiserliche Resolution an Liechtenstein de dato in Wien den 31ten Decembris Anno 1623“. Hofkammerarchiv Wien (HKA), Gedenkbücher, Böhmische Reihe, Buch 333, 31. 12. 1623, fol. 247v. Bílek, T.: Dějiny konfiskací v Čechách (Geschichte der Konfiskationen), S. 878-879.

67 Oliva, Otto: Finanční politika v Čechách po Bilé hoře do kalady r. 1623 (Die Finanzpolitik in Böhmen nach der Schlacht am Weißen Berg bis zur Münzreform im Jahre 1623). Praha 1925. Zur Währungs- und Münzpolitik in den böhmischen Ländern in jüngerer Zeit auch Pošvář, Jaroslav: Měna v Čechách, na Moravě $a$ ve Slezsku (Die Währung in Böhmen, Mähren und Schlesien). Praha 1977; Kostlán, Antonín: Dlouhá 
Im Jahre 1627, nach dem Tod des langjährigen obersten Statthalters in Böhmen und zugleich der führenden Gestalt der damaligen Konfiskationen, Karls von Liechtenstein, musste eine weitere „Transaktions-„Kommission gebildet werden, die den gesamten Prozess zu Ende führen sollte.

\section{Das Herzogtum Troppau: Der Streit zwischen Karl von Liechtenstein und dem Kaiser um das Konfiskationsrecht}

Karl I. von Liechtenstein wurde im Jahre 1608 durch den Habsburger Matthias der Fürstentitel verliehen. 1633 erfolgte dann auf der Grundlage der Entscheidung dieses Monarchen und damals bereits rechtmäßigen römischen Kaisers der mit dem Herzogtum Troppau (Opava) verbundene Fürstentitel. Faktisch handelte es sich um eine Belohnung für Liechtensteins Verhalten im sog. habsburgischen Bruderzwist. ${ }^{68}$ Wie die Eintragungen im sog. Roten Buch des Herzog- bzw. Fürstentums Troppau bezeugen, rief Liechtenstein Ernennung auch in den Reihen der Troppauer Stände einen gewissen Widerstand hervor, zumal diese mit Unmut die Anstrengungen Karls von Liechtenstein zur Eingliederung Troppaus unter die schlesischen Fürstentümer und eine Begrenzung der Macht der Stände zu Lasten der fürstlichen Gewalt verfolgten. ${ }^{69}$ Die Niederlage des Ständeaufstands, dessen Konföderation sich die böhmischen Stände im Unterschied zu den Mährern einmütig anschlossen, war daher für Karl I. von Liechtenstein zumindest theoretisch eine Gelegenheit, seine Regierung zu festigen und im Herzogtum wirklicher Landesherr zu werden. Einen Bestandteil der Legalisierung der zuvor erfolgten Erhebung zum Fürsten und der Festigung der Macht im Herzogtum Troppau bildete mit dieser Absicht im Übrigen auch die „Bestätigung des Fürstenstandes“, die zu Gunsten des Liechtensteins Kaiser Ferdinand II. im Jahre 1620 verfügt hatte. ${ }^{70}$

mince v Čechách (Die lange Münze in Böhmen). Acta Universitatis Carolinae. Philosophica et Historica 1, 1989, S. 101-127; Knoz, T.: Finančni aspekty pobělohorských konfiskaci (Finanzielle Aspekte der Konfiskationen nach 1620). Český časopis historický 100, 2002, S. 774-814; Leins, Steffen: Das Prager Münzkonsortium 1622/23. Ein Kapitalgeschäft im Dreissigjährigen Krieg am Rande der Katastrophe. Münster 2012. Zum Prozess gegen Karl Eusebius von Liechtenstein vgl. Haupt, Herbert: Fürst Karl Eusebius von Liechtenstein 1611-1684. Herausgegeben von Johann Kräftner. München - Berlin - London - New York 2007, v. a. das Kapitel Liechtenstein Prozes und Generalabsoluturium vom 15. Mai 1655, S. 141-145. Dokumente hierzu im HAL Wien, FA, Kart. 503, 1627-1650, Ausgleich mit dem Fiscis. Vorgehen desselben gegen Fürst Karl u. dessen Erben.

68 Haupt, Herbert: Fürst Karl I. von Liechtenstein, Obersthofmeister Kaiser Rudolfs II. und Vizekönig von Böhmen. Hofstaat und Sammeltätigkeit. Edition der Quellen aus dem liechtensteinischen Hausarchiv. Textband. Quellen und Studien zur Geschichte des Fürstenhauses Liechtenstein. 1/1. Wien - Köln - Graz 1983.

69 Kozák, Petr (Hg.): Červená kniha Opavského knižectví (Das Rote Buch des Herzogtums Troppau). Opava 2015.

70 ÖStA Wien, AVA, Adelsakten, Liechtenstein, Karl, 1620. Bestätigung des Fürstenstandes. Vgl. Frank, K. F.: Standeserhebungen, III. S. 140. 


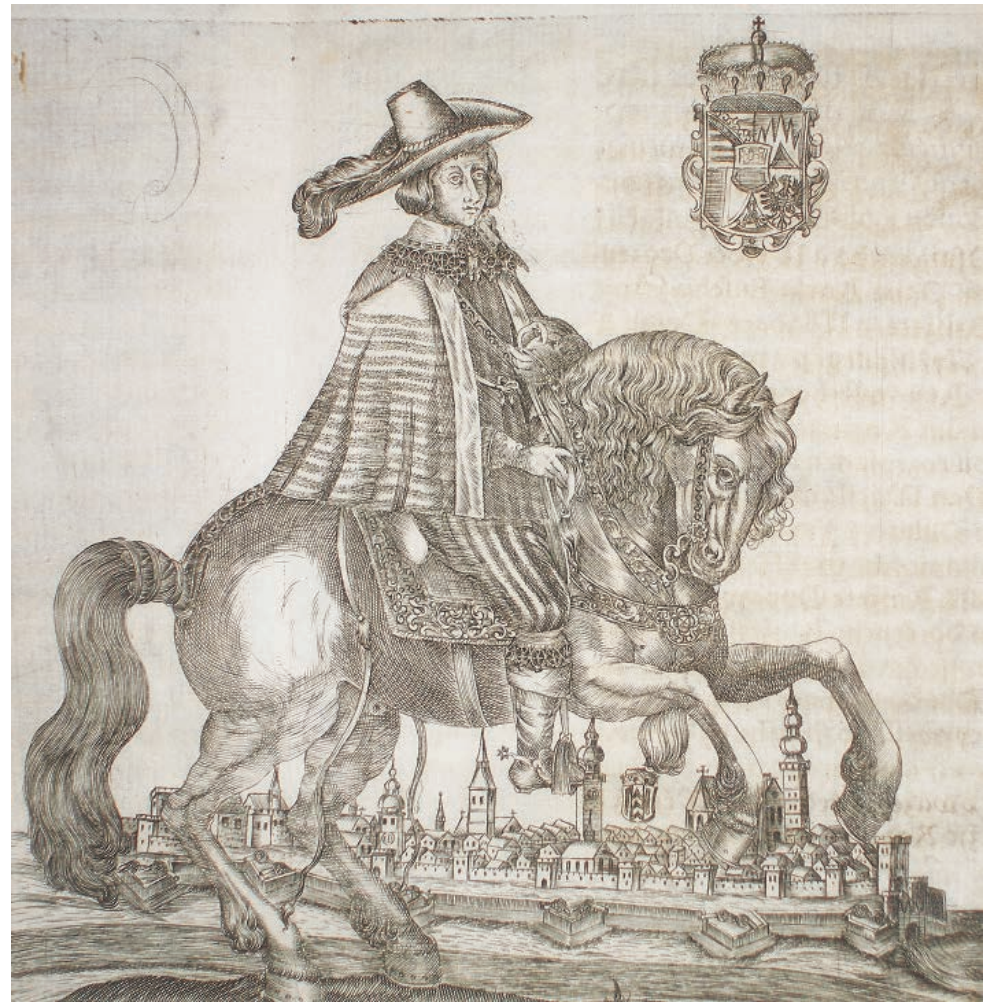

Abb. 3. Karl Eusebius von Liechtenstein als Fürst von Troppau

Der Verlauf des Ständeaufstands und auch jener der Konfiskationen nach der Schlacht am Weißen Berg reflektierte die staatsrechtliche und politische Situation in den Herzogtümern Troppau und Jägerndorf (Krnov) unter den spezifischen rechtlichen Bedingungen. ${ }^{71}$ Die genannte Spezifik hing in erheblichem Umfang mit dem Bemühen der

71 Josef Zukal spricht im Zusammenhang mit Jägerndorf und Troppau von „Mährisch-Schlesien“. Während sich Schlesien selbst dank der Intervention des sächsischen Kurfürsten nach dem Ständeaufstand mit Hilfe des Sächsischen Akkords ein Pardon verschaffte, wurde Johann Georg von Jägerndorf von diesem Akkord ausgeschlossen. Jiří Brňovják zufolge wurde selbst zu Beginn der zwanziger Jahre des 17. Jahrhunderts das Fürstentum Troppau noch nicht als schlesisches Territorium angesehen, sondern als eigenständiges Lehen der Böhmischen Krone, und es galt hier u. a. das mährische Lehnsrecht. Die Troppauer Stände erreichten im Jahre 1622 eine Aufnahme unter die schlesischen Fürstentümer gerade deshalb, da sich auf diese der Dresdner Akkord bezog. Dessen Gültigkeit wurde allerdings dem Fürstentum nach dem Einfall des Mansfelders als Strafe für die Zusammenarbeit mit dem Feind abgesprochen. Dies bedeutete u. a., dass sich die Verneuerte mährische Landesordnung auch auf Troppau und Jägerndorf bezog, die konfessionellen Freiheiten nicht geschützt waren und umfangreiche Konfiskationen stattfanden, die vor allem mit dem Aufstand in Mähren verbundene Personen betrafen. Für freundliche Unterstützung in der Frage des Verhältnisses der schlesischen Stände zum Dresdner Akkord und zur Politik Karls I. in Troppau und Jägerndorf dankt der Autor Jiří Brňovják. Des Weiteren vgl. Zukal, J.: Slezské konfiskace 1620-1630. Pokutování provinilé šlechty v Krnovsku, Opavsku a Osoblažsku po bitvě na Bílé hoře a po vpádu Mansfeldově (Die schlesischen Konfiskationen 1620-1630. Die Bestrafung des schuldigen Adels in Jägerndorf, Troppau und Hotzenplotz (Osoblaha) nach der Schlacht am Weißen Berg und dem Einfall des Manfelders.). Praha 1916, S. 1. Zum Prozess der Angliederung Troppaus an Schlesien vgl. d'Elvert, Christian: Verfassung 
Troppauer Stände zusammen, dass der Dresdner Akkord das Land einschließen möge, zumal dieser für die schlesischen Fürstentümer galt (der Dresdner Akkord sollte zumindest auf theoretischer Ebene den vormals nichtkatholischen Adel vor umfangreicheren Konfiskationen schützen), doch auch für die Politik Karls I. von Liechtenstein, der offenkundig hoffte, mit Hilfe der Position unter den schlesischen Ständen später auch unter den Reichsfürsten einen Platz einzunehmen. ${ }^{72}$ Allerdings bezog sich dessen Gültigkeit weder auf Troppau noch auf Jägerndorf, wo die Konfiskationen vielmehr ein beachtliches Ausmaß erreichten. ${ }^{73}$ Den eigenständigen Verlauf der Troppauer Konfiskationen (zumindest im Rahmen einiger ihrer Wellen) unterstreichen Bezeichnungen wie „Troppauische Confiscations-Commission", "Jägerndorfische Confiscations-Commission" sowie die Erstellung des „Troppauischen Confiscations-Protocolls“.${ }^{74}$

Die Aktivitäten der Stände im Fürstentum Troppau unterschieden sich von den Verhältnissen in Schlesien, aber auch in Böhmen und Mähren doch ein wenig. Vor allem spielt die Tatsache hier eine Rolle, dass im Herzogtum keine Repräsentant einer protestantischen Dynastie an der Spitze stand, sondern ein katholischer Aristokrat, der hier die Interessen der habsburgischen Politik verteidigen sollte. Während die Troppauer Bürger eher Breslau und Schlesien zuneigten, pflegte der Adel des Fürstentums

und Verwaltung von Oesterreichisch-Schlesien. Schriften der historisch-statistischen Sektion 7. Brünn 1854, Fünfte Periode, Kap. Das Fürstenthum Troppau - ein Lehen der Fürsten Liechtenstein (1613-1854), Die Überlassung an die Fürsten Liechtenstein und feste Vereinigung mit Schlesien, S. 106-37; Korbelářová, Irena: K územně-správnimu členěni Slezska před rokem 1740 (Zur territorial-administrativen Gliederung Schlesiens vor 1740). Slezský sborník 100, 2002, S. 161-180, hier S. 172, Anm. 53; Šmerda, Milan: K dualismu zemi České koruny v pobělohorské době (Zum Dualismus der Länder der Böhmischen Krone vor der Schlacht am Weißen Berg). In: Borovský, Tomáš - Jan, Libor - Wihoda, Martin (Hg.): Ad vitam et honorem. Brno 2003, S. 363-372.

72 Schlesien wurde auf Intervention Johann Heinrichs von Sachsen auch die Gültigkeit von Rudolfs Majestätsbrief konfirmiert. Merian, Matthäus: Topographia Bohemiae, Moraviae et Silesiae. Francfurt 1650, pag. 123; Tieftrunk, Karel (Hg.): Pavla Skály ze Zhoře Historie česká (Pavel Skála von Zhoře. Böhmische Geschichte). V. Praha 1870, S. 43-44, 63; Śreniowski, Stanislaw: Historia ustroju Ślasku (Geschichte der schlesischen Herrschaft). Katowice - Wrocław 1948. Die Oberlausitz fiel in dieser Zeit dank der Politik des sächsischen Kurfürsten vollständig unter dessen Herrschaft. Leszczyński, Jósef: Przejcie Górnych Łużyc pod panowanie saskie (Der Übergang der Oberlausitz an die Herrschaft Sachsens). Śląski Kwartalnik Historyczny Sobótka 17, 1962, s. 345-374; Barteček, Ivo: Saská politika a české stavovské povstáni (květen 1619-srpen 1619) [Die sächsische Politik und der böhmische Ständeaufstand (Mai 1619-August 1619)]. Sborník historický 30, 1984, S. 5-47.

73 Fukala, Radek: Role Jana Jiř́ho Krnovského ve stavovských hnutích (Die Rolle Johann Georgs von Jägerndorf in den Ständebewegungen). Opava 1997; Ders.: Státoprávni spor o opavské knižectvi a stavovstvi ve Slezsku (1529-1621). K úloze mocenských elit v raném novověku (Der staatsrechtliche Streit und das Fürstentum Troppau und das Ständewesen in Schlesien (1529-1621). Zur Rolle der Machteliten in der Frühen Neuzeit). In: Malíř, Jiří - Vlček, Radek (Hg.): Morava a české národní vědomí od středověku po dnešek. Brno 2002, S. 85-92; Biermann, Gotlieb: Geschichte der Herzogtümer Troppau und Jägerndorf. Teschen 1874; Přehled dějin Opavska (Abriss der Geschichte des Troppauer Landes). Opava 1982.

74 Ein Exemplar des Troppauer Konfiskationsprotokolls befindet sich heute im Prager Nationalarchiv. NA Praha, 23, ČDKM - Rukopisy, Nr. 2, Troppauisches Confiskations-Protocoll de anno 1630. Der Begriff „Troppauer Konfiskationskommission“ findet sich häufig in den Büchern der kaiserlichen Hofkammer. Beispielsweise im Zusammenhang mit der zweiten Welle der sog. post-mansfeldischen Konfiskationen im Fürstentum Troppau entspricht die Bezeichnung „Troppauer Konfiskations- und Liquidierungskommission“ auch dem erwähnten „Troppauer Konfiskationsprotokoll“. HKA Wien, Gedenkbücher, Böhmische Reihe, Karton 335, 11. 4. 1635 und 13. 4. 1635, fol. 165-168. 
Troppau traditionell enge Bindungen zu Mähren. Die Streitigkeiten zwischen der gefühlten Bindung des Fürstentums an Schlesien bzw. Mähren spiegelten sich auch im Verlaufe des Aufstands wider. Beide Seiten mussten darüber hinaus eine Übereinkunft mit der Politik Karls von Liechtenstein suchen, der unter dem Vorwand einer Erkrankung und Befürchtungen hinsichtlich der militärischen Situation es wiederholt ablehnte, sich nach Breslau zu begeben. Im Ergebnis dieses Verhaltens schlossen sich die Troppauer Stände der Konföderation erst mit großer zeitlicher Verspätung im Januar 1620 an, als sie zugleich Friedrich von der Pfalz als König anerkannten. Der Winterkönig begab sich danach nach Freudenthal (Bruntál), wo ihm die Troppauer Stände im Schloss Johanns von Würben auf Freudenthal huldigten. Der Fürstentag in Breslau hatte zur gleichen Zeit bereits entschieden, dass - angesichts des faktischen Herrschaft Karls von Liechtenstein vornehmlich über Stadt und Schloss - dem Fürsten Liechtenstein Troppau „zu Händen der Fürsten und Stände" konfisziert werden und dass der Ertrag, der hieraus floss, der Verteidigung des Landes dienen sollte. Der neue König ernannte neue höhere Beamte im Lande - zum neuen Landeshauptmann Johann von Würben auf Freudenthal, zum neuen Kammerherrn Johann Wenzel Sedlnický, zum neuen Landrichter Heinrich Donata und zum obersten Schreiber Johann Georg Kotulínský von Kotulín. ${ }^{75}$

Wenngleich die Troppauer Stände nicht sehr radikal in Erscheinung traten und in den ersten Jahren sich nicht offen an der Führung der Kämpfe beteiligten, unternahmen sie dennoch einige Schritte, die als gegen den Kaiser gerichtetes Auftreten interpretiert werden konnten. Hierzu gehörten die Besetzung der Marienkirche in Troppau und deren Übergabe an die protestantische Gemeinde, der bereits erwähnte Beitritt zur Konföderation mit den böhmischen Ständen im Jahre 1619 oder die Huldigung König Friedrichs von der Pfalz Mitte Februar 1620. Die Habsburger beobachteten die Schritte der Troppauer Stände dabei mit großer Sorge. ${ }^{76}$

Kurz nach der Huldigung Friedrichs von der Pfalz kam es zur Schlacht am Weißen Berg, die nach ihrem Ausgang auch die Bestrafung der schlesischen Aufständischen einschloss. Besonders, als sich der „Winterkönig“ nach der Niederlage durch die kaiserlichen Truppen entschied, Prag zu verlassen und sich für einige Zeit gerade in Schlesien

75 Die Toppauer Stände schlossen sich auf dem Landtag in Troppau am 20.-23. Januar 1620 der Konföderation bei gleichzeitigem Schwur an, und nach „mährischer Sitte“ wurden zahlreiche Defensoren ernannt. An die Stelle des liechtensteinischen obersten Hauptmanns Paul Tvorkovský trat vorläufig der Ritter Salomon Mosch von Bittendorf. Zugleich entsandten die Troppauer Stände eine Delegation nach Mähren, die Friedrich von der Pfalz begrüßen und ihn zur Huldigung in das Herzogtum einladen sollte. Die Huldigung fand danach am 17. Februar 1620 in Freudenthal statt. Die Troppauer Bürger schlossen sich Zukals zur Folge freilich weder dem Schwur auf die Konföderation noch der Huldigung Friedrichs von der Pfalz offiziell an. Erneut zeigte sich also die unterschiedliche Haltung des mährischen Adels und der Bürgerschaft. Zukal, J.: Slezské konfiskace (Die schlesischen Konfiskationen), S. 34-36. Vgl. darüber hinaus auch Zukal, J.: Die Liechtensteinische Inquisition in den Herzogtümern Troppau und Jägerndorf aus Anlass der Manzfeldischen Rebellion 1626-1627. Zeitschrift für Geschichte und Kulturgeschichte Osterreichisch-Schlesiens 7, 1912, Heft 1/3, S. 4-260.

76 Zukal, J.: Slezské konfiskace (Die schlesischen Konfiskationen), S. 30-35; Dlugoborski, Waclaw - Gierowski, Jósef - Maleczyński, Karol: Dzieje Wroctawia do roku 1807 (Geschichte Breslaus bis zum Jahre 1807). Warszawa 1958, S. 340. 
aufzuhalten. ${ }^{77}$ Die Troppauer Stände, die vergeblich um Fürsprache Kardinal Dietrichsteins baten, mussten deshalb ihre bis dahin verfolgten politischen Ziele aufgeben und sich Schlesien anschließen. Die Katholiken konnten sich dank Dietrichsteins und der Beendigung des bisherigen Bündnisses mit den evangelischen Ständen automatisch des Pardons erfreuen. Darüber hinaus mussten sich die Troppauer Stände mit der Rückkehr Karls von Liechtenstein abfinden. ${ }^{78}$

Mit im Prinzip größerer Rasanz entschied Ferdinand II. über die Konfiskationen der Anhänger Friedrichs von der Pfalz im Fürstentum Troppau. ${ }^{79}$ Ähnlich wie in Mähren wurden auch im Fürstentum Troppau zuerst Restitutionen realisiert. Karl von Liechtenstein konnte hierbei erneut die Güter des Fürstentums in Besitz nehmen. Hierzu übertrug der Kaiser per Dekret am 15. März 1621 Liechtenstein auch das Herzogtum Jägerndorf. Über Johann Georg von Jägerndorf wurde nämlich - genau wie über Friedrich von der Pfalz - die kaiserliche Acht verhängt; eingeschlossen hierin war eine Konfiskation seiner Güter. Deren Zuschreibung an den Fürsten Liechtenstein wurde mit den Schäden begründet, die dieser wegen seiner Treue zum Kaiser hatte erleiden müssen. Hieran änderten auch die scharfen Proteste der deutschen Hohenzollern nichts, die das Ziel verfolgten, ein gemäßigteres Vorgehen des Kaisers gegen ihren schlesischen Verwandten zu erreichen.

Der Konfiskationsprozess im Fürstentum Troppau verlief keineswegs komplikationsfrei. Ein spezifisches Merkmal des Herzogtums Troppau bestand nämlich darin, dass hier neben dem Kaiser auch Karl von Liechtenstein und Franz von Dietrichstein einen Anspruch auf eine Verkündigung der Konfiskationen geltend machten. Während Karl dies als Herzog von Troppau tat, agierte der Franz als Bischof von Olmütz. Beide begründeten ihren Anspruch vor allem mit verschiedenen Lehnsrechten. Die kaiserlichen Organe zweifelten allerdings mit der Zeit diesen Rechtsanspruch an. Karl von Liechtenstein wurde das Recht, über Konfiskationen im Fürstentum Troppau zu entschieden, zu keinem Zeitpunkt offiziell zuerkannt. Vielmehr behielt sich dies der Kaiser selbst vor. Die Güter, die Liechtenstein als Konfiskate ohne kaiserliche Erlaubnis beschlagnahmte,

77 Bereits am 17. November 1620 begab sich Friedrich von der Pfalz nach Breslau, wo er versuchte, den weiteren Widerstand gegen das Heer Kaiser Ferdinands II. zu organisieren. Zu diesem Zweck berief er auch für den 2. Dezember 1620 einen Fürstentag nach Breslau ein. Als er jedoch von der Resignation der Mährer erfuhr, gab es diesen Plan auf und reiste nach Brandenburg weiter. Zukal, J.: Slezské konfiskace (Die schlesischen Konfiskationen), S. 37; Tieftrunk, K. (Hg.): Pavla Skály ze Zhoře Historie česká (Pavel Skála von Zhoře Böhmische Geschichte), S. 172-180.

78 Der erneuerte Lehnsbrief für den Fürsten Karl von Liechtenstein für das Troppauer Land und jener für Jägerndorf ist in Prag für den 13. Mai 1623 datiert, wurde also während des Aufenthalts des Kaisers in der Hauptstadt des Königreichs Böhmen ausgefertigt, als Liechtenstein für den Kaiser in der Funktion des böhmischen Statthalters alle Hände voll zu tun hatte. Zukal, J.: Slezské konfiskace (Die schlesischen Konfiskationen), S. 43.

79 Einigen Einträgen in den Memorialbüchern der kaiserlichen Hofkammer zufolge dauerte es mehr als vier Jahre, ehe es gelang, die im Urteil als Rache für die „kriminelle Taten“ Johann Georgs von Jägerndorf erwähnten Sanktionen durch die faktische Umsetzung der Konfiskationen seiner Besitztümer auch zu applizieren. HKA Wien, Gedenkbücher, Böhmische Reihe, Karton 333, 9. 7. 1622, fol. 69r. Schulze, Hans: Markgraf Johann Georg von Brandenburg und der Streit um Jägerndorf, Beuthen und Oderberg in den Jahren 1611-1624. Zeitschrift für Geschichte und Altertum Schlesiens 33, 1895, s. 177-214; Zukal, J.: Slezské konfiskace (Die schlesischen Konfiskationen), S. 53. 
musste er dem Fiskus übergeben. Demgegenüber konnte Kardinal Dietrichstein als Lehnsherr über entsprechende Güter des Bistums Olmütz einige Konfiskate im Fürstentum Troppau zumindest zu seinen Lebzeiten behalten. ${ }^{80}$

Die erste Runde der im Herzogtum Troppau und im benachbarten Jägerndorf verlaufenden Konfiskationen betraf am Ende lediglich eine relativ kleine Gruppe von gut 16 Personen. In der Regel handelte es sich um diejenigen, die sich am aktivsten in der Rebellion gegen Ferdinand II. engagiert und die in der kurzen Regierungszeit Friedrichs von der Pfalz im Lande bedeutende Ämter bekleidet hatten. Die protestantischen Stände wollten sich nicht damit abfinden, dass sich die Strafe für eine Rebellion gegen Ferdinand in der Praxis vor allem auf sie bezog, während die katholischen Rebellen (u. a. dank der erwähnten Intervention Kardinal Dietrichsteins) nicht im Fokus standen. Hannibal Burggraf von Dohna, der in dieser Zeit mit der Umsetzung der kaiserlichen Verfügungen betraut war, lehnte es jedoch ab, hier ein Entgegenkommen zu zeigen.

Noch bevor die erste Welle der Konfiskationen im Fürstentum Troppau völlig beendet war, kam es im Jahre 1626 - also am Lebensende Karls von Liechtenstein - zum Mansfeldischen Feldzug, der sich anschließenden Niederlage und der Verkündung der zweiten Welle der Troppauer Konfiskationen.

Diese Beschlagnahmungen nach dem genannten Feldzug beeinflussten unmittelbar Troppau und Jägerndorf. Ähnlich wie zuvor in Mähren oder in der Grafschaft Glatz wurden besondere Konfiskationskommissionen - „Troppauische Confiscations-Commission“ und "Jägerndorfische Confiscations-Commission" - eingerichtet, die die Aufgaben hatten, die in den Fürstentümern Troppau und Jägerndorf verlaufenden Konfiskationen umzusetzen und so an die Arbeit der Untersuchungskommission anzuknüpfen. ${ }^{81}$ Zur Aktualisierung der dortigen Problematik trugen unbestritten nicht allein der dänische Feldzug im Jahre 1627, sondern auch der fast zeitgleiche Tod des bisherigen Troppauer Fürsten Karl von Liechtenstein bei. Die Aufgabe der Untersuchungs- und Konfiskationskommission in Troppau und Jägerndorf bestand darin festzustellen, wer sich in Schlesien den Dänen angeschlossen und somit gegen den Kaiser gestellt hatte. Die Kommissare sollten nach dem Vorbild ähnlicher, in Böhmen und Mähren ausgefertigter Dokumente ein Verzeichnis der beschuldigten Personen und ihres Besitzes zusammenstellen, das den Titel „Troppauer Konfiskationsprotokoll“ trug. Sie verzeichneten hierin die Schwere der Delikte der einzelnen Personen, die Art und Weise ihrer Rechtfertigung vor dem Kaiser, das durch die kaiserliche Kommission verhängte Urteil sowie eine Übersicht über die finanziellen Transaktionen. ${ }^{82}$

80 Zukal, J.: Slezské konfiskace (Die schlesischen Konfiskationen), S. 45-46. Das Konfiskationsrecht Kardinal Dietrichsteins wurde nach dessen Tod in Zweifel gezogen. Hierzu vgl. d'Elvert, Ch.: Schriften, S. XXII, 331.

81 Nachrichten über die Troppauer und Jägerndorfer Konfiskationskommission und die entsprechenden Kommissare finden sich in den Unterlagen der kaiserlichen Hofkammer gleich mehrfach, z. B. „Kaiserlicher Befehl an die Troppau und Jägerndorfische Liquidations- und Confiscations-Commissarien“. HKA Wien, Gedenkbücher, Böhmische Reihe, Karton 335, 11. 4. 1635 und 13. 4. 1635, fol. 165r-168r.

82 Das überlieferte Konfiskationsprotokoll im Fürstentum Troppau ist auf das Jahr 1630 datiert, es wurde also als Folge der zweiten Welle an Konfiskationen verfasst. Die Beschlagnahmungen aus der ersten Welle sind hier jedoch rückwirkend verzeichnet. NA Praha, 23, ČDKM - Rukopisy, Inv. Nr. 2, Troppauisches Confiskations-Protocoll de anno 1630. 
Die Bemühungen der kaiserlichen Kammer hinsichtlich einer raschen Regelung der ganzen Angelegenheit, zu der die Erfahrungen aus vorangegangenen Konfiskationsprozessen sowie die rechtliche Klärung des Vorgehens beitragen sollten, komplizierten die von Maximilian von Liechtenstein erhobenen Ansprüche. Dieser verteidigte in Schlesien die Interessen seines verstorbenen Bruders Karl von Liechtenstein. Er tat dies zu Gunsten seines Neffen und Karls Sohn Karl Eusebius von Liechtenstein. Maximilian knüpfte damit an Karls juristische Schritte zu Beginn der zwanziger Jahre an, denen zufolge der Troppauer Fürst ein Anrecht darauf besaß, die Konfiskationen selbst durchzuführen ohne Rücksicht auf den Kaiser und seine Behörden. Die Liechtenstein gingen am Ende soweit, dass sie für eine gewisse Zeit eine eigene Konfiskationskommission ernannten, die in erheblichem Maße als Konkurrent zu den Troppauer Konfiskationskommission agierte. Zu deren Mitglieder gehörten Bernhard von Würben, Tobias Fleck von Fleckenau und Martin Sigismund Freier. ${ }^{83}$ Daneben engagierte sich im Konfiskationsprozess in Schlesien darüber hinaus auch Kardinal Dietrichstein, der mit Hilfe einer eigenen Kommission Exekutionen auf den Lehensgütern des Bistums Olmütz durchführte. ${ }^{84}$ Kaiser Ferdinand II. behielt sich allerdings das souveräne Recht bei den Konfiskationen in Schlesien vor, Karl von Liechtenstein und Kardinal Dietrichstein gegenüber zeigte er sich lediglich bereit, diese in der Frage zu konsultieren, wem das konfiszierte Gut in Zukunft zufallen sollte. ${ }^{85}$

Wie ersichtlich, gelang es Karl I. von Liechtenstein offenkundig nicht, die Rolle eines wirklichen fürstlichen Landesherrn in Troppau und Jägerndorf auszufüllen. Jiř́ Brňovák zufolge stellt sich die Frage, ob er überhaupt bereit war, sich mit der Rolle des Troppauer Herzogs oder schlesischen Fürsten zu begnügen bzw. in wieweit seine Ambitionen mit Hilfe Schlesiens eher auf den Wiener Hof bzw. letztendlich auf einen Platz im Kollegium der Reichsfürsten zielten. In jedem Fall weisen die Kenner des schlesischen Milieus auf die Tatsache hin, dass sich weder Karl I. von Liechtenstein noch dessen Erben in Schlesien bzw. im Herzogtum Troppau und Jägerndorf allzu stark engagierten, hier nicht residierten und sich eher der Hofpolitik und ihren österreichischen und mährischen Gütern widmeten. Um so stärker jedoch nutzten sie ihren Troppauer Fürstentitel symbolisch, und zwar auf sichtbare Weise, etwa die Prägung von Münzen. ${ }^{86}$

83 Josefa Zukal zufolge besaß die liechtensteinische Konfiskationskommission unter den schlesischen Ständen keine allzu große Autorität. Vgl. Zukal, J.: Slezské konfiskace (Die schlesischen Konfiskationen), S. 1 sowie S. 80-82.

Ebd., S. 91-92.

85 Ebd., S. 80.

86 Jiř́ Brňovják wirft in diesem Zusammenhang die Frage auf, in wieweit die Liechtenstein in Troppau und Jägerndorf die Beschränkungen nach dem Prager Frieden limitierten, auf dessen Grundlage die Rolle der schlesischen Fürsten auf eine „passive“ Rolle (wirtschaftliche Aktivitäten und symbolische Benefizien) beschränkt wurde. Die Preußen bezeichneten im Jahre 1740 die Liechtenstein in deren Verhältnis zu ihren schlesischen Fürstentümern als „abwesend“. Vgl. Conrads, Norbert: Friedrich der Große und der schlesische Adel. In: Kurilo, Olga V. (Hg.): Friedrich II. und das östliche Europa. Deutsch-polnisch-russische Reflexionen. Berlin 2013, S. 82-83. Für den freundlichen Hinweis dankt der Autor Jiří Brňovják. 


\section{5. Mähren: Karl von Liechtenstein als Erwerber der aus den kaiserlichen Konfiskationen stammenden Güter}

Auch in Mähren trat Fürst Karl I. von Liechtenstein in gewissem Sinne als Mitorganisator der Konfiskationen nach der Schlacht am Weißen Berg in Erscheinung. Bereits im April 1621, also nahezu ein Jahr vor der offiziellen Ernennung Liechtensteins zum Statthalter in Böhmen, informierte der Kaiser in einem speziellen Brief Karl I. von Liechtenstein über die neue Funktion Dietrichsteins. Dabei rief er die beiden Amtsträger zu einer gemeinsamen Koordination der Schritte bei der Verwaltung des Landes und bei der Bestrafung der Aufständischen auf. Deren gegenseitiger Kontakt sollte dergestalt funktionieren, dass ein jeder den anderen über die jeweils erlassenen Verfügungen unterrichte. ${ }^{87}$ Dietrichstein bat Liechtenstein in der Folge um eine Zusammenarbeit bei der Bestrafung der mährischen Aufständischen. Anschließend wurde nach böhmischem Vorbild ein Straftribunal zusammengestellt, dem zwar der Gubernator Dietrichstein vorstand, dessen ungeachtet beteiligte sich auch Liechtenstein an diesem Akt. Unter den Mitgliedern des Tribunals tauchen neben - Kaiser Ferdinand II. treu ergebenen - Angehörigen des mährischen Adels auch die Namen weiterer Mitglieder des böhmischen Gerichtsorgans, einschließlich einiger kaiserlicher Wiener Hofbeamter, auf.

Am 25. Juni 1622 wurde ein an Karl von Liechtenstein adressiertes Schreiben Kardinal Dietrichsteins ausgefertigt, in dem der Kardinal den Empfänger zu einer Zusammenarbeit bei der Organisation des Gerichtsprozesses in Mähren aufforderte, dessen Beginn auf den 5. Juli 1622 festgelegt war. Der mährische Gubernator kam somit dem vorausgegangenen kaiserlichen Wunsch nach, die böhmischen und mährischen Statthalter mögen sich gegenseitig über alle mit der Verwaltung der beiden Hauptländer der St. Wenzels-Krone verbundenen Schritte informieren. ${ }^{88}$ Kardinal Dietrichstein selbst ging es darum, dass Liechtenstein die Zusendung schriftlicher Unterlagen, die böhmischen Rebellen in Mähren betreffend, garantierte. Der mährischen Gerichtskommission sollte so das Vorgehen bei der Bestrafung der Aufständischen in Böhmens als Präzedenzfall dienen. Darüber hinaus erwies es sich als notwendig, dass sich unverzüglich jene Mitglieder der Kommission nach Mähren begaben, die aus Böhmen stammten. Dabei handelte es sich um Christoph Wratislaw von Mirowitz, Johann Daniel Kapper und Raffael Menisch. ${ }^{89}$

Karl I. von Liechtenstein engagierte sich auch im enger aufgefassten Prozess der Konfiskationen in Mähren. So beteiligte er sich beispielsweise bereits am eigentlichen Beginn der Konfiskationsmaßnahmen Anfang Januar 1621 bei deren Organisation. Die

87 NA Praha, 17/2, Morava (Mähren), Nr. 6141.

88 Kardinal Dietrichstein habe sich der Auffassung einiger Historiker zufolge darum bemüht, das Amt des Stathalters in Böhmen zu erhalten. Den Vorzug erhielt jedoch gerade der erwähnte Fürst Karl von Liechtenstein. In breiterem Kontext zur Situation hinsichtlich der Übernahme des Amts des mährischen Gubernators durch Dietrichstein Balcárek, Pavel: Kardinál František z Ditrichštejna (1570-1636) (Kardinal Franz von Dietrichstein (1570-1636)). Kroměříž 1990, S. 55-57.

89 NA Praha, 17/2, Morava (Mähren), Nr. 6147, Kardinal Dietrichstein an Karl von Liechtenstein, die Rebellion betreffend. 


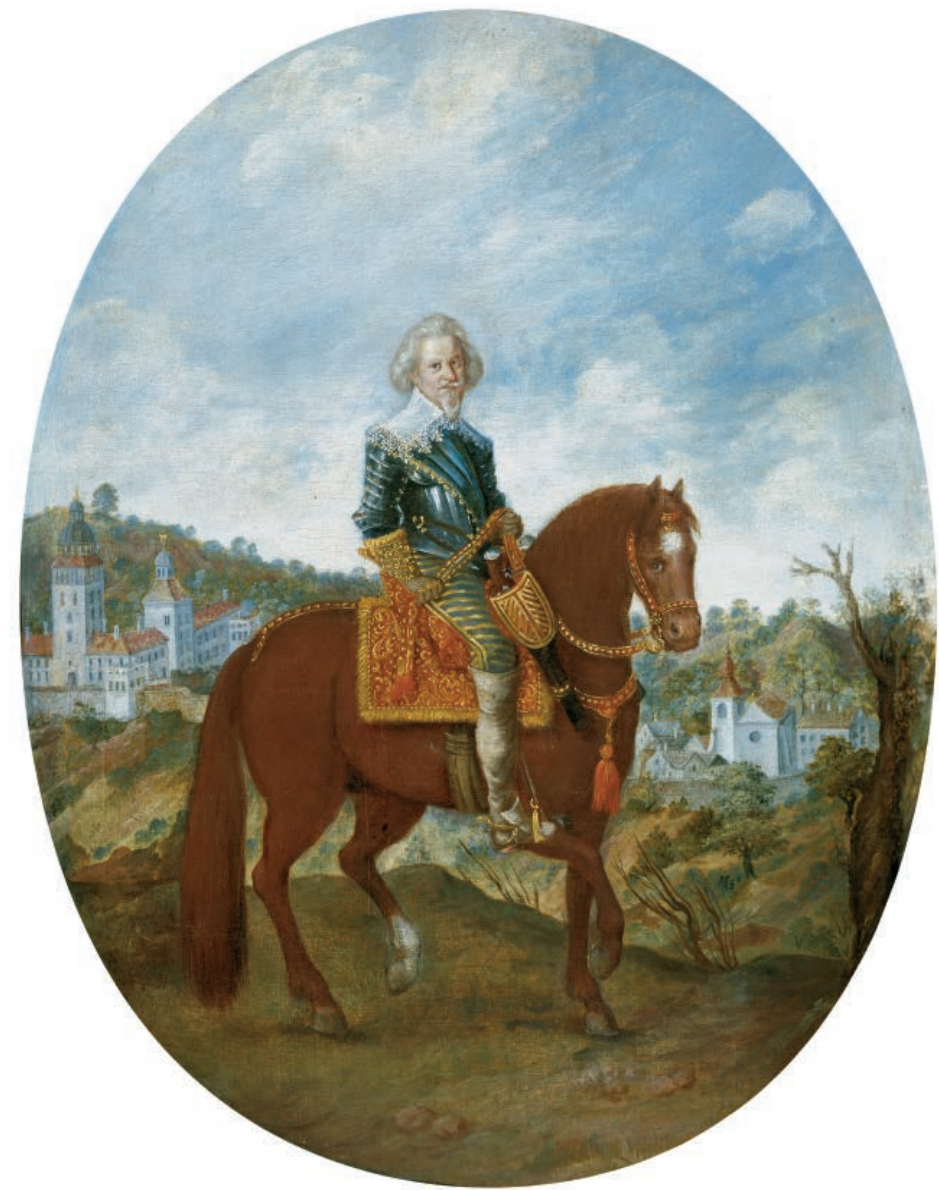

Abb. 4. Gundaker von Liechtenstein als Herr des konfiszierten Dominiums Mährisch Kromau

Konfiszierungen begannen sehr rasch und ohne die Entscheidungen des Tribunals abzuwarten. Liechtenstein wies bereits am 2. Januar 1621, also unmittelbar nach der Niederlage der nichtkatholischen Stände, den Olmützer Kanoniker und führenden Vertreter der prokaiserlichen Partei in Mähren, den Olmützer Kanoniker Johann Ernst Platejs, an, er solle zu Gunsten des Monarchen die Güter der Emigranten Joachim Andreas Schlick von Pasaun, Erfrieds, Georgs und Rudolfs von Herbersdorf sowie Theobald Hocks sichern..$^{90}$

90 NA Praha, 17/2, Morava (Mähren), Nr. 6137, Karl von Liechtenstein weist Platejs an, der solle die Güter der geflohenen Rebellen Joachim Andreas Schlick von Pasaun, Erfried, Georg und Rudolf von Herbersdorf sowie Theobald Hock beschlagnahmen: „[...] Ihre Gnaden, der erlauchte Fürst Karl, Regent des Hauses Liechtenstein, Fürst von Troppau, Ihrer Gnaden des römischen Kaisers, ungarischen und böhmischen Königs Geheimer Rat, Ihrer kaiserlichen Gnaden bevollmächtigter oberster Kommissar geruht im 
Eine wichtige Tatsache gilt es zu beachten, dass Karl I. von Liechtenstein aus der Position des höchsten kaiserlichen Beamten in Böhmen auch in jenen Fällen der mährischen Konfiskationen handelte, an denen er ein persönliches politisches bzw. eigentumsrechtliches Interesse besaß und in denen er einen gewissen Interessenkonflikt besonderer Art einging. Karl von Liechtenstein war beispielsweise - zusammen mit Kardinal Franz von Dietrichstein, dem böhmischen Kanzler Zdeněk Adalbert von Lobkowitz, dem kaiserlichen Beichtvater Wilhelm Lamormain, dem Präsidenten der kaiserlichen Hofkammer Seifried Christoph Breuner bzw. den Kammerräten Johann Baptist Weber von Piesenberg, Sigmund von Mühlheim und Johann Ruprecht Hegenmüller von Tübenweiler Mitglied der General-Konfiskationskommission in Mähren. ${ }^{91}$ Diese Kommission, in einigen Quellen auch als „Mährische Rebellen-Commission“ bezeichnet, ${ }^{92}$ entschied mehrere Jahre lang über die Konfiskationen der Rebellen und die sich anschließende Zuteilung der beschlagnahmten Güter an Anhänger des Kaisers. Es war sicherlich keineswegs Zufall, dass die Namen der Mitglieder der Kommission sich zugleich auch im Verzeichnis der belohnten Personen finden. Eine der ersten Fälle, über die die Kommission zu entscheiden hatte, betraf dabei die Konfiskation der Güter Ladislaus Velens von Žerotín im Mai 1621 sowie deren nachfolgende Zuteilung an Karl I. von Liechtenstein. Die Rolle als den Prozess der Konfiskationen mitausführender Beamter verband sich somit mit jener eines Erwerbers beschlagnahmter Güter nach der Schlacht am Weißen Berg.

Wie bereits angedeutet, wurden Karl von Liechtenstein automatisch sämtliche durch das Direktorium in der Zeit des Aufstands konfiszierten Güter zurückgegeben. Zur Restitution kamen darüber hinaus Gewinne hinzu, mit denen Kaiser Ferdinand Karls Loyalität in der Zeit der Rebellion honorierte. In erster Linie ging es dabei um die Zuteilung von Herrschaften in Nordostmähren, die bislang einer der bedeutendsten Persönlichkeiten des mährischen Ständeaufstands, Ladislaus Velen von Žerotín, gehört hatten ${ }^{93}$ Mit ziemlicher Sicherheit handelte es sich hierbei um einen gut durchdachten Schachzug. Aus Sicht des Kaisers wurde es als vorteilhaft angesehen, dass die bislang dem reichsten Vertreter der nichtkatholischen Opposition gehörenden Güter in die Hände des ver-

Namen Ihrer kaiserlichen Gnaden, unseres allergnädigsten Herrn, dem hochwürdigen Priester Johann Platejs, Kanoniker der Stadt Olmütz, zu befehlen, dass er sich überall erkundige in der Sache Joachim Graf Schlick, sodann Erfried, Georg und Rudolf Herbersdorf wie auch Theobald Hock betreffend, und mir Ihre kaiserlichen Gnaden treulose Untertanen und aus dem Lande Geflohenen betreffende Angelegenheiten unverzüglich klären möge und zu einem für Ihre kaiserliche Gnaden guten Ende führe. Dabei befehlen wir, dass dem Priester Johann Platejs hierin von keinem Menschen unter wahrhaftiger Strafe keinerlei Hindernis eingeräumt werde, sondern ein jeder, wo immer Hilfe erforderlich sei, ihm hierin beistehe, wissend, dass hierbei Ihrer kaiserlichen Gnaden huldvoller Wille erfüllt werde. Prag, 2. Januar Anno 1621."

91 „Mährische General Confiscations Commission“. HKA Wien, Gedenkbücher, Österreichische Reihe, Buch 168, 16. 12. 1624, fol. 540v.

92 „Confiscations- und anderen von ihme verrichtene Commissionen“. HKA Wien, Gedenkbücher, Österreichische Reihe, Buch 168, 4. 12. 1630, fol. 76r-77r.

93 MZA Brno, G 140, Rodinný archiv Dietrichsteinů (Familienarchiv der Dietrichstein), Nr. 407, Kart. 136, März 1622. Roztomilá, Barbora: Lichtenštejnové jako nabyvatelé žerotinských konfiskátů po roce 1620 (Die Liechtenstein als Erwerber der den Žerotín konfiszierten Güter nach 1620). Bachelorarbeit an der Philosophischen Fakultät der Masaryk-Universität Brünn. Brno 2017. 
mögendsten Repräsentanten der prohabsburgischen Partei fielen. Ferdinand II. konnte auf diese Weise indirekt erkennen lassen, dass Loyalität, Treue in der Politik und Einheit im Glauben in seinen Augen nicht allein bedeutende christliche Werte symbolisierten, sondern zugleich auch ein entsprechendes Handelsobjekt. Ladislaus Velen von Žerotín verlor seine Besitzungen, und es halfen auch keine Bemühungen um Vermittlung und das Angebot künftiger Dienste für den Kaiser. Die kaiserliche Hofkammer profitierte so von einem großen Besitz, durch dessen nachfolgende - mehr oder weniger geschlossene - Weitergabe Ferdinand II. einen seiner wichtigsten Mitspieler belohnen konnte, unter den gerade Karl I. von Liechtenstein herausragte. Das Verdienst Liechtensteins wurde als derart bedeutend und einzigartig wahrgenommen, dass der Besitzgegenstand nicht einmal ansatzweise durch die Schätzungskommission eine Bewertung erfuhr, so dass man seinen Wert in den Finanzdokumenten des Konfiskationsprozesses nicht vermerkte. In ähnlicher Weise findet sich auch nicht im entferntesten ein Lizitieren über den Preis, der Besitz wurde im Gegenteil auf der Grundlage eines eindeutig bestimmten kaiserlichen Befehls übergeben. Vom Standpunkt Karls I. von Liechtenstein handelte es sich ebenfalls um eine vorteilhafte Transaktion. Mährisch Trübau und die hierzu gehörenden Güter kannte er gut, Ladislaus Velen von Žerotín hatte er hier noch vor Ausbruch des Aufstands häufig einen Besuch abgestattet. Karl von Liechtenstein konnte schließlich ohne größere Zäsur auch im Ausbau des repräsentativen manieristischen Schlosses in Mährisch Trübau fortfahren, was vermutlich auch für das Schloss in Eisenberg an der March (Rudá nad Moravou) galt. Mit den Herrschaften in der nordöstlichen Markgrafschaft Mähren gewann Liechtenstein zudem an Wäldern und Jagdgründen reiche Güter, zugleich aber auch bergige und im Vorgebirgsland liegenden Gebiete, für die ein mineralischer Reichtum und die Verarbeitung von Erzen sich als charakteristisch erwies. ${ }^{94}$ Der Erwerb von Mährisch Trübau stellte für den Fürsten Liechtenstein darüber hinaus ein nicht zu vernachlässigendes symbolisches Kapital dar, zumal es sich nicht allein um die vormaligen Güter Žerotíns handelte, sondern in erster Linie um das einstige Erbe der Herren von Boskowitz. Karl von Liechtenstein konnte folglich auf die Familientradition seiner Gemahlin Anna Maria von Boskowitz verweisen. ${ }^{95}$

Nur wenige Monate später kamen noch die vormaligen königlichen und Kammerstädte Mährisch Neustadt (Uničov) und Mährisch Schönberg (Šumperk) hinzu, die aufgrund ihrer langen Tradition als freie Städte mit einer selbstbewussten Bürgerschaft zu den bedeutendsten Zentren in Nordmähren gehörten. Eine ähnliche Bedeutung kam dem Erwerb der Burg Eulenberg (Sovinec) zu. ${ }^{96}$ Der Regent des Hauses Liechtenstein hob somit seinen Fürstentitel auf eine noch höhere Ebene und dehnte seinen Güterbesitz

94 Oberhammer, E.: Viel ansehnliche Stuck und Güeter, S. 40. Vgl. auch Matějek, F.: Bílá hora a moravská feudálni společnost (Der Weiße Berg und die mährische Feudalgesellschaft). Československý časopis historický 22, 1974, S. 85, 90-92.

95 Knoz, T.: Erinnerungsorte der Liechtenstein, Einleitende Thesen. In: Liechtensteinisch-Tschechische Historikerkommission $(\mathrm{Hg}$.$) : Liechtensteinische Erinnerungsorte in den böhmischen Ländern. Vaduz 2012,$ S. 11-31.

96 Zuerkennung einer Reihe von Städten an den Fürsten Karl von Liechtenstein, MZA Brno, G 140, Rodinný archiv Dietrichsteinů (Familienarchiv Dietrichstein), Nr. 407, Kart. 136, März 1622. Streit um Eulenberg, ebd. Nr. 409, Kart. 137, Mai 1622. 
zwischen Österreich, Böhmen, Mähren und Schlesien weiter aus. In Mähren beherrschte der Fürst nun nicht mehr nur den Süden des Landes, der für die Liechtenstein ein traditionelles Herrschaftsgebiet darstellte, sondern auch die Mitte und den Nordwesten der Markgrafschaft. In diesem Falle zweifelte man an der Zuschreibung der erbetenen Güter nicht im Geringsten und Kaiser Ferdinand II. segnete (zumindest im Zeitraum der ersten Jahre unmittelbar nach der Schlacht am Weißen Berg) sämtliche Übertragungen an Karl von Liechtenstein sozusagen automatisch ab. Karl von Liechtenstein nahm somit mit seinen mährischen Gütern nicht allein den ersten Platz unter den mährischen Grundbesitzern ein, sondern entfernte sich durch den Umfang seines Güterbesitzes von allen anderen mährischen Adeligen immer mehr. ${ }^{97}$

Die Gewinne Karls von Liechtenstein in Mähren im Zeitraum der Konfiskationen nach 1620 müssen darüber hinaus im Kontext der Gewinne seiner Brüder Maximilian und Gundaker gesehen werden, und dies u. a. auf der Grundlage des Textes des liechtensteinischen Majoritätsvertrages aus dem Jahre 1606. ${ }^{98}$

Karls jüngerer Bruder Maximilian von Liechtenstein, der den Unterlagen der kaiserlichen Hofkammer zufolge für seine Verluste und Dienste Anspruch auf den Gewinn von 100.000 Gulden aus der Staatskasse hatte, erhielt als Kompensation für das Scheitern seiner Bemühungen um den Erwerb der Herrschaft Lundenburg (Břeclav) (diese behielt zu jener Zeit die kaiserliche Hofkammer ein) mehrere ostmährische Güter der Herren von Kaunitz - die Herrschaft Steinitz (Ždánice) und vier bislang zum Dominium Austerlitz (Slavkov) gehörende Dörfer. ${ }^{99}$ Maximilian konnte auf diese Weise seine östlich von Brünn liegenden Besitzungen erweitern, die er zuvor bereits durch die Heirat mit Katharina Černohorská von Boskowitz - das Zentrum lag in Butschowitz - hatte erwerben können. Für kurze Zeit gewann Maximilian von Liechtenstein auch die Luhatschowitzer Herrschaft der Bartodějský von Bartoděj, die er allerdings einem weiteren großen Gewinner der Konfiskationen nach der Schlacht am Weißen Berg, dem ungarischen Adeligen Gabriel Serenyi, weiterverkaufte. ${ }^{100}$ Maximilian von Liechtenstein trat so in der Position eines Erwerbers von Konfiskaten an die Seite seines Bruders.

97 František Matějek zufolge verfügte Karls Erbe Karl Eusebius von Liechtenstein in Mähren über Güter, auf denen insgesamt 9.349 Untertanen lebten. Matějek, F.: Bílá hora a moravská feudální společnost (Der Weiße Berg und die mährische Feudalgesellschaft), S. 92.

98 HAL Wien, FA, Kart. 5, Majoratvertrag, 1606.

99 HKA Wien, Gedenkbücher, Böhmische Reihe, Buch 333, an Dietrichstein, 10. 12. 1622, fol. 36. Hierzu MZA Brno, Rodinný archiv Dietrichsteinů (Familienarchiv der Dietrichstein), Nr. 416, Kart. 140, Dezember 1622 , fol. $48-49$.

100 Maxmilian von Liechtenstein erwarb die Herrschaft Mořitz (Mořice), auf die freilich auch die Witwe Wilhelm Friedrichs von Žerotín Anspruch erhob. MZA Brno, G 140, Rodinný archiv Dietrichsteinů (Familienarchiv der Dietrichstein), Nr. 436, Kart. 145, August 1624, Nr. 440, Kart. 146, Dezember 1624, Nr. 442, Kart. 147, Februar 1625. Kaiserliche Zustimmung, das Großgut Luhatschowitz Maximilian von Liechtenstein zur Deckung seiner Forderungen zu übertragen. Ebd., Nr. 450, Kart. 149, Oktober 1625. Die Summe von 12.000 Gulden, die er für die Herrschaft Luhatschowitz zahlen sollte, hielt Maximilian jedoch für ziemlich hoch, dessen ungeachtet wurde der Kauf im Juli 1626 vollzogen. Ebd., Nr. 453, 459, Kart. 151, Januar und July 1626. Im Dezember 1626 wird das Gut Luhatschowitz bereits als im Besitz von Gabriel Serenyi befindlich erwähnt. Ebd., Nr. 500, Kart. 162, Dezember 1626. 
Die Übertragung der Herrschaften Ungarisch Ostra (Uhersky Ostroh) und Mährisch Kromau (Moravsky Krumlov) an Gundaker von Liechtenstein, den dritten und jüngsten Bruder aus dieser bedeutenden Generation des Fürstenhauses, fand im Sommer und Herbst 1622 statt. Im Falle von Ungarisch Ostra geschah dies auf der Grundlage der liechtensteinischen Supplik über die Übertragung aller Dominien aus dem vormaligen Besitz der Herren von Kunowitz. ${ }^{101}$ Ungarisch Ostra hatte während der gesamten Zeit nach 1620 eines der zentralen Dominien der Kunowitzer gebildet (es wurde Bernhard von Kunowitz beschlagnahmt), wenngleich die Liechtenstein hier an der Wende vom 15. zum 16. Jahrhundert bereits einmal für kurze Zeit residiert hatten. ${ }^{102}$ Wenngleich in den Schriftquellen nicht explizit belegt, kann nicht ausgeschlossen werden, dass Gundaker von Liechtenstein bei seiner Bitte um Überschreibung von Ungarisch Ostra auch diese Familientradition vor Augen hatte und er dieser eine gewisse Rolle in der entsprechenden, an den Kaiser adressierten Supplik beimaß. ${ }^{103}$ Die kaiserliche Überschreibung von Ungarisch Ostra und Wessely an der March (Veselí nad Moravou) ist in Wien auf den 13. Juli 1622 datiert und verweist auf Gundakers Pflicht, für die erwähnten Güter einen Preis entsprechend der Taxierung zu zahlen, die auf 25.000 Gulden festgesetzt worden war. ${ }^{104}$ Zur Bezahlung der Summe für Ungarisch Ostra und Mährisch Kromau kam es schließlich im November 1622, ${ }^{105}$ doch noch im Mai des darauffolgenden Jahres forderte die kaiserliche Hofkammer von Liechtenstein die Ausstände ein. ${ }^{106}$ Gundaker von Liechtenstein verlangte demgegenüber wie zahlreiche weitere Erwerber konfiszierter Dominien auch den Abzug des Heeres aus seinen neu gewonnenen Gütern und damit verbunden eine Erleichterung der Situation der neuen Untertanen. ${ }^{107}$

Wie bereits František Hrubý auf der Grundlage der die Zahl der Untertanen aufzeigenden Statistik nachweisen konnte, war Karl von Liechtenstein bereits im Jahre 1619 der reichste Besitzer von in den Landtafeln verzeichneten Gütern in Mähren. Auf

101 MZA Brno, G 140, Rodinný archiv Dietrichsteinů (Familienarchiv der Dietrichstein), Nr. 417, Kart. 140, Januar 1623 .

102 Hosák, Ladislav - Zemek, Metoděj (Hg.): Hrady, zámky a tvrze. Jižní Morava (Burgen, Schlösser und Kastelle. Südmähren). Praha 1981, s. 239; Holub, J. (Hg.): Uherský Ostroh. Uherský Ostroh 2000.

103 Zur Residenzpolitik Gundakers von Liechtenstein vgl. Winkelbauer, T.: Fürst und Fürstendiener, S. 338409. Vgl. des Weiteren auch Knoz, Tomáš: Liechtensteinové, Morava a Valtice v 17. Století (Die Liechtenstein, Mähren und Feldsberg im 17. Jahhrundert). In: Kordiovský, E. (Hg.): Město Valtice. Valtice 2001, S. 301-315, hier S. 307-308.

104 „Kaiserliche Verschreibung an Gundaker von Liechtenstein“. HKA Wien, Gedenkbücher, Böhmische Reihe, Buch 333, 13. 7. 1622, fol. 69v.

105 Bezahlung der Herrschaften Mährisch Kromau und Ungarisch Ostra durch Fürst Gundaker von Liechtenstein. MZA Brno, G 140, Rodinný archiv Dietrichsteinů (Familienarchiv der Dietrichstein), Nr. 415, Kart. 140, November 1622.

106 Urgenz, betreffend die Ausstände des Fürsten Gundaker von Liechtenstein für die konfiszierten Güter Mährisch Kromau und Ungarisch Ostra. MZA Brno, G 140, Rodinný archiv Dietrichsteinů (Familienarchiv der Dietrichstein), Nr. 421, Kart. 141, Mai 1623, fol. 92r.

107 MZA Brno, G 140, Rodinný archiv Dietrichsteinů (Familienarchiv der Dietrichstein), Nr. 421, Mai 1623, fol. 94. Über die den Untertanen in Mähren zugefügten Schäden vgl. darüber hinaus auch Matějek, František: Morava za třicetileté války (Mähren in Dreißigjährigen Krieg). Praha 1992; Ders: Škody zpuisobené na Moravě řáděním vojáki̊ za třicetileté války (Die in Mähren durch das Wüten von Soldaten im Dreißigjährigen Krieg hervorgerufenen Schäden). Časopis Matice moravské 113, 1994, S. 83-94. 
seinen Herrschaften lebten damals insgesamt 3.672 ansässige Untertanen. Im Verlaufe des Prozesses der Konfiskationen nach der Schlacht am Weißen Berg in den zwanziger und dreißiger Jahren des 17. Jahrhunderts verdreifachte sich diese Zahl, und zwar (verzeichnet bei seinem Sohn Karl Eusebius) auf 9.349 Untertanen. Karl von Liechtenstein bzw. dessen Sohn wahrten die Position des reichsten mährischen Aristokraten, darüber hinaus konnten sie sich von ihren größten Konkurrenten absetzen. In ähnlicher Form lässt sich eine Besitzzunahme auch bei seinen Brüdern feststellen. Maximilian kletterte dank seiner Gewinne aus den Konfiskationen vom 15. (1.050 Untertanen im Jahre 1619) auf den vierten Platz (2.204 Untertanen 1644). Gundaker von Liechtenstein gehörte vor der Schlacht am Weißen Berg nicht zu den Besitzern von Tafelgütern in Mähren, in den vierziger Jahren des 17. Jahrhunderts umfasste sein dortiges Eigentum 3.906 sesshafte Untertanen und belegte damit im Lande den dritten Platz. Insgesamt beherrschten die Brüder Liechtenstein an der Schwelle der Ära des Barock in der Markgrafschaft Mähren einen Besitz, auf dem insgesamt 15.449 Untertanen lebten, wobei ihnen Güter in den Regionen Eisgrub und Lundenburg im Südosten Mährens, Güter um Ungarisch Ostra und Mährisch Kromau im Süden des Landes, Güter in den Regionen Butschowitz und Posořitz in der Region Brünn, um Prossnitz und Plumenau in Mittelmähren, um Mährisch Trübau im Westen der Markgrafschaft sowie um Mährisch Schönberg, Hohenstadt an der March und Mährisch Aussee im Norden des Landes gehörten. ${ }^{108}$

Der Familie Liechtenstein verfügte über Grundbesitz auf dem Territorium der Markgrafschaft Mähren bereits seit dem Mittelalter. Ihre Güter erfuhren bereits im ausgehenden 16. Jahrhundert einen bedeutsamen Zuwachs, und zwar dank der Doppelhochzeit mit den Erbinnen Johann Šemberas von Boskowitz und aufgrund weiterer - durch Erbschaft und Kauf realisierter - Teilgewinne. Dank der Konfiskationen nach 1620 und geschickte taktische, politische und wirtschaftliche Aktivitäten verbindende Schritte stiegen Karl I. von Liechtenstein und seine Brüder Maximilian und Gundaker zu den größten großgrundbesitzenden Magnaten im Lande auf. ${ }^{109}$

\section{Schlussbemerkungen: Karl von Liechtenstein im Kontext der Veränderungen nach 1620}

Eine der bekanntesten zeitgenössischen Charakteristiken Karls von Liechtenstein stammt aus der Feder des Hauptmanns der Friedrich von Žerotín gehörenden Herrschaft Groß Seelowitz (Židlochovice), Samuel Matúškas von Topoltschan: „In dem angezeigten Jahr

108 Merki, Ch. M.: Lichtenštejnské majetky a práva v Čechách, na Moravě a ve Slezsku od pozdniho středověku až do 20. Století (Die liechtensteinischen Güter und Rechte in Böhmen, Mähren und Schlesien vom Spätmittelalter bis in das 20. Jahrhundert). In: Merki, Ch. M. - Löffler, J.: Lichtenštejnové v českých zemích od středověku do 20. století. Majetky, práva, správa. Brno 2015.

109 Die Verbindung des gesellschaftlichen Aufstiegs und des Besitzgewinns im Kontext der mährischen Gesellschaft nach 1620 haben vor allem František Hrubý, František Matějek, Evelin Oberhammer, Thomas Winkelbauer und in gewissem Umfang Christoph Maria Merki nachgezeichnet. Matějek, F.: Bílá hora a moravská feudální společnost (Der Weiße Berg und die mährische Feudalgesellschaft), S. 89-92; Winkelbauer, T.: Fürst und Fürstendiener, S. 338-353; Oberhammer, E.: Viel ansehnliche Stuck und Güeter, S. 33-45. 


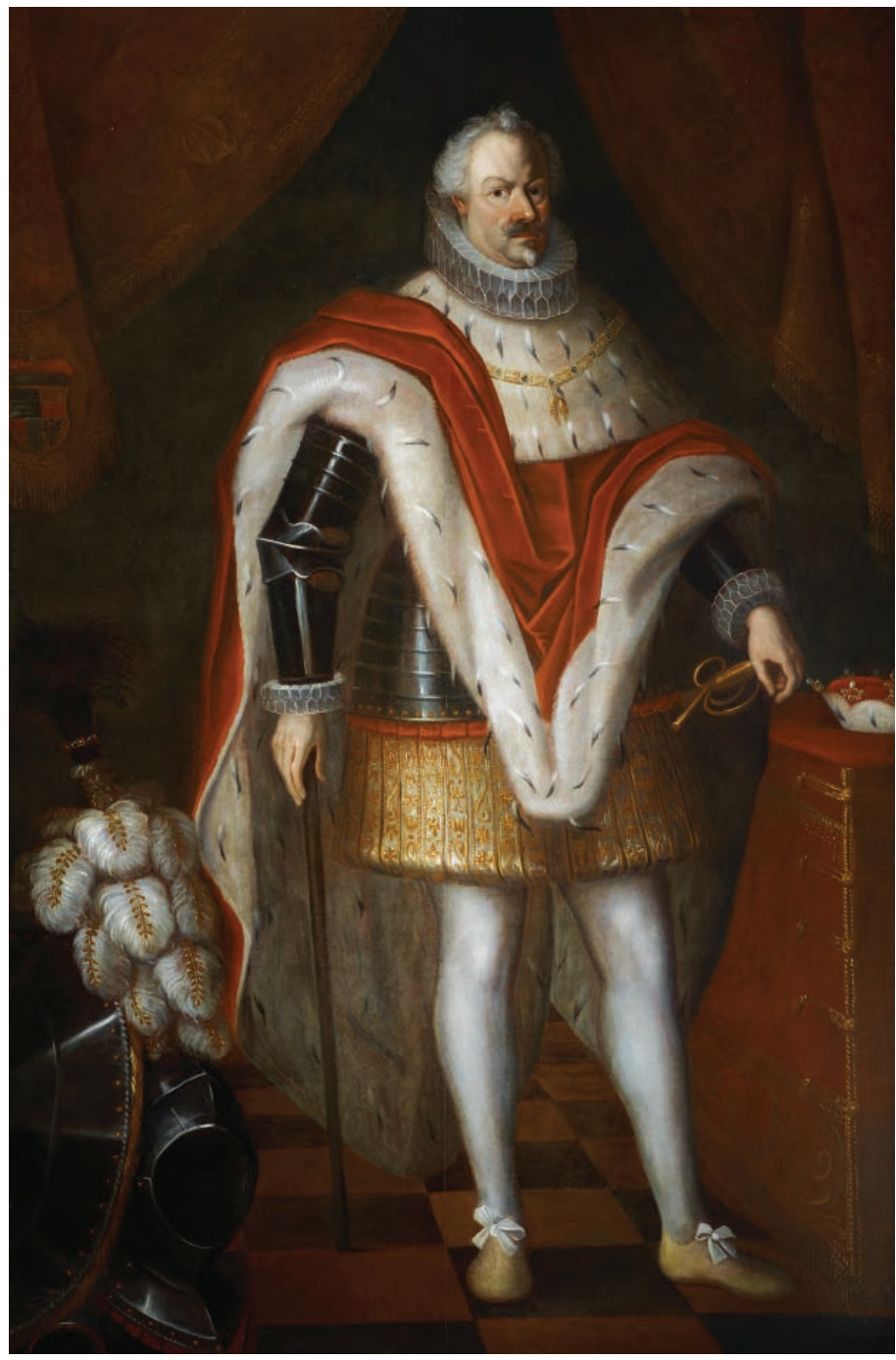

Abb. 5. Karl von Liechtenstein als Fürst und Ritter des Ordens vom Goldenen Vlies

(1599) hat ein gewisser Herr Karl von Liechtenstein, dem Feldsberg gehörte und der die Tochter Johann Šemberas zur Frau hatte, als erster vorangehend, aber auch mit seinen Ahnen die evangelische Religion um des weltlichen Ruhmes wegen fallengelassen und ist zum römischen Glauben übergetreten, wobei er seine Frau und seinen Bruder zu ebendieser Religion mitgeführt hat und nachfolgend eine nicht geringe Tyrannei um des Glaubens willen mit seinen Leuten und insbesondere seinen Untertanen führte, dabei nicht einmal dies der eigenen Mutter ersparte, so dass diese seine Mutter, die vor ihm wegen des Glaubens nicht in Ruhe leben konnte, vor ihm außer Landes floh, und aus diesen Gründen hat er bei den Jesuiten und dem Papst Liebe empfangen, die ihn dann um seiner Konversion zum Geheimen Rat dem römischen Kaiser Rudolf anvertraut haben. Nachfolgend blieb er in diesem Amt, wobei er dem Lande Mähren und seinem Geschlecht 
wie auch den Bewohnern dieses Landes beim Kaiser einen schlechten Dienst erwiesen hat. "110 Dieser Charakterisierung zufolge bildeten die grundlegende Motivation im Verhalten Karls I. von Liechtenstein seine große Ambitionen und die „Sehnsucht nach weltlichem Ruhm“, für die er seine ursprüngliche Konfession und die guten Beziehungen innerhalb der Familie opferte. Im Einklang mit diesen Auffassungen zeitgenössischer Zeugen und späterer Historiker lassen sich die genannten Motive im übertragenen Sinne auch seinen Aktivitäten im Verlaufe des Konfiskationsprozesses nach 1620 zuordnen.

Fürst Karl I. von Liechtenstein personifizierte zweifellos den Prozess der Konfiskationen nach der Schlacht am Weißen Berg und auf spezifische Art den gesamten Prozess der politischen und gesellschaftlichen Umwälzungen der Ära nach 1620, und dies bei weitem nicht allein in der modernen tschechischen Historiographie. Offenkundig wird, dass Liechtensteins Rolle in eben diesem Prozess sich als bedeutsam erweist, und zwar sowohl für seine persönliche Karriere, als auch im Kontext allgemeiner verstandener Prozesse. Liechtenstein war Träger allerhöchster Ambitionen, die unmittelbar die verfassungsrechtlichen Merkmale in den Ländern der St. Wenzels-Krone und in der Habsburgermonarchie beeinflussten und gleich in mehrfacher Hinsicht in die politischen Absichten Kaiser Ferdinands II. eingriffen. Der österreichische Historiker Hans Sturmberger hat daher in den fünfziger Jahren des 20. Jahrhunderts die Auffassung vertreten, dass Liechtenstein nach der Ernennung zum böhmischen Statthalter in Böhmen versucht habe, einen eigenen Absolutismus zu schaffen. In ähnlicher Weise hatte sich - mit Blick auf Liechtensteins Herrschaftsmethoden in den Herzogtümern Troppau und Jägerndorf - bereits zu Beginn des 20. Jahrhunderts Josef Zukal geäußert. ${ }^{11}$

Im erwähnten Kontext ließe sich also feststellen, dass die Karriere Karls von Liechtenstein über mehrere Jahrzehnte geradlinig nach oben führte und dass der Zeitraum der Konfiskationen nach der Schlacht am Weißen Berg in den zwanziger Jahren des 17. Jahrhunderts eine Akzellierung seines Aufstiegs auf der gesellschaftlichen Stufenleiter repräsentierte. Der Karriereaufstieg Karls von Liechtenstein lässt sich in drei Phasen untergliedern. In einem ersten Zeitraum, an der Wende vom 16. zum 17. Jahrhundert, konzentrierte sich Liechtenstein auf seine Karriere in den Landesämtern der Markgrafschaft Mähren. In der zweiten Phase, die sich der Unterzeichnung des Familienvertrags im Jahre 1606 und dem Erwerb des Fürstentitels 1608 anschloss, widmete sich Karl von Liechtenstein dem Aufbau seiner Position als Regent des Fürstenhauses Liechtenstein. Für die dritte - de facto parallel verlaufende - Periode ist charakteristisch der Aufstieg in

110 „Toho líta oznámeného (1599) nějaký pan Karel z Lichtenštejna, který Valtice držel a dceru pana Jana Šembery za manželku měl, budouce prve, i s predky svými náboženstvi evangelického pro slávu světskou kotrlec prevrhl a $k$ náboženstvi řimskému přistoupil, ženu svou i bratra $k$ témuž náboženství prívedl, potom tyranstvi nemalý o náboženstvi s lidmi a zuláště s poddanými suými vedl, ani vlastni máteře své neušetřujice. Že jest musela táž máteř jeho, nemohouce před nim o to náboženstvi pokoje užiti, do jinej země před ním ujeti, a tak z těch př́čin obdržel, u jezuitů a papeže, lásku, takže sou jej v službu za tejnou radu císaři Rudolfovi ř́mskýmu komendovali. Potomně jsouce v tom ouřadu, zemi moravské jsouce rodičem jejím, i obyvatelom té země při tom císaři zle sloužil. " MZA Brno, G 10, Sbírka rukopisů (Sammlung der Handschriften), Nr. 656, Erinnerungen des Matthias Matúška von Topoltschan, Groß Seelowitz.

111 Sturmberger, H.: Ferdinand II. und das Problem des Absolutismus, S. 25-26; Zukal, J.: Slezské konfiskace (Die schlesischen Konfiskationen), S. 59-63. 
Diensten des Monarchen, der mit der Ernennung zum böhmischen Statthalter und Mitglied des kaiserlichen Geheimen Rates seinen Höhepunkt erreichte. Zugleich wird für gewöhnlich darauf verwiesen, dass sich Liechtensteins gesellschaftlicher Aufstieg stets im Zusammenhang mit seinem konkreten Handeln zu Gunsten der Politik der Habsburger vollzog:

1595 Heirat mit Anna Maria von Boskowitz $\rightarrow 1596$ Erbe der Boskowitzer Güter, einschließlich der Familientradition;

1599 Konversion $\rightarrow 1599$ oberster Richter und 1604 Erwerb des Amtes des mährischen Landeshauptmanns;

1608 Unterstützung Erzherzog Matthias' im sog. Bruderzwist $\rightarrow 1608$ Erwerb des Fürstentitels;

1611 Unterstützung von Matthias in der Zeit des Einfalls der Passauer $\rightarrow$ Übertragung des Herzogtums Troppau;

1618-1620 Unterstützung für Kaiser Ferdinand II. in der Zeit des Ständeaufstands $\rightarrow$ Ernennung zum kaiserlichen Statthalter in Böhmen und Überschreibung von Konfiskaten in Mähren;

Auch wenn dieses Schema etwas vereinfachend wirkt, zeigt es doch, dass der in etwa in die Jahre zwischen 1606 und 1622 fallende Zeitraum für Karl I. von Liechtenstein aus Sicht seines Karriereaufstiegs sich als eine sehr glückliche Periode erwies.

\begin{tabular}{|c|c|c|}
\hline LANDESÄMTER & DYNASTISCHE TITEL & HOFÄMTER \\
\hline $\begin{array}{c}\text { 1599-1601 } \\
\text { Oberster mährischer Richter }\end{array}$ & & \\
\hline $\begin{array}{c}\text { Mährischer-1607 } \\
\text { mann }\end{array}$ & & $\begin{array}{c}1606-1607 \\
\text { Oberster Hofmeister }\end{array}$ \\
\hline & $\begin{array}{c}1608 \\
\text { Regent des Hauses Liechten- } \\
\text { stein }\end{array}$ & $\begin{array}{c}\text { Kaiserlicher Rat und Kammer- } \\
\text { herr }\end{array}$ \\
\hline & $\begin{array}{c}1608 \\
\text { Fürstenstand }\end{array}$ & $\begin{array}{c}1621 \\
\text { Ritter des Goldenen Vlieses }\end{array}$ \\
\hline & $\begin{array}{c}1613 \\
\text { Herzogtum Troppau }\end{array}$ & $\begin{array}{c}1622 \\
\text { Statthalter in Böhmen }\end{array}$ \\
\hline & & 1623 \\
& Herzogtum Jägerndorf & \\
\hline
\end{tabular}

Wie in der vorliegenden Studie offenkundig wird, spielte Karl I. von Liechtenstein im Prozess der Konfiskationen nach der Schlacht am Weißen Berg eine sehr heterogene Rolle - abhängig von der Etappe dieses Prozesses, abhängig aber auch von seiner Stellung in den einzelnen Ländern der Krone. In seinem heimischen Mähren betraf diese 
Rolle vor allem seinen Grundbesitz. In der Zeit des Ständeaufstands, als sich Karl unmissverständlich auf die Seite des Kaisers stellte, geschah dies in Form von Güterverlusten. Nach dem Ende der Rebellion wiederum ging es um Restitutionen und nachfolgend Besitzgewinne. Während es im Sommer des Jahres 1618 schien, dass Karl von Liechtenstein in der Markgrafschaft dauerhaft seines gesamten Besitzes ohne Rücksicht auf seine Herkunft und die zeitliche Länge des Besitzes verlustig gehen würde, machten die Konfiskationen aus ihm den reichsten Aristokraten im Lande, und zwar vor allem zu Lasten seines einstigen Freundes Ladislaus Velen von Žerotín. Auf dem Territorium des Königreichs Böhmen war die Einbeziehung in den Konfiskationsprozess weniger mit dem Grundbesitz verbunden (wenngleich es auch hier im Verlaufe der Konfiskationen zu partiellen Besitzgewinnen kam, diesmal vornehmlich zu Lasten der Smiřitzký von Smiřitz), sondern stärker mit seinen Ämtern als Vorsitzender der Exekutionskommission und nachfolgend des Statthalters. Karl übte die Gerichtsagenda über die Rebellen aus, deren Bestandteil auch die die Konfiskationen betreffende Gesetzgebung und gerichtliche sowie exekutive Applikationen bildeten. Zugleich wandten sich an Karl von Liechtenstein betroffene Personen mit Appellationen oder Bitten um Erteilung individueller und massenhafter Begnadigungen. In der Zeitspanne zwischen Konfiskation und der Zuteilung eines Konfiskats musste Karl die Verwaltung der konfiszierten Herrschaften regeln, einschließlich der Disziplinierung der örtlichen Bevölkerung und der Leitung (gegen)reformatorischer Kommissionen. Vermutlich am wenigsten erforscht ist Karls Rolle im Verhältnis zu den Konfiskationen in den Herzogtümern Troppau und Jägerndorf, wo er versuchte, die Konfiskationen aus der Position des fürstlichen Landesherrn zu leiten, dabei aber mit der Autorität des Kaisers und seiner Zentralbehörden in Konflikt geriet.

Wenngleich der Karrieresprung Karls I. von Liechtenstein im Prozess der Konfiskationen nach 1620 in gewisser Weise ein einzigartiges Phänomen darstellte, spielte sich dieser keineswegs in einem luftleeren Raum ab. Im Milieu der böhmischen Länder lässt sich ein analoger Aufstieg vor allem bei Albrecht von Wallenstein und Franz von Dietrichstein feststellen. Albrecht von Wallenstein war dabei zusammen mit Liechtenstein im Finanzkonsortium aktiv, von wo aus ihm u. a. Gelder zuflossen, die er in seine Gewinne der Konfiskate investierte. Ähnlich wie Karl von Liechtenstein basierten seine Gewinne auf der Kooperation mit einem Team von Familienangehörigen und eigener Klientel; einer Prozedur von imaginärem Kauf, Austausch und Verkauf, was auf eine Zentralisierung der erworbenen Güter und die Bildung einer fürstlichen Domäne zielte. Ähnlich wie Liechtenstein erblickte auch Wallenstein in den Konfiskationen nach der Schlacht am Weißen Berg eher eine säkulare Handelsgelegenheit und zeigte kein allzu großes Interesse an dessen geistigen, rechtlichen bzw. letztlich geistlichen Aspekten. Nach dem Tode Karls I. von Liechtenstein im Jahre 1627 übernahm Wallenstein schließlich auf der Grundlage einer kaiserlichen Verfügung für eine gewisse Zeit die Leitung des Konfiskationsprozesses im Königreich Böhmen. Sofern es um Kardinal Dietrichstein geht, verbanden diesen mit Liechtenstein die Rolle als Vorsitzender der Exekutionskommission (Liechtenstein in Böhmen, Dietrichstein in Mähren) sowie darüber hinaus die Rolle als - den gesamten Prozess der Konfiskationen leitenden - Statthalter bzw. Gubernator des 
Landes. Ähnlich wie Liechtenstein im Fürstentum Troppau, versuchte auch Dietrichstein den Prozess der Konfiskationen als Landesherr, in diesem Falle auf den bischöflichen Lehensgütern und Enklaven in Troppau und in Schlesien, zu leiten. Wenngleich Dietrichstein in Mähren die Stellung eines Bischofs und Landesgubernators bekleidete (später trug er den Titel Landeshauptmann), griff er auch in die Konfiskationsgewinne ein. Sein Klientelsystem fiel zwar zahlenmäßig geringer und bedeutsamer als im Falle Wallensteins und Liechtensteins aus, doch gelang es auch ihm, die verschiedenartigsten Transaktionen und Austausche zu organisieren. Aus der Position als Fürst und Gubernator erwirkte darüber hinaus, dass zu seinen Gunsten einige Objekte der Konfiskationen (Schmuck, Bücher) gelangten. Wichtig ist, dass diese drei bedeutendsten Repräsentanten der neuen Fürstenschicht (und in ähnlicher Form auch zahlreiche andere - Lobkowitz, Collalto, Náchod, Schaumburg usw.) im Prozess der Konfiskationen nicht allein als Kooperateure, sondern auch als harte Konkurrenten auftraten. Dietrichstein zierte sich lange Zeit, Besitzgewinne in der Markgrafschaft Zdenek Adalbert von Lobkowitz zu gestatten, der für ihn aufgrund seiner gesellschaftlichen Stellung eine Gefahr für die eigene privilegierte Fürstenstellung im Lande darstellte. Demgegenüber betraute Karl I. von Liechtenstein in einem seiner Briefe seinen Bruder Gundaker damit, den Aufstieg Kardinal Dietrichsteins zu beobachten und dessen Anstrengungen, die auf Vorteile auf steuerlichem Gebiet zielten und zu Lasten des Fürstenhauses Liechtenstein gehen würden, zu begrenzen. Für alle drei betrachteten Aristokraten gilt darüber hinaus, dass sie nach der Mitte der zwanziger Jahre des 17. Jahrhunderts einen gewissen Dorn im Auge Kaiser Ferdinands II. und der vordringenden Wiener Bürokratie darstellten. Es wurden daher Maßnahmen beschlossen, die deren Macht zu Gunsten der Zentralgewalt des Staates begrenzten. Kardinal Dietrichsteins Stellung wurde in der zweiten Hälfte der zwanziger Jahre beschnitten und sein Gehalt gekürzt. Gegen Karl von Liechtenstein und schließlich auch gegen seinen Sohn wurde ein Gerichtsverfahren angestrengt. Albrecht von Wallenstein wurde zunächst entlassen und schließlich der Befehl erteilt, den Generalissimus zu liquidieren. Doch auch diese Maßnahmen vermochten keineswegs den langfristigen Aufstieg des Fürstenhauses Liechtenstein aufzuhalten. ${ }^{112}$

Die Ergebnisse des Wirkens Karls I. von Liechtenstein im Prozess der Konfiskationen nach der Schlacht am Weißen Berg lassen sich in mehreren Thesen zusammenfassen:

Die Rolle Karls I. von Liechtenstein im Prozess der Konfiskationen erwies sich als vielschichtig. Karl I. von Liechtenstein gilt nicht allein als Profiteur der kaiserlichen Konfiskationen, worauf am häufigsten verwiesen wird. Er war zugleich Opfer der im Verlaufe des Aufstands durchgeführten ständischen Konfiskationen, darüber hinaus fungierte er in kaiserlichen Diensten auch als Beamter und Organisator dieses Prozesses bzw. als Haupt des entstehenden Fürstenhauses.

Die Ära um 1620 veränderte zwar nicht gänzlich die vorangegangene Entwicklung und zahlreiche gesellschaftliche Prozesse vollzogen sich im Vergleich zum vorangegangenen

112 Knoz, T.: Dietrichstein, Wallenstein, Liechtenstein - Drei Wege zum Erfolg. In: Vařeka, Marek - Zářický Aleš (Hg.): Das Fürstenhaus Liechtenstein in der Geschichte der Länder der böhmischen Krone. Ostrava Vaduz 2013, S. 119-146. 
Zeitraum eher in einer gewissen Kontinuität denn in einer absoluten Diskontinuität, wie dies früher häufig interpretiert wurde.

Die Umbruchzeit schuf die Voraussetzungen für die Ausformung spezifischer Persönlichkeiten. Diese konnten mit Blick auf die großen gesellschaftlichen und Besitzveränderungen hervortreten.

Karl I. von Liechtenstein beteiligte sich in unterschiedlichen Rollen praktisch an allen Prozessen der zeitgenössischen Veränderungen. Die Historiker haben sich dabei wiederholt die Frage gestellt, inwieweit sich Karl bemühte, einige Veränderungen aufzuhalten, inwiefern er weniger deren passiver Ausführer bzw. deren aktiver Handlungsträger war, der neben dem Interesse des Kaisers vor allem seine eigenen Interessen verteidigte.

Karl I. von Liechtenstein war eine Persönlichkeit, die im Verlaufe des eigenen Lebens diese Veränderungen in größtmöglichem Umfang verdeutlichte.

Aus dem Angehörigen einer gewöhnlichen Herrenfamilie wurde ein exklusiver Repräsentant der neuen Fürstenschicht mit Besitz einer eigenen Fürstenstimme (Fürstenwürde) in den Herzogtümern Troppau und Jägerndorf.

Aus einem - mit Blick auf dessen Besitz - gewöhnlichen Adeligen wurde dank der Heiratspolitik und den Gewinnen aus den Konfiskationen der reichste Aristokrat in Mähren.

Aus dem Angehörigen einer Familie, die sich in der Ständepolitik des Landes engagierte, wurde ein Mitglied der obersten kaiserlichen Institutionen (Geheimer Rat), das die höchsten kaiserlichen Funktionen (vicerex Bohemiae) personifizierte.

Aus dem Angehörigen des regionalen Adels in Österreich und in Mähren wurde ein Repräsentant der mitteleuropäischen Aristokratie.

Aus dem Angehörigen eines zwar alten, dessen ungeachtet keineswegs bedeutendsten Geschlechts wurde der Exponent einer zeitübergreifenden Fürstendynastie.

Aus dem Repräsentanten einer Familie mit eingeschränkter Rechtsposition wurde der Vertreter einer Fürstendynastie mit einer einzigartigen etatisierenden Ambition, die sich mit jenen Ambitionen der bedeutendsten Reichsfürsten maß und die auf ihrer Art mit der herrschenden Kaiserdynastie konkurrierte.

Aus einem gewöhnlichen Adeligen ohne stärker dokumentierte Beziehung zu den Musen entwickelte sich ein Förderer der Kunst rudolfinischen Typs, was später zu einem dauerhaften Merkmal der ganzen Familie und der eigenen Selbstdarstellung wurde.

Karl von Liechtenstein entwickelte sich von einer Person ohne größere Tragweite (,irgendein Liechtenstein“) in der Historiographie und im allgemeineren Bewusstsein zu einer Persönlichkeit, die nicht allein den Prozess der Konfiskationen nach 1620 personifizierte, sondern am Ende sogar den gesamten Betrachtungszeitraum. 


\section{Zusammenfassung \\ Role Karla I. z Lichtenštejna v pobělohorských konfiskacích}

Karel z Lichtenštejna v české historiografii personifikuje proces pobělohorských konfiskací a svým způsobem ztělesňuje i celý proces politických a společenských proměn v pobělohorských českých zemích. V období kolem roku 1918 a 1945 se dokonce stal předmětem historiografické i publicistické diskuse v prostředí české historiografie, jež bezprostředně souvisela se vznikem a upevněním Československé republiky. V rámci uvedených postojů došlo i k diskusi mezi historiky stojícími na pozicích vznikající Československé republiky a historiky z okruhu knížete Lichtenštejna. Jak ukazuje současný výzkum, role Karla I. z Lichtenštejna v procesu nebyla jednoznačná. Byla dána osobními ambicemi vladaře rodícího se knížecího domu, ale také komplikovaným historickým kontextem, kdy představitelé středoevropské aristokracie hledali místo mezi stavovskou obcí a vládnoucí dynastií. V př́ípadě Karla I. z Lichtenštejna byla navíc diferencována také geograficky, podle jednotlivých zemí, v nichž Lichtenštejn zastával různé pozice, funkce a úřady. Především, v Moravském markrabství byl Karel I. z Lichtenštejna již v průběhu stavovského povstání obětí konfiskací, vyhlášených povstaleckým direktoriem. Až po porážce povstání mohlo dojít k jeho návratu do země k restituci pozemkového majetku. V Čechách se Liechtenstein za své zásluhy o Rakouský dům, které prokázal v průběhu rebelie, stal velmi brzy císařským komisařem a posléze císařským místodržícím. Z titulu těchto funkcí zatýkal a vyšetřoval čelné povstalce a předsedal jejich staroměstské popravě. Ve dvacátých letech v Čechách řídil proces císařských konfiskací. Na Opavsku, jež postupně směřovalo mezi slezská knížectví, se Liechtenstein snažil vystupovat jako svrchovaný zeměpán a z této pozice také organizovat vlastní konfiskační proces. Tyto snahy nicméně narážely na zájmy císaře Ferdinanda II. a jeho centrálních úřadů, které s takovým štěpením monarchie nesouhlasili. Za velký úspěch lze naopak považovat zisky Karla I. z Lichtenštejna na Moravě, kde za své zásluhy získal velké majetky po svém někdejším souputníku, povstaleckém zemském hejtmanovi Ladislavu Velenu ze Žerotína, na čele s dominiem Moravská Třebová. Karel I. z Lichtenštejna zemřel roku 1627, na prahu konečné pacifikace a normalizace českých zemí ze strany císaře. Jeho role v průběhu konfiskačního procesu, byt̉ nebyly bez určitých stínů, nicméně přispěly k velkému a několik století trvajícímu rozmachu knížecího domu Lichtenštejnů. 
